\title{
Pressure-volume loops in cardiac surgery
}

Citation for published version (APA):

Dekker, A. L. A. J. (2003). Pressure-volume loops in cardiac surgery. [Doctoral Thesis, Maastricht University]. Datawyse / Universitaire Pers Maastricht. https://doi.org/10.26481/dis.20030912ad

Document status and date:

Published: 01/01/2003

DOI:

10.26481/dis.20030912ad

Document Version:

Publisher's PDF, also known as Version of record

\section{Please check the document version of this publication:}

- A submitted manuscript is the version of the article upon submission and before peer-review. There can be important differences between the submitted version and the official published version of record.

People interested in the research are advised to contact the author for the final version of the publication, or visit the DOI to the publisher's website.

- The final author version and the galley proof are versions of the publication after peer review.

- The final published version features the final layout of the paper including the volume, issue and page numbers.

Link to publication

\footnotetext{
General rights rights.

- You may freely distribute the URL identifying the publication in the public portal. please follow below link for the End User Agreement:

www.umlib.nl/taverne-license

Take down policy

If you believe that this document breaches copyright please contact us at:

repository@maastrichtuniversity.nl

providing details and we will investigate your claim.
}

Copyright and moral rights for the publications made accessible in the public portal are retained by the authors and/or other copyright owners and it is a condition of accessing publications that users recognise and abide by the legal requirements associated with these

- Users may download and print one copy of any publication from the public portal for the purpose of private study or research.

- You may not further distribute the material or use it for any profit-making activity or commercial gain

If the publication is distributed under the terms of Article $25 \mathrm{fa}$ of the Dutch Copyright Act, indicated by the "Taverne" license above, 
Pressure-Volume Loops in Cardiac Surgery 
(C) A.L.A.J. Dekker, Maastricht 2003

ISBN 90-5278-381-0

Druk: Datawyse | Universitaire Pers Maastricht 


\title{
Pressure-Volume Loops in Cardiac Surgery
}

\author{
Proefschrift
}

ter verkrijging van de graad van doctor aan de Universiteit Maastricht, op gezag van de Rector Magnificus, Prof.dr. A.C. Nieuwenhuijzen Kruseman, volgens het besluit van het College van Decanen, in het openbaar te verdedigen, op vrijdag 12 september 2003 om 14:00 uur

door

\section{André Dekker}

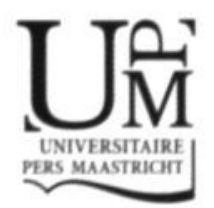




\section{Promotor}

Prof.dr. B. Mochtar

\section{Co-Promotores}

Dr. J.G. Maessen

Dr.ir. F.H. van der Veen

\section{Beoordelingscommissie}

Prof.dr.ir. T. Arts (voorzitter)

Prof.dr. J. Baan, Universiteit Leiden

Prof.dr. M.J.H.M. Jacobs

Prof.dr. B. Meyns, Katholieke Universiteit Leuven

Dr. G.V.A. van Ommen

Financial support by the Netherlands Heart Foundation and Stichting Hartsvrienden Rescar for the publication of this thesis is gratefully acknowledged.

Additional support was granted by Medtronic, CD Leycom, Datascope, TD Medical, AB Medical and Sulzer Cardiovascular. 


\section{Contents}

Chapter 1 Introduction

Pressure-volume loops in valvular disease

Chapter 2 Aortic stenosis

Chapter 3 Aortic regurgitation

Pressure-volume loops in off-pump coronary artery bypass grafting

Chapter 4 Cardiac tilting

Chapter 5 Right ventricular support

Pressure-volume loops in mechanical support

Chapter 6 Intra Aortic Balloon Pump in acute mitral regurgitation

Chapter 7 Propeller pump versus Intra Aortic Balloon Pump

Chapter 8 Future pressure-volume loops in cardiac surgery

Summary

Samenvatting

Nawoord

Publicaties

Biografie 



\section{Chapter 1}

\section{Introduction}

1.1 Relationships between pressure and volume

1.2 Interpretation of pressure-volume loops

1.3 Measurement of pressure-volume loops

1.4 Pressure-volume loops in cardiac surgery

1.5 Aim and outline of the thesis

1.6 References 



\subsection{Relationships between pressure and volume}

Relationships between pressure and volume are part of thermodynamics. They were first employed at the start of the nineteenth century as a result of the industrial revolution, when the interest in steam engines sparked the start of a new theoretical framework now known as thermodynamics. Until then, heat was assumed to be a substance named caloric, but this theory could not explain the principles governing steam engines which were not well understood at that time. The French engineer Carnot took on this challenge and constructed a theoretical model of an ideal heat engine which he applied to study real heat engines (Figure 1-1). Carnot's work ultimately led to the formulation of the Second Law of Thermodynamics which is among the most basic and powerful in physics (or as Einstein put it: "It is the only physical theory of universal content, which I am convinced [...] will never be overthrown"1)
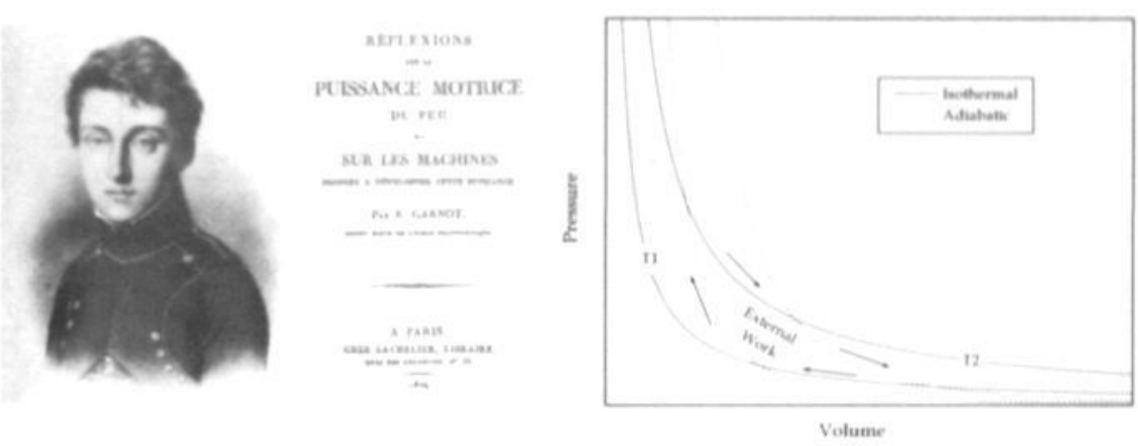

Figure 1-1: Left: Nicolas Sadi Lazare Carnot (1796-1832). French engineer and founder of thermodynamics. Middle: Carnot's pivotal publication "Réflexions sur la puissance motrice du feu...". Right: A Carnot cycle for an ideal gas consisting of reversible phases.

The second law of thermodynamics can be applied to numerous subjects and therefore surfaces in many different forms. The one most useful for this introduction is: A pressure-volume loop of a maximally efficient engine consists only of reversible phases. This ideal pressure-volume loop is called a Carnot cycle (Figure 1-1). The Carnot cycle of a heat engine of an ideal gas can be found in every physics textbook; it consists of reversible adiabatic (at constant entropy) and isothermal phases.

Carnot and university thermodynamics deal with heat engines made of an ideal gas. However, this thesis focuses on pressure-volume loops of another thermodynamic subject: the heart. The largest difference with a heat engine is that the heart is a biochemical engine and does not rely on a difference in temperature to perform mechanical work. So, rather than using differences 
in temperature as the driving force, a change in biochemical potential should by analyzed.

Although such a "biochemical" thermodynamic analysis is more complicated than the "thermal" case for an ideal gas, the Carnot principle still holds in the human heart ${ }^{2}$ : The maximally efficient pressure-volume loop of the heart consists of only reversible phases. In that case the available biochemical energy is maximally converted into mechanical work.

The real pressure-volume loop of the heart, discussed shortly, is not an ideal Carnot cycle. The main deviation is that a certain blood pressure needs to be maintained, so valves and thus isovolumic phases are present in a cardiac pressure-volume loop. However, Carnot's theorem does enable us to define the maximum achievable efficiency with a certain amount of biochemical energy available. It can be shown ${ }^{2}$ that Carnot's principles lead to the pressure-volume area concept of $\mathrm{Suga}^{3}$, which will be introduced in detail later. First the pressure-volume loop of the heart is discussed. 


\subsubsection{Pressure-volume loop of the heart}

During a heart beat, the pressure and volume inside the heart change with time as shown in Figure 1-2. Each beat can be divided into four phases: (isovolumic) contraction, ejection, (isovolumic) relaxation and the filling phase that consists of rapid filling, diastasis and the atrial kick. Note that pressure and volume are out-of-phase; when pressure is high, volume is low and vice versa. A consequence of this phase difference, is that the plot of pressure versus volume results in a loop: the pressure-volume loop.

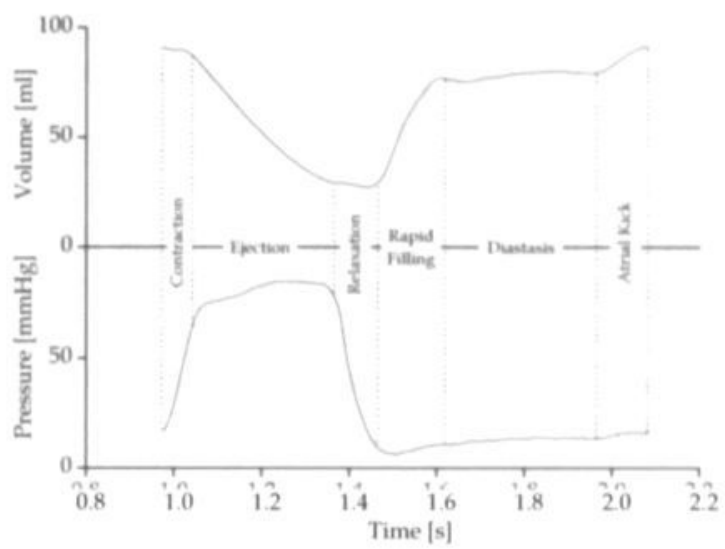

Figure 1-2: Changes in left ventricular pressure and volume over time.

The pressure-volume loop constructed from the data of Figure 1-2 is shown in Figure 1-3. Each heartbeat is represented by one pressure-volume loop. The aforementioned four phases are visible. Starting at the bottom right corner and working counterclockwise, these are: contraction, ejection, relaxation and the filling phase. The four corners of the loop are determined by valve opening and closure. For the left ventricle these are counterclockwise mitral valve closure, aortic valve opening, aortic valve closure and mitral valve opening.

A pressure-volume loop is constructed from the simultaneous measurement of volume and pressure over time, but the variable time is not seen in the loop. Part of the time aspect can be brought back by showing the individual samples as is done on the right in Figure 1-3 (time between points is 12ms). It can be seen that contraction and relaxation are very fast phases, while the filling phase consists of a rapid phase followed by a waiting period, the diastasis. After diastasis, the atrial contribution to filling takes place (atrial kick). 

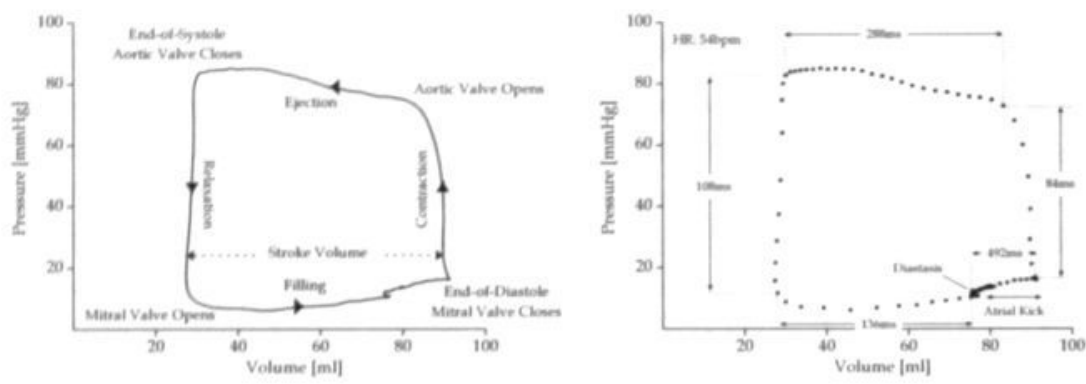

Figure 1-3: A normal left ventricular pressure-volume loop. Left: The four phases and corners of the loops. The width of the loop is the stroke volume. Right: Individual samples of pressure and volume, time between samples is $12 \mathrm{~ms}$. The diastasis and the atrial kick can clearly be seen.

The loop of Figure 1-3 is taken from a healthy pig and it has the normal almost rectangular shape. This shape is determined by the valves; in patients with valvular disease the rectangular appearance is lost. In this thesis, two valvular diseases will be discussed: aortic stenosis (Chapter 2) and aortic regurgitation (Chapter 3).

In aortic stenosis, the aortic valve has become too narrow, usually due to calcific deposits on the leaflets. With this disease a high pressure gradient between the left ventricle and the aorta is needed to eject the blood through the stenosis. This results in an ejection phase that is no longer isobaric; the ejection does not occur at constant left ventricular pressure. In the pressurevolume plane, aortic stenosis therefore leads to a "house-shaped" pressurevolume loop (Figure 1-4). In aortic regurgitation, the aortic valve leaks. Due to the leakage, the left ventricle might already be filled during relaxation: the relaxation phase is no longer isovolumic. In a pressure-volume loop this leads to a rounded bottom left corner (Figure 1-4)

In both parts of Figure 1-4 the relation between aortic pressure and ventricular volume is presented. With the help of this novelty, the time point of aortic valve opening and closure can be identified. Furthermore, the high pressure gradient between aorta and ventricle in aortic stenosis is visible. In aortic regurgitation, the fall in aortic pressure during diastole can be seen. 

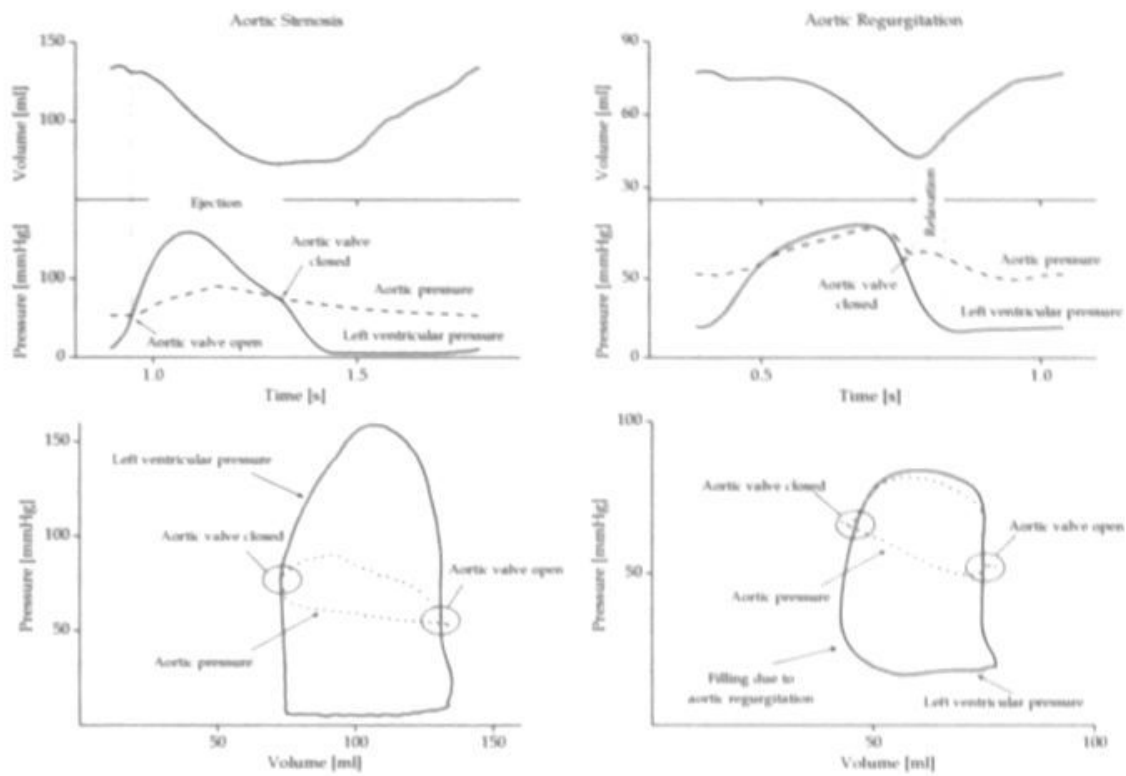

Figure 1-4: Upper left: Left ventricular volume and pressure and aortic pressure over time in a patient with aortic stenosis. Bottom left: Aortic and left ventricular pressure-volume loops in a patient with aortic stenosis. Note the pressure gradient between the left ventricle and the aorta and the triangular "house" shape of the pressure-volume loop.

Upper right: Left ventricular volume and pressure and aortic pressure over time in a patient with aortic regurgitation. Lower right: Aortic and left ventricular pressure-volume loop during aortic regurgitation. The relaxation phase is no longer isovolumic as important filling occurs in this period. The filling pressure is also elevated.

In conclusion, a pressure-volume loop is a graphical representation of the changes in ventricular pressure and volume during a heartbeat. If valvular disease is absent, a pressure-volume loop is rectangular in shape and consists of four clearly delineated phases: contraction, ejection, relaxation and filling. 


\subsection{Interpretation of pressure-volume loops}

In this section the heart and circulation are described from three viewpoints: A thermodynamic, physiological and an empirical viewpoint. In all three, data obtained by pressure-volume loops play a crucial role.

\subsubsection{The heart from a thermodynamic viewpoint}

From a thermodynamic viewpoint the heart is a converter of biochemical energy into mechanical energy. It is a consequence of the second law of thermodynamics that this conversion can not occur without heat production, meaning a loss of useful energy. This heat production can be measured and the sum of the heat produced and the work done by the heart is equal to the total chemical energy consumed, as predicted by the first law of thermodynamics ${ }^{4}$. Assuming fully aerobic metabolism, the available chemical energy can be calculated by multiplying the oxygen consumption of the heart by its energy equivalent, which is the total energy released when oxidizing carbohydrates, fat or protein (about $20 \mathrm{~J}$ per mole $\left.\mathrm{O}_{2}\right)^{4}$.

A commonly used energy transfer diagram ${ }^{3}$ is shown in Figure 1-5 sutlining the steps from axidation to the work ${ }_{\mathrm{r}}$ erformed bv the ventricle as well as their efficiency. The overall efficiency of the heart (external work divided by oxygen consumption) is about $25 \%$ in a normal heart ${ }^{5}$. The remainder is the heat loss.

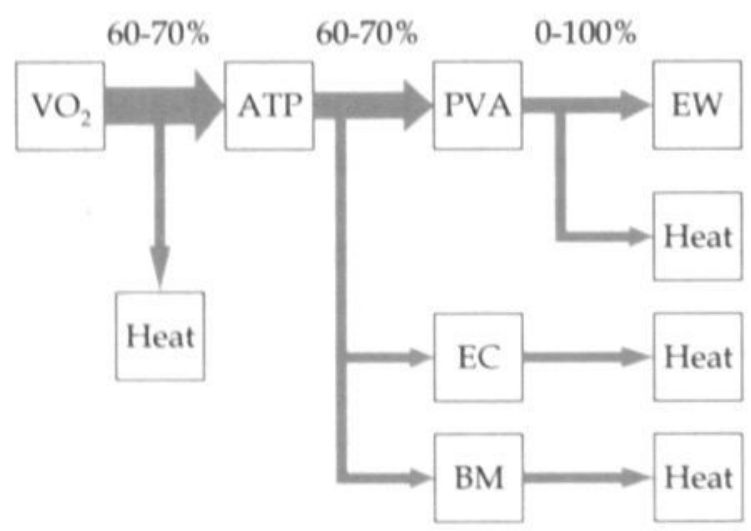

Figure 1-5: Efficiency of the conversion of chemical energy to external work. $\mathrm{VO}_{2}$ : Energy released during oxidation of carbohydrates, fat and protein; ATP: Adenosine triphosphate; EC: Excitation-contraction coupling; BM: Basal metabolism; PVA: Pressure-volume area; EW: External work. Modified from Suga'? 
The variables myocardial oxygen consumption $\mathrm{VO}_{2}$ pressure-volume area PVA and external work EW can relatively easily be measured and the $\mathrm{VO}_{2}$ PVA-EW relation is therefore intensively studied (see Figure 1-6). The classic work in this field by Suga ${ }^{3}$ has the key result that the pressurevolume area is proportional to the oxygen consumption ${ }^{6}$, as shown in Figure 1-6. The PVA to EW conversion efficiency depends on loading conditions $^{7}$ and is essentially the result of the Starling mechanism to be discussed later.
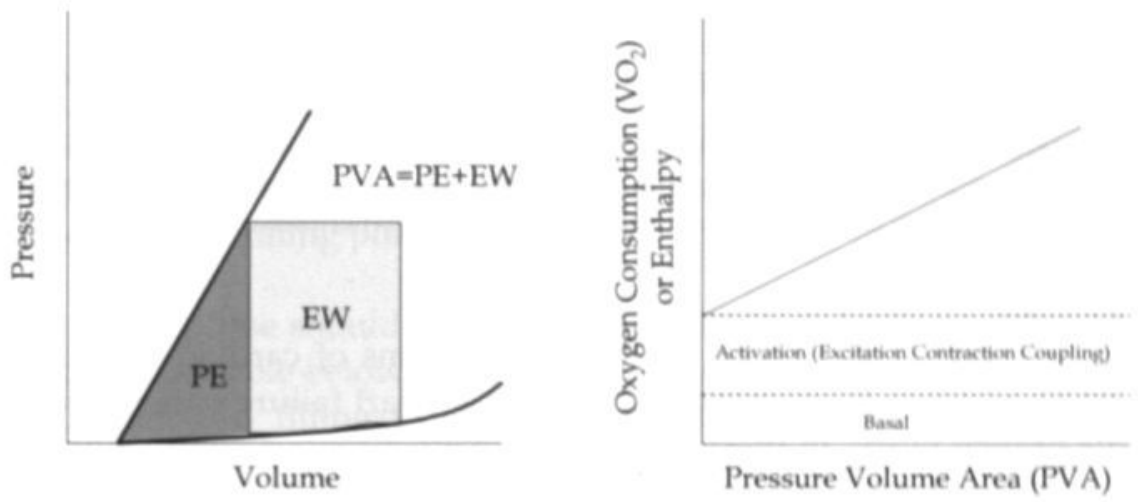

Figure 1-6: Left: Definition of pressure-volume area (PVA) as the sum of external work (EW) and potential energy (PE) (which is energy released if the contraction would continue and the ventricle could fully eject). Right: Oxygen consumption is linearly related to pressure volume area. Redrawn from Westerhof.

An example of the usefulness of the PVA-concept is the demonstration that pressure work is less efficient than volume work ${ }^{8}$. This is illustrated in this thesis in Chapter 6 which describes an experiment done during acute mitral regurgitation. It was observed that coronary blood flow was not increased when acute mitral regurgitation was created while external work strongly increased. Figure 1-7 shows the pressure-volume loops before and during mitral regurgitation. Stroke volume increases threefold, while pressure volume area and thus oxygen consumption are barely changed.

The thermodynamic approach, more commonly referred to as ventricular energetics, is used to study the ventricle with questions such as:

- Can the ventricle improve its efficiency (e.g. ischemic preconditioning $\left.{ }^{9}\right)$ ?

- Which part of the energy transfer changes with disease (e.g. myocardial stunning ${ }^{10}$ or heart failure $\left.{ }^{11,12}\right)$ ?

- Is the heart designed to maximize external work or to maximize its efficiency and what happens in the diseased heart ${ }^{7}$ ? 

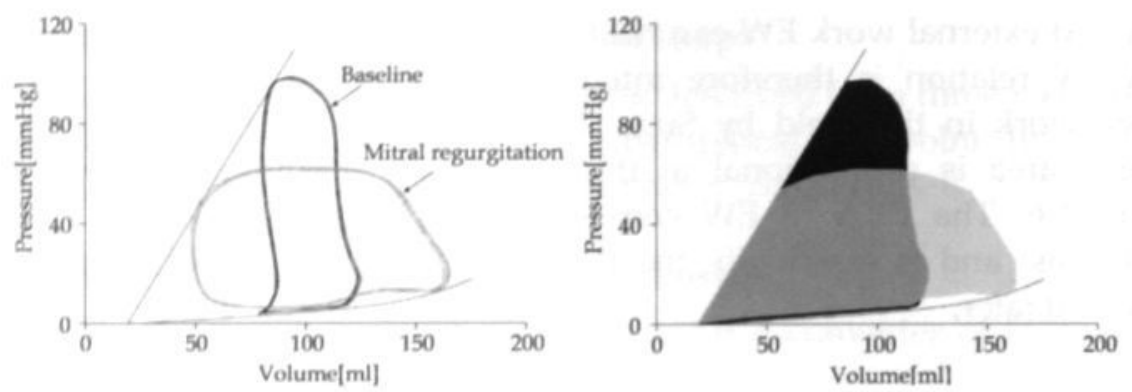

Figure 1-7: Pressure-volume loops (left) and area (right) before and during acute mitral regurgitation. The stroke volume increases strongly during acute mitral regurgitation with the higher preload. In contrast, pressure-volume area barely changes so oxygen consumption is the same before and during acute mitral regurgitation. For this reason no change in coronary blood flow was observed during the experiments.

Others investigate the effects of therapy in terms of cardiac efficiency ${ }^{13-15}$. The latest addition is biventricular pacing for heart failure patients with left bundle branch block. In these patients, an asynchronous contraction occurs because not all parts of the left ventricle are simultaneously activated. Resynchronization by pacing restores the synchronous contraction and increases cardiac efficiency ${ }^{16}$.

In conclusion, in energetic studies pressure-volume loops are applied to determine pressure-volume area and external work. Furthermore, by measuring the pressure-volume area and oxygen consumption at different loading conditions and contractility, their relation can be determined. 


\subsubsection{The heart from a physiological viewpoint}

In physiology one often describes the cardiac pump by stating the Starling law of the heart. This law reads that "the greater the heart is filled, the greater will be the quantity of blood ejected into the aorta"17. So both the filling characteristics (diastolic function) and the ejection properties of the heart (systolic function) are important. The assessment of diastolic and systolic function with the help of pressure-volume loops is the subject of this paragraph.

\section{Diastolic function}

The goal of diastole is to fill the heart. Although the exact start and duration of diastole is disputable ${ }^{18}$, in this thesis diastole is defined as compromising the relaxation and filling phase.

The relaxation phase should be as short as possible and pressure should fall as quickly as possible below atrial pressure, to allow the mitral or tricuspid valve to open and filling to start. The parameters describing the fall in pressure and the duration of the relaxation phase are given in Table 1-1. This table includes a summary of typical values found in literature.

\begin{tabular}{|c|c|c|c|c|}
\hline Variable & Unit & Normal & Abnormal & Reference' \\
\hline dPdtmin & $\begin{array}{l}m m H g s^{-1} \\
m m H g s^{-1} \\
m m H g s^{-1} \\
m m H g s^{-1} \\
m m H g s^{-1} \\
m m H g s^{-1}\end{array}$ & $\begin{array}{l}2660 \\
2922 \\
1864 \\
1825 \\
\\
1830\end{array}$ & $\begin{array}{l}<1260 \\
<1422 \\
<1084 \\
<1303 \\
<1100 \\
<1232\end{array}$ & $\begin{array}{l}19 \\
19 \\
19 \\
19 \\
20 \\
21\end{array}$ \\
\hline$\tau$ & $\begin{array}{l}\mathrm{ms} \\
\mathrm{ms} \\
\mathrm{ms} \\
\mathrm{ms} \\
\mathrm{ms} \\
\mathrm{ms}\end{array}$ & $\begin{array}{l}38 \\
33 \\
31 \\
\end{array}$ & $\begin{array}{l}>52 \\
>49 \\
>37 \\
>48 \\
>70 \\
>67\end{array}$ & $\begin{array}{l}19 \\
19 \\
19 \\
20 \\
21 \\
22\end{array}$ \\
\hline IVRT & ms & & $>100$ & 23 \\
\hline PHT & ms & 27 & $>39$ & 22 \\
\hline
\end{tabular}

The relaxation phase can be prolonged due to heart disease. A typical example is hypertrophy due to aortic stenosis which is the subject of Chapter 2. The problem with a prolonged relaxation phase is that filling can only start if ventricular pressure is lower than atrial pressure. So, the longer 
the relaxation phase, the less time there is available for filling. The main compensatory mechanism of a prolonged relaxation phase, is an increase of filling pressure.

The filling phase starts when the mitral valve opens (although with valvular regurgitation filling can also occur during the relaxation phase, see Figure 1-4). Normal filling starts with a rapid filling phase in which the heart actively sucks blood from the atrium ${ }^{18}$. Then a rather long pause occurs, called diastasis. Next, the atrium actively fills the heart by contracting and emptying its content into the ventricle. Immediately after the atrial contraction, the contraction of the ventricle starts. The parameters describing the filling phase are given in Table 1-2.

\begin{tabular}{|c|c|c|c|c|}
\hline Variable & Unit & Normal & Abnormal & Reference \\
\hline EDVI & $\begin{array}{l}\mathbf{m l} \mathbf{m}^{2} \\
\mathbf{m l} \mathbf{m}^{2} \\
\mathbf{m l} \mathbf{m}^{2} \\
\mathbf{m l} \mathbf{m}^{2} \\
\mathbf{m l} \mathbf{m}^{2} \\
\mathbf{m l} \mathbf{m}^{2} \\
\mathbf{m l} \mathbf{m}^{2}\end{array}$ & $\begin{array}{l}72 \\
70 \\
79 \\
71 \\
77 \\
93 \\
82\end{array}$ & $\begin{array}{l}>102 \\
>110 \\
>101 \\
>111 \\
>107 \\
>105 \\
>112\end{array}$ & $\begin{array}{l}24 \\
24 \\
24 \\
24 \\
25 \\
26 \\
22\end{array}$ \\
\hline LVPe & $\begin{array}{l}\mathrm{mmHg}_{\mathrm{g}} \\
\mathrm{mmHg} \\
\mathrm{mmHg} \\
\mathrm{mmHg}\end{array}$ & $\begin{array}{l}11 \\
8 \\
12\end{array}$ & $\begin{array}{l}>16 \\
>19 \\
>12 \\
>22\end{array}$ & $\begin{array}{l}20 \\
21 \\
27 \\
28\end{array}$ \\
\hline PFReanty & $\begin{array}{l}\text { EDV } s^{-1} \\
\text { EDV } s^{-1} \\
\text { EDV } s^{-1} \\
m l s^{-1} \\
m l s^{-1} \\
m l s^{-1} m^{-2} \\
m l s^{-1} m^{2}\end{array}$ & $\begin{array}{l}3.3 \\
3.2 \\
483 \\
330 \\
269\end{array}$ & $\begin{array}{l}<2.1 \\
<1.6 \\
<2.6 \\
<261 \\
<188 \\
<160 \\
<87\end{array}$ & $\begin{array}{l}19 \\
20 \\
29 \\
21 \\
29 \\
20 \\
22\end{array}$ \\
\hline IPFR & $\begin{array}{l}\mathrm{ms} \\
\mathrm{ms}\end{array}$ & $\begin{array}{l}136 \\
140\end{array}$ & $\begin{array}{l}>182 \\
>160\end{array}$ & $\begin{array}{l}19 \\
29\end{array}$ \\
\hline E/A & & $\begin{array}{l}1.9 \\
1.4\end{array}$ & $\begin{array}{l}<0.5 \\
<0.9 \\
<0.8\end{array}$ & $\begin{array}{l}20 \\
30 \\
30\end{array}$ \\
\hline $\mathrm{C}_{\text {tha }} / \mathrm{E}_{\text {est }}$ & $\begin{array}{l}\mathrm{ml} \mathrm{mmH}^{-1} \\
\mathrm{ml} \mathrm{mmH}^{-1} \\
\mathrm{ml} \mathrm{mmH}^{-1} \\
\mathrm{ml} \mathrm{mmH}^{-1}\end{array}$ & $\begin{array}{l}6.12 \\
10.0 \\
17 \\
13.3\end{array}$ & $\begin{array}{l}<3.7 \\
<7.0 \\
<10\end{array}$ & $\begin{array}{l}31 \\
31 \\
32 \\
33\end{array}$ \\
\hline$K_{e} / \beta$ & $\begin{array}{l}\mathrm{ml}^{-1} \mathrm{~m}^{2} \\
\mathrm{ml}^{-1} \mathrm{~m}^{-2}\end{array}$ & $\begin{array}{l}0.032 \\
0.044\end{array}$ & $\begin{array}{l}>0.060 \\
>0.096\end{array}$ & $\begin{array}{l}21 \\
22\end{array}$ \\
\hline
\end{tabular}

EDVI: Left ventricular end-diastolic volume index; LVPw: Left ventricular end-diastolic pressure; PFR-aity : Peak filling rate during the first part of diastole; tPFR: Time to peak filling rate; E/A: Ratio between early and late peak filling rate;

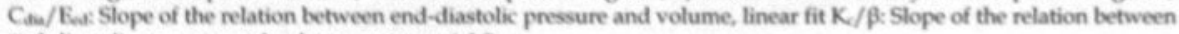
end-diastolic pressure and volume, exponential fit.

'Tf the reference does not give a normal and abnormal value, abnormal value are based on two times standard deviation. 
The end result of the filling phase is the end-diastolic volume or preload of the ventricle. The preload depends on the filling pressure and the compliance of the ventricle in diastole. By varying the filling pressure (e.g. by caval vein occlusion), the end-diastolic pressure-volume relation can be drawn. This relation is curvi-linear and gives an impression of chamber stiffness (Figure 1-8). A steep end-diastolic pressure-volume relation indicates a stiff ventricle, as more pressure is needed to fill the ventricle.
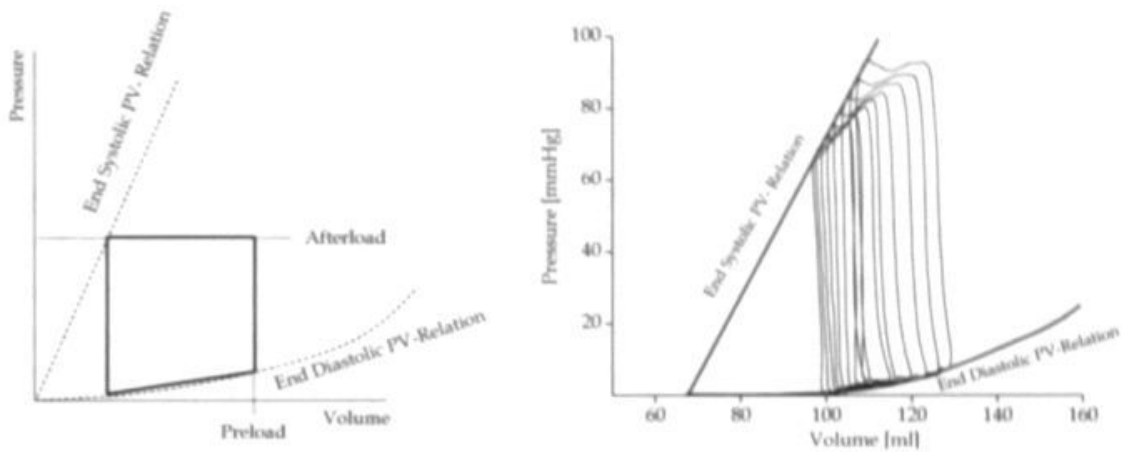

Figure 1-8: Left: Preload, afterload, end-diastolic and end-systolic pressure-volume relation. Right: Inferior caval vein occlusion reduces preload and afterload of the left ventricle. The end-systolic and end-diastolic pressure-volume relation can then be drawn.

The filling phase may be abnormal in heart disease. As discussed above, the relaxation phase can be so long that rapid filling is not possible. Furthermore, the ventricle may be too stiff, which can be the case in aortic stenosis patients (Chapter 2). In these patients the heart muscle thickens (hypertrophy) in order to maintain enough strength to eject through the narrowed valve.

Pathologic hypertrophy causes a severely prolonged relaxation phase and a stiffer muscle which eventually leads to diastolic heart failure. Here filling pressure becomes so high that congestion occurs in the lungs, causing pulmonary edema, or a filling that is inadequate for the required output. In Figure 1-9 the end-diastolic pressure-volume relation is drawn for six aortic stenosis patients. Clear differences can be observed: Some patients have a very stiff ventricle, while others have a normal, flat end-diastolic pressurevolume relation. This difference may be prognostically significant. 


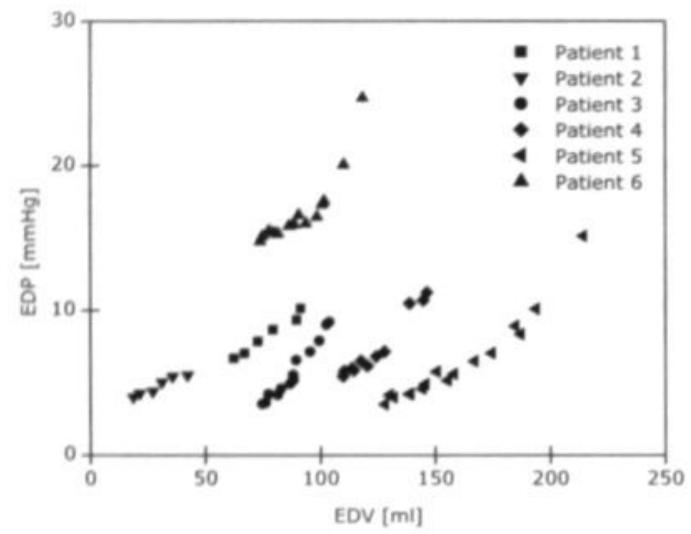

Figure 1-9: End-diastolic pressure volume relation in six aortic stenosis patients. Patient 6 has a very stiff ventricle and requires extreme filling pressures.

\section{Systolic function}

Systole starts at the end-of-diastole and compromises the contraction and ejection phases. The goal of systole is to eject blood into the aorta.

In the contraction phase, the pressure in the ventricle rapidly rises to achieve a pressure high enough to open the aortic or pulmonary valve. Contraction is usually the fastest phase (see Figure 1-3). Parameters describing the left ventricular contraction phase are given in Table 1-3. The parameter most often used is the maximum of the ventricular pressure derivative, $\mathrm{dPdt}_{\max }$ as this parameter is directly linked to the strength of the cardiac contraction and thus to the heart muscle's condition. As dPdt $\max$ is highly preload dependent, the slope of the $\mathrm{dPdt}_{\max }$ versus preload (enddiastolic volume) relation is sometimes applied ${ }^{34}$.

Table 1-3: Normal and abnormal values for left ventricular contraction phase parameters

\begin{tabular}{|c|c|c|c|c|}
\hline Variable & Unit & Normal & Abnormal & Reference' \\
\hline dPdtmax & 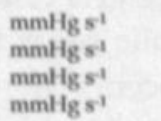 & $\begin{array}{l}1610 \\
1670 \\
1661 \\
1677\end{array}$ & $\begin{array}{l}<1030 \\
<1030 \\
<1015 \\
<811\end{array}$ & $\begin{array}{l}19 \\
19 \\
19 \\
21\end{array}$ \\
\hline dPdtMax vs. EDV & $\mathrm{mmH}_{\mathrm{g}} \mathrm{s}^{-1} \mathrm{ml}^{-1}$ & 23 & & 35 \\
\hline$(\mathrm{dPt} / \mathrm{P})_{\max }$ & $s-1$ & 44 & 27 & 19 \\
\hline I(dP/dt)/DPlor-w & $s-1$ & 38 & $<13$ & 19 \\
\hline
\end{tabular}

dPdtow: Maximal left ventricular pressure derivative; dPdtMax vs. EDV: Slope of the relation between dPdtan and end-diastolic volume during preload reduction; (dPdt/P) max : Maximal ratio of left ventricular pressure derivative and left ventricular pressure: I(dP/dt)/DP/or-a: Ratio of left ventricular pressure derivative and developed left ventricular pressure at $40 \mathrm{~mm} / \mathrm{g}$ of developed pressure.

"If the reference does not give a normal and abnormal value, abnormal value are hased on two times standand deviation. 
The ejection phase starts at the opening of the aortic or pulmonary valve and ends at the end-systolic point. During ejection the sarcomeres of the ventricle need to shorten but first they have to develop enough force to overcome the systolic ventricular pressure. Systolic ventricular pressure ${ }^{36}$ is therefore called afterload but, because it is easier to measure, one often assumes systolic blood pressure to be a measure of left ventricular afterload*.

The goal of many therapies (beta-blockade, nitroprusside, IABP), is a reduction in afterload as this leads to either an increase in stroke volume (see Figure 1-10) or a reduction in myocardial oxygen consumption (see previous paragraph).

The end-systolic point marks the end of ejection. The volume and pressure at end-of-systole are determined by the afterload and the end-systolic pressure-volume relation (Figure 1-8). Like the end-diastolic relation, the end-systolic pressure volume relation can be determined during caval vein occlusion $^{37}$. The position and especially the slope of this relation, Ees, is an indicator for the intrinsic strength of the ventricle, the contractility. The higher the contractility, the steeper the slope of the end-systolic pressurevolume relation. In Table 1-4 a number of ejection phase indices are given.

\section{Starling's law: Preload, Afterload \& Contractility}

From the previous paragraph, the quantities preload, afterload and contractility emerge as the key variables to describe the cardiac function. These will be summarized with the aid of the pressure-volume loops of Figure 1-10.
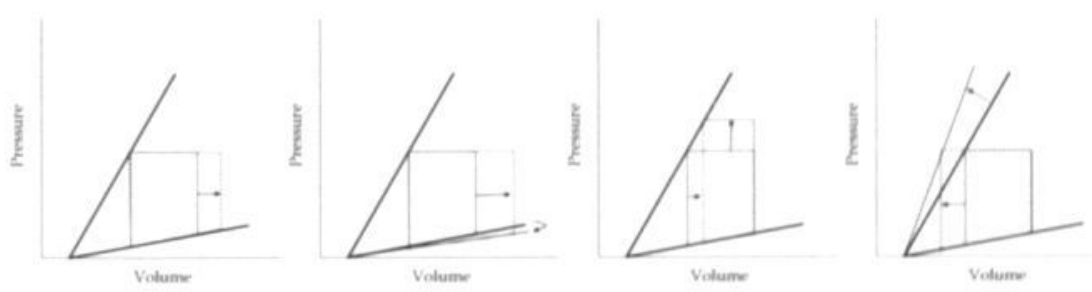

Figure 1-10: From left to right: Effect on pressure-volume loop of an increase in filling pressure (increased preload), positive lusitropy (increased preload), afterload and positive inotropy (increased contractility) ${ }^{s}$.

\footnotetext{
- The correct definitions of preload and afterload are the wall stress at end-of-diastole and the wall stress during ejection, respectively. Wall stress is related to volume, pressure and wall thickness of the ventricle via Laplace's law. In this thesis a common simplication is made: Enddiastolic volume is taken as preload and systolic left ventricular pressure is taken as afterload.
} 
Preload is the end-diastolic volume which can be increased by increasing the filling pressure or decreasing the stiffness of the ventricle. An increased preload leads to more ejection (Starling's law).

Afterload is systolic ventricular pressure. An increase in afterload leads to a decrease in ejected blood.

Contractility is the intrinsic strength of the muscle; it is represented in the pressure-volume plane by the end-systolic pressure-volume relation. An increase in contractility leads to an increased stroke volume.

Table 1-4: Normal and abnormal values for left ventricular ejection parameters

\begin{tabular}{|c|c|c|c|c|}
\hline Variable & Unit & Normal & Abnormal & Reference' \\
\hline \multirow[t]{7}{*}{ ESVI } & $\mathbf{m l} \mathbf{m}^{2}$ & 20 & $>36$ & 24 \\
\hline & $\mathbf{m l} \mathbf{m}^{2}$ & 24 & $>44$ & 24 \\
\hline & $\mathbf{m l} \mathbf{m}^{2}$ & 28 & $>40$ & 24 \\
\hline & $\mathrm{ml} \mathrm{m} \mathbf{m}^{2}$ & 30 & $>50$ & 24 \\
\hline & $\mathrm{ml} \mathrm{m}^{2}$ & 29 & $>45$ & 25 \\
\hline & $\mathbf{m l} \mathbf{m}^{2}$ & 37 & $>43$ & 26 \\
\hline & $\mathbf{m l} \mathbf{m}^{2}$ & 28 & $>42$ & 22 \\
\hline \multirow[t]{2}{*}{ SVI } & $\mathbf{m l} \mathbf{m}^{2}$ & 45 & $>71$ & 23 \\
\hline & $\mathrm{ml} \mathbf{m}^{2}$ & 58 & $>68$ & 26 \\
\hline \multirow[t]{4}{*}{ LVP'man } & $\mathrm{mmH} \mathrm{H}_{\mathrm{g}}$ & 130 & $<90,>140$ & 27 \\
\hline & $\mathrm{mmHg}$ & 119 & $<77,>161$ & 25 \\
\hline & $\mathrm{mmH}$ & 121 & $<101,>131$ & 26 \\
\hline & $m m b$ & an & $\cos -6 v$ & $a$ \\
\hline \multirow[t]{4}{*}{ SW(I) } & $\mathrm{g} \mathrm{m}$ & 81 & $<35$ & 19 \\
\hline & $g \mathrm{~m} \mathrm{~m}^{2}$ & 53 & $<9$ & 19 \\
\hline & $g \mathrm{~m} \mathrm{~m} \mathrm{~m}^{2}$ & 41 & $<17$ & 19 \\
\hline & joule $\mathrm{m}^{2}$ & 0.76 & $<0.62$ & 26 \\
\hline \multirow[t]{4}{*}{ EF } & 8 & 72 & $<56$ & 19 \\
\hline & 8 & & $<45$ & 20 \\
\hline & 8 & 62 & $<48$ & 25 \\
\hline & 8 & 66 & & 22 \\
\hline MNSER & EDV $\mathrm{s}^{-1}$ & 3.3 & $<1.6$ & 19 \\
\hline \multirow[t]{7}{*}{ Ees } & $\mathrm{mmH}^{\mathrm{H}} \mathrm{ml}^{-1}$ & 2.7 & $<2$ & 31 \\
\hline & $\mathrm{mmH} \mathrm{g} \mathrm{ml}^{\mathrm{l}}$ & 2.0 & $<1.4$ & 31 \\
\hline & $\mathrm{mmH}^{-1} \mathrm{ml}^{-1}$ & 20 & & 25 \\
\hline & $\mathrm{mmH}_{\mathrm{g}} \mathrm{ml}^{-1}$ & 2.5 & & 33 \\
\hline & $\mathbf{m m H g} \mathbf{~ m l - 1}^{-1}$ & 2.0 & & 32 \\
\hline & $\mathrm{mmH}_{\mathrm{g}} \mathrm{ml}^{-1}$ & 3.0 & & 35 \\
\hline & $\mathrm{mmH}^{-1} \mathrm{ml}^{-1}$ & 1.8 & & 28 \\
\hline \multirow[t]{4}{*}{ PRSW } & $\mathrm{mmH} / \mathrm{g}$ & 101 & 46 & 31 \\
\hline & $\mathrm{mmH} / \mathrm{g}$ & 90 & $<74$ & 31 \\
\hline & $\mathrm{mmH}_{\mathrm{g}}$ & 53 & $<21$ & 35 \\
\hline & $\mathrm{mmH}$ & 62 & $<30$ & 38 \\
\hline
\end{tabular}

ESVI: End systolic volume index; SVI: Stroke volume index; LVPme: Maximal left ventricular pressure; SW(I): Stroke work index EF: Ejection fraction: MNSER: mean normalized systolic ejection rate; Ees: Slope of the relation between end systolic pressure and volume during preload reduction: PRSW: Preload recruitable stroke work, slope of the relation between stroke work and end-diastolic volume during preload reduction.

'If the reference does not give a normal and ahnormal value, abnormal value are based on two times standard deviation. 


\section{The right ventricle}

The focus in this paragraph was the left ventricle, as this thesis primarily deals with the left ventricle. However, most of this section equally applies to the right ventricle, but this ventricle is much less studied as it is the left ventricle that is often the problem in heart disease. Normal and abnormal values for parameters describing right ventricular function are therefore difficult to find in the literature. Some of them are given in Table 1-5.

\begin{tabular}{|c|c|c|c|c|}
\hline Variable & Unit & Normal & Abnormal & Reference' \\
\hline RVEDV & $\mathrm{ml}$ & 176 & & 39 \\
\hline RVESV & $\mathrm{ml}$ & 149 & & 39 \\
\hline RVPmex & $\begin{array}{c}\mathrm{mmH}_{\mathrm{g}} \\
\mathrm{mmH} \mathrm{g}\end{array}$ & $\begin{array}{l}25 \\
35\end{array}$ & $<15,>30$ & $\begin{array}{l}27 \\
39\end{array}$ \\
\hline RVPed & $\begin{array}{l}\mathrm{mmH}_{\mathrm{g}} \\
\mathrm{mmH}\end{array}$ & 4 & $>7$ & $\begin{array}{l}27 \\
39\end{array}$ \\
\hline RVSW & $\mathrm{mmH} / \mathrm{g} \mathbf{~ m l}$ & 500 & & 39 \\
\hline
\end{tabular}




\subsubsection{The heart from an empirical viewpoint}

Physics and medicine are both empirical sciences, but when trying to perform physical measurements in the body, one is inevitably confronted with the many interactions between the system of interest and the rest of the body. Likewise, the in-situ heart is not an isolated pump. It is part of the circulation and is servo-controlled by many feedback mechanisms. In a classic article by Guyton ${ }^{40}$, the circulation and its regulation are described as a block scheme, depicted in Figure 1-11. Because of this intense regulation and the many negative feedback mechanisms, the system is extremely stable. However, from an empirical standpoint, this stability has some negative aspects: it is difficult to see from the end-result (flow and pressure) whether a certain part is dysfunctional. Likewise it is difficult to know the cause of certain changes in pressure and flow.
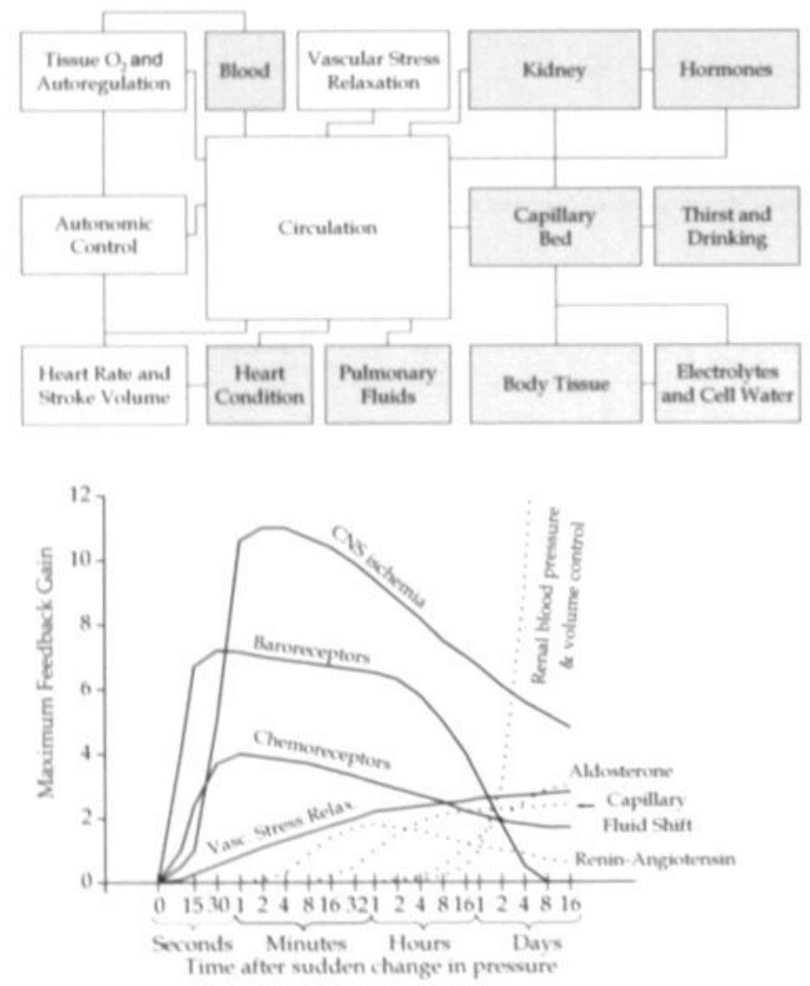

Figure 1-11: The overall regulation of the circulation ${ }^{1740}$. Top: The circulation and its regulatory mechanisms. The central circulation block compromises the heart and all vessels. All other blocks have a direct or indirect interaction with the circulation. The grey shaded blocks are slow mechanisms taking more than 5 minutes to react to sudden changes in blood pressure. Bottom: The feedback gain and response time of various regulatory mechanisms. 
In cardiac surgery, the heart is the organ of interest and it is thus cardiac information that needs to be extracted from the complex circulation system. The first and obvious step, is to identify the key cardiac function variables. Secondly, to separate cardiac information from other systems, the circulation is disturbed via an intervention. The third step used in this thesis, is to eliminate possible variables by measuring quickly after an intervention. All three steps are now discussed in detail.

\section{Key cardiac function variables: Preload, Afterload, Contractility \& Heart Rate}

As described in the previous section on heart physiology (1.2.2), the stroke volume of the ventricle is determined by how well it is filled (preload), the pressure against which it has to eject (afterload) and the intrinsic strength of the ventricle (contractility). These three parameters and a fourth one, the heart rate, determine cardiac output (liters per minute). To a large extent, preload, afterload and heart rate are determined by the regulatory mechanisms of Figure 1-11 and not by the heart itself. In contrast, contractility is much more a heart muscle property which is only mildly regulated.

The fundamental question when assessing a change in heart function are thus: Is there a change in preload, afterload, contractility, heart rate or a combination? Heart rate, left ventricular afterload and right ventricular preload can be estimated with relative ease (by distal arterial and venous pressure measurement). The determination of left ventricular preload and right ventricular afterload is more difficult and often requires a direct pressure measurement at the point of interest by catheterization. A good contractility measurement is even more difficult; one of the best contractility indices is probably the slope Ees of the end-systolic pressure-volume relation ${ }^{19}$, as described in the previous paragraph.

The strength of pressure-volume loop measurements (with the help of a conductance catheter) is the ability to determine all key cardiac function variables.

\section{Disturbing the system via interventions}

One way to characterize a highly regulated system such as the circulation, is by disturbing it. In this thesis the interventions applied are: Cardiac tilting, caval vein occlusion, acute mitral regurgitation and switching mechanical support on and off. One of the goals of these interventions, is to establish a chain of events. An example of this approach is presented in Figure 1-12. 
This approach can only be used if the method of measurement is continuous and has a sufficiently high sample frequency. Pressure-volume loop measurements with a conductance catheter have these properties.

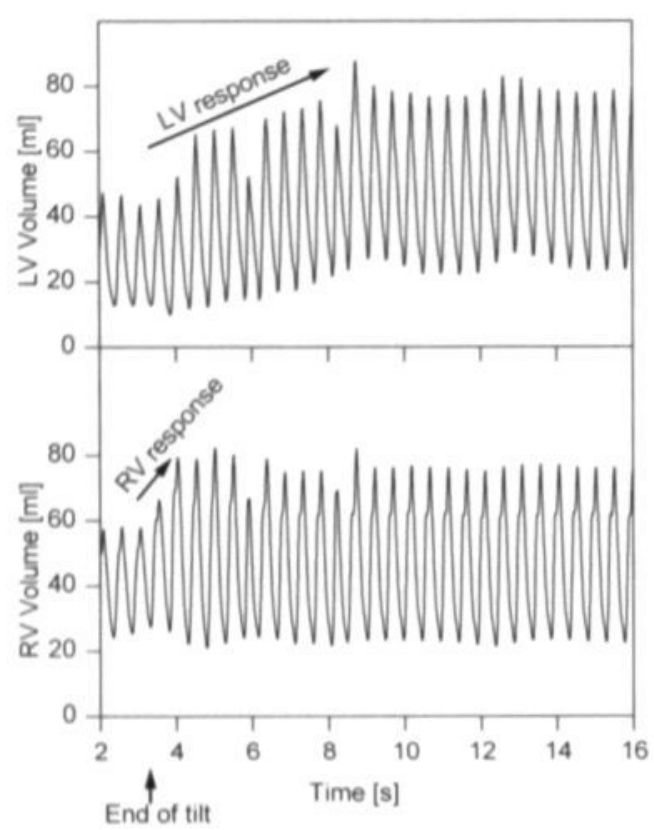

Figure 1-12: Changes in left and right ventricular volume upon repositioning of the heart from a tilt into its normal position. The right ventricle immediately responds to the new situation by an increase in end-diastolic volume within two to three beats. In contrast, the left ventricle slowly accommodates to the new situation in about ten beats.

\section{Limiting the variables: the time factor}

The response of the heart to changes in preload, afterload and heart rate are instantaneous, while changes in contractility are either very quick (e.g. ischemia ${ }^{41}$ ) or take quite a long time (as in hypertrophy).

One way to remove some of the complexity of the circulation is therefore by time. If measurements can be done quickly, the heart response can be detected while many of the feedback mechanisms mentioned in Figure 1-11, have not yet kicked in. In this thesis this approach is used many times. Usually measurements are done within 5 minutes after an intervention so that all the grey blocks from Figure 1-11, can be excluded from the analysis. Even more so, preload variation by caval vein occlusion takes only seconds, and not one of the feedback mechanisms is quick enough to respond. This leads to an evaluation of only the heart itself, which, as mentioned before, can be used to measure contractility and stiffness of the ventricle. 
Again, this approach requires a method of measurement that can detect changes quickly, preferably beat-to-beat.

In conclusion, pressure-volume loops, if measured by a conductance catheter, give a beat-to-beat, continuous, and high sample-frequency measurement of all the key cardiac function variables. From an empirical standpoint it is therefore the ideal measuring tool to investigate the heart itself and the loading conditions under which it has to operate. 


\subsection{Measurement of pressure-volume loops}

\subsubsection{Available techniques}

The determination of a pressure-volume loop requires simultaneous measurement of ventricular pressure and volume over time. Since pressure can only be measured in the cavity where it exists, a non-invasive measurement of pressure-volume loops is not possible. So, true left ventricular pressure-volume loops require invasive testing, although systolic parameters may be determined by combining arterial pressure measurement at proper time delay with non-invasive volume measurements, e.g. by echocardiography ${ }^{42,43}$.

\section{Pressure}

The most common invasive pressure measurement method is the one in which an extracorporeal pressure sensor is connected to a fluid-filled catheter with its end hole placed at the site of interest (i.e. the ventricle). The main drawback of this method is its limited frequency response: the column of water serves as a low-pass filter with a typical cut-off frequency of around $20 \mathrm{~Hz}^{4}$. This is especially troublesome when measuring ventricular pressure, as the rapid up and down stroke of pressure causes high frequencies to be present in the signal. Another drawback is that the position of the sensor relative to the catheter's end-hole is crucial to ensure that no inappropriate hydrostatic pressure is included. Finally, fluid-filled systems are susceptible to motion artifacts such as the whipping of the catheter during a heartbeat.

Miniature pressure transducers mounted on the tip of a catheter are more expensive but do not have the drawbacks of fluid-filled systems ${ }^{44}$. Currently two miniature pressure transducers are widely used, the brands Millar (Millar Instruments, Houston, TX) ${ }^{45}$ and Sentron (Sentron/CD Leycom, Zoetermeer, The Netherlands). Both are based on the piezoresistive effect: the resistance of a material changes when a mechanical force is applied. More recently a fiber-optic method of blood pressure measurement has been proposed, but this technique has not yet been extensively validated in humans ${ }^{46}$.

\section{Volume}

The in-vivo volume measurement can be carried out in a number of ways. Most are derived from images acquired by a variety of techniques followed by dimensional measurements. 
The most common technique to determine ventricular volume, is echocardiography which in combination with edge contour analysis can give online ventricular area ${ }^{43}$. This method has been found to be reasonably accurate at least for steady state conditions ${ }^{47-49}$. Worse results have been obtained at interventions such as preload reduction by caval vein occlusion $^{47,48}$. Another drawback of echocardiography is its limited sample frequency of about $30 \mathrm{~Hz}^{42,43}$.

With ventriculography the area of the ventricle is measured under fluoroscopy during a contrast injection. It requires a ventricular edge detection algorithm, much like echocardiography. The main drawbacks of ventriculography are that it requires a fluoroscopy system, that the sample frequency is limited to about $30 \mathrm{~Hz}$ and that the volume is only available after significant post-processing and cannot be obtained continuously ${ }^{50}$.

Radionuclide angiocardiography is very similar to ventriculography, but it instead of a contrast material and fluoroscopy, a radioactive material is used in combination with a gamma camera. The main disadvantages of this method are it being rather cumbersome, its use of radioactive materials, the limited sample frequency of approximately $20 \mathrm{~Hz}$ and the post-processing required to obtain the volume data ${ }^{51}$.

Another, less often applied technique is anatomical mapping, which gives an accurate $3 \mathrm{D}$ picture of the ventricular cavity ${ }^{52}$, but requires tremendous acquisition times, limiting its use for pressure-volume loops. Newer techniques, not extensively validated in humans, are magnetic resonance imaging and the transcardiac conductance technique ${ }^{53,54}$.

This thesis focuses on an alternative method for measuring pressurevolume loops, the conductance catheter technique. It has the advantage that it measures volume at a high frequency $(250 \mathrm{~Hz}$ or higher), in real time and continuously making it ideal to measure pressure-volume loops.

\subsubsection{Conductance catheter technique}

The conductance catheter was developed by Baan and colleagues in Leiden ${ }^{55}$ and measures volume via the conductance of the blood in the ventricular cavity. The conductance method is based on the realization that the conductance $G$ of a cylinder with cross-sectional area $A$, length $L$ made of a homogeneous, pure-resistive material with resistivity $\rho$ is related to its volume $\mathrm{V}$ by the following equation:

$$
G=\frac{A}{\rho L}=\begin{gathered}
V \\
\rho L^{2}
\end{gathered}
$$


This concept is applied in the heart by positioning a catheter carrying a sequence of electrodes in the right or left ventricle. A known current is applied inside the ventricle via the four outer electrodes. Then the voltage difference is determined across each inner electrode pair, and the conductance of a particular segment can be calculated. By summing up the individual segments, the total conductance and thus volume can be determined. This is illustrated in Figure 1-13.

To convert the segmental conductance (in Siemens) to the volume (in $\mathrm{ml}$ ) of the ventricle the following equation is applied:

$$
V={ }_{\alpha}^{\rho} L^{2} \sum_{1}^{N} G_{n}-V_{p c}
$$

In this equation $L$ is the inter-electrode distance and $G_{n}$ is the measured conductance of segment $\mathrm{n}$. In order to obtain the absolute volume $\mathrm{V}$, three parameters need to be known: resistivity $\rho$, parallel conductance $V_{p c}$ and slope factor $\alpha$. These parameters vary between patients, with the position of the catheter in the ventricle and with blood properties. Therefore they need to be determined each time via calibration measurements.
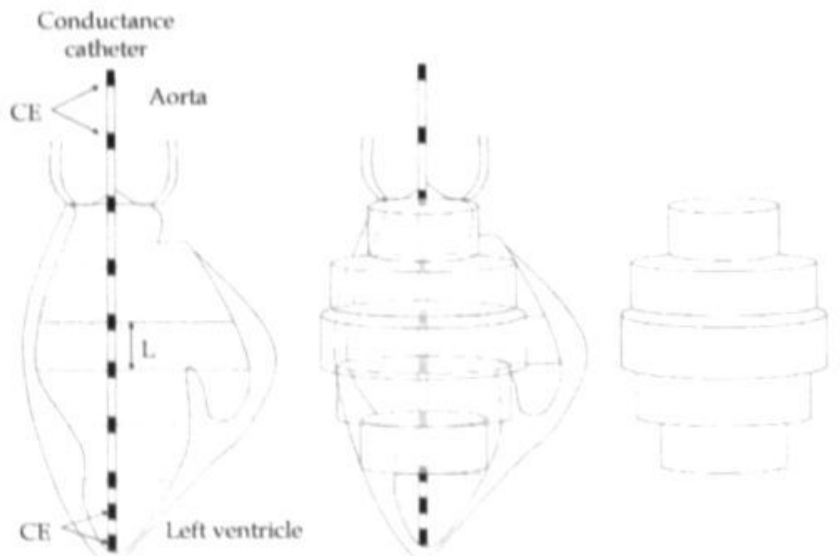

Figure 1-13: The conductance catheter measures the volume of the ventricle by summing up the conductance of individual segments. The ventricle is thus modeled as a stack of cylinders. $\mathrm{CE}=\mathrm{Current}$ electrode; $\mathrm{L}=$ interlectrode distance.

\section{Conductance catheter calibration}

The calibration procedure to obtain $\rho, V_{p x}$ and $\alpha$ used in all studies is:

First, the resistivity $\rho$ of the blood of the patient is measured. This is done be measuring the conductance of a cylinder of blood with known dimensions. Via equation (1) the resistivity can then be determined. 
Second, the parallel conductance $V_{p c}$ is determined. It corrects for the fact that the tissues surrounding the blood in the ventricle are also conductive materials (i.e. the heart muscle and the other ventricle but not the lungs ${ }^{56}$ ). The parallel conductance is measured via hypertonic saline injection ${ }^{57}$. Third, the slope factor $\alpha$ needs to be determined. Commonly one argues that this factor corrects for any volume the catheter 'misses' at the top and bottom of the ventricle (see Figure 1-13). But more correctly, the slope factor also corrects for the fall of the electric current density at the edges of the ventricle ${ }^{58,59}$. It is measured by comparing conductance derived stroke volume to actual stroke volume measured by another technique (in this thesis: aortic flow probe or thermodilution).

\section{Conductance catheter position}

As can be appreciated from the theory behind the conductance technique, the catheter needs to lie straight (so that it lies perpendicular to the electric field), with its tip in the apex (so it does not 'miss' volume) and in the middle of the ventricle (so that it has equal sensitivity for the whole cylinder it measures). To achieve such a position in the left ventricle, two routes are followed in this thesis. One is the retrograde catheterization across the aortic valve. During surgery the antegrade catheterization via the pulmonary vein is usually easier and sometimes the only option, like in the aortic stenosis patients. 


\subsection{Pressure-volume loops in cardiac surgery}

\subsubsection{Requirements}

If pressure-volume loops are to be measured during cardiac surgery, the method of choice is the conductance catheter which has procedural and technical benefits over other techniques (see previous section). A number of requirements must be met to be able to perform this measurement.

First of all, a conductance catheter needs to be positioned in the ventricle of interest. During surgery this can be done by

a) retrograde catheterization either via a distal systemic artery ${ }^{55}$, the aortic $\operatorname{root}^{60}$, the right ventricular outflow tract ${ }^{61}$ or the pulmonary artery $^{62}$,

b) antegrade catheterization via the pulmonary vein ${ }^{33,48}$ or a systemic vein ${ }^{39}$ or

c) by apical puncture ${ }^{63}$.

To check the correct position of the catheter, trans-esophageal echocardiography or fluoroscopy is used.

If a conductance catheter is placed, uncalibrated volume measurements are immediately available. In some cases (e.g. biventricular pacing) uncalibrated volume measurements are sufficient as only relative changes in long axis synchrony or stroke volume are of interest. However, as discussed in section 1.3.2, for absolute volume measurements a calibration procedure must be performed. This requires a measurement of blood resistivity (which may vary considerably during surgery ${ }^{64}$ ), a reference stroke volume or cardiac output measure (usually with a Swan-Ganz thermodilution catheter) and a hypertonic saline injection to determine parallel conductance. The hypertonic saline is injected either in the right atrium or pulmonary artery ${ }^{56}$, or via a systemic vein ${ }^{39,65}$.

Finally, a preload reduction is often performed to get the all-important loadindependent indices of cardiac function (see section 1.2.2). During surgery the inferior caval vein is usually banded. 


\subsubsection{Overview of cardiac surgery studies}

The application of pressure-volume loops in cardiac surgery has been rather limited ${ }^{66}$. A few notable exceptions are discussed in this section.

\section{Operative care}

Cardiac surgery is meant to treat heart disease, but to be able to perform the operation a number of procedures are necessary that result in a depression of ventricular function (e.g. ischemia), for which a number of protecting countermeasures are employed (e.g. cardioplegia). Pressure-volume loops have been used to study the impact and relative merits of various surgical procedures. These include studies into cardioplegia ${ }^{32} 28,67$, the right ventricle during surgery ${ }^{61}$, hypothermia ${ }^{60}$, ultrafiltration ${ }^{6 s}$, surgery for congenital heart disease $\mathrm{e}^{63,69}$ and ventricular function during valve operations ${ }^{70}$.

\section{Cardiomyoplasty}

Cardiomyoplasty is the surgical procedure in which the latissimus dorsi muscle is wrapped around the failing, dilated heart to increase its contractility. Pressure-volume loops were useful to demonstrate the effects of this procedure on systolic and diastolic function ${ }^{71-73}$.

\section{Congenital heart disease}

Congenital heart disease has an impact on cardiac function for which conventional diagnostic methods are sometimes less useful. Pressurevolume loops offer useful information on the right ventricle in congenital diseases such as transposition of the great arteries ${ }^{74}$ and tetralogy of Fallot ${ }^{75}$ and on the systemic ventricle in the Fontan procedure ${ }^{76}$.

\section{Ventricular remodeling}

Surgical ventricular remodeling is a surgical treatment for heart failure patients with (very) dilated hearts. The procedure consists of the removal a piece of the left ventricle and subsequent ventricular reconstruction, thereby reducing ventricular size and improving its function. Pressure-volume loops have been used in these patients to study the systolic and diastolic performance of the heart after the Batista procedure ${ }^{77-80}$ and after aneurysmectomy ${ }^{81.82}$. 


\subsection{Aim and outline of the thesis}

The subject of this thesis is the application of pressure-volume loops by conductance catheter in cardiac surgery. So the central theme is not a disease nor treatment but a diagnostic modality. Furthermore, the modality as such is not new; it has been extensively validated. However, despite the increasing experimental and clinical use of pressure-volume loops by conductance catheter in other areas like physiology and cardiology, few studies have been conducted in the field of cardiac surgery.

It is the aim of this thesis to describe the use of the conductance catheter technique in typical cardiac surgery subjects: valvular disease, coronary artery bypass grafting and mechanical support. Pressure-volume loops offer specific insights which no other diagnostic modality can offer and which can contribute to the correct diagnosis and useful treatment of patients. This thesis should contribute to the wider use of pressure-volume loops in general and the conductance catheter in cardiac surgery in particular.

\section{Valvular disease}

Aortic stenosis is a disease which leads to left ventricular hypertrophy, diastolic dysfunction, systolic dysfunction and eventually overt heart failure. Therefore, in patients having severe and symptomatic aortic stenosis, aortic valve replacement is recommended. However, a significant percentage of these patients do not show improvement of function or regression of hypertrophy. It is our hypothesis that these symptomatic patients have been operated too late. On the other hand aortic valve replacement in asymptomatic patients has inconsistent results and is not recommended ${ }^{83}$. This has lead to the hypothesis that in some patients symptoms develop after left ventricular dysfunction has become irreversible. In Chapter 2 "Aortic stenosis", pressure-volume loops are used to determine in detail the systolic and diastolic function of the left ventricle. The goal of this ongoing study, is to identify prognostically important indices for the regression of hypertrophy and the normalization of left ventricular function after aortic valve replacement.

Apart from valvular stenosis, valvular leakage (regurgitation) also affects ventricular function. This raises a fundamental question, which has not been answered before: Can we diagnose aortic regurgitation in a pressurevolume loop? Conceptually, one would expect to detect aortic regurgitation as an increase in volume in the relaxation phase of the loop. Chapter 3 "Aortic regurgitation" discusses this concept but shows disappointing results: no correlation was found between the volume increase in the relaxation phase and the severity of aortic regurgitation determined by echocardiography. 


\section{Off-pump coronary artery bypass grafting}

Conventional coronary artery bypass grafting is performed on the arrested heart with the aid of the cardiopulmonary bypass. It has been demonstrated that beating heart or off-pump coronary artery bypass grafting (OPCAB) can be performed safely with good results ${ }^{84}$. This advancement is due to the introduction of tissue stabilizers such as the Octopus ${ }^{85}$. Besides tissue stabilization for the anastamosis, the Octopus can also be used as a cardiac positioning device thereby allowing grafting of vessels on the posterior and inferior wall. However, performing OPCAB to these vessels is limited by hemodynamic instability that results from tilting the heart in order to reach the posterior and inferior wall of the left ventricle ${ }^{86}$.

Chapter 4 "Cardiac tilting" is a study in which pressure-volume loops proved that the right ventricle is the problem during tilting of the heart with an Octopus. As soon as the right ventricle emerged as the problem during tilting, various types of right or bi-ventricular support devices have been suggested ${ }^{87}$. Chapter 5 "Right ventricular support" describes in detail one of such devices: the Enabler.

The identification of the right ventricle as the cause of the hemodynamic deterioration, has led to a change in strategy. Nowadays the Octopus is only used to stabilize the anastomosis site, while pericardial sutures or apical suction devices are used to position the heart with much better hemodynamic results ${ }^{88,89}$. This change in strategy has also limited the need for right ventricular support and currently only two devices are marketed as $\operatorname{such}^{90,91}$.

\section{Mechanical Support}

Mechanical support is indicated when the heart can not pump enough blood to sustain viable circulation, in spite of maximum medical treatment ${ }^{92.93}$. This can occur during myocarditis, after acute and large myocardial infarction, acute mitral regurgitation, post-cardiotomy and acute worsening of chronic heart failure. Currently, two methods of circulatory support are widely used: The first is the intra-aortic balloon pump (IABP) ${ }^{94}$, the second is an assist device placed either via a thoracotomy ${ }^{95}$ or via the femoral vessels ${ }^{96}$. While the IABP is minimally invasive, it has limited capacity to support the heart. By contrast, assist devices are all very invasive and have numerous complications, but have excellent unloading and supporting characteristics. A minimal invasive device with better supporting characteristics than the IABP would be very useful in cardiac surgery. 


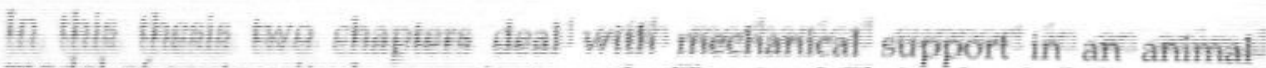

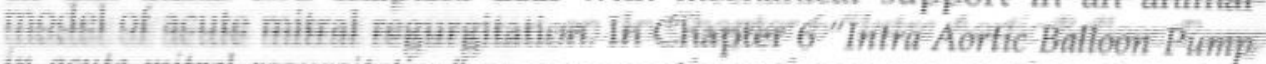

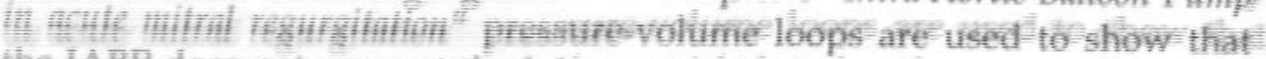

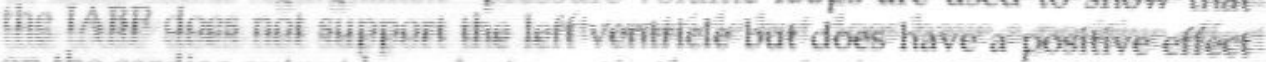
on the cardiac gatput by reducingomital regurgitation.

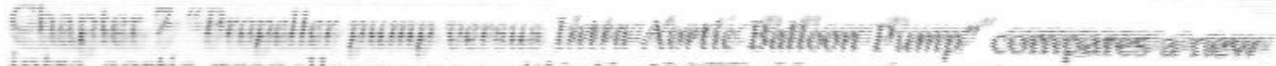

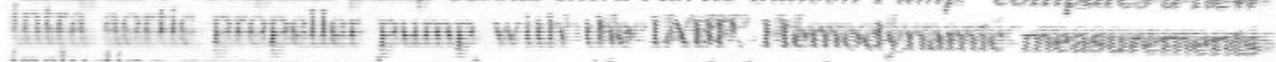

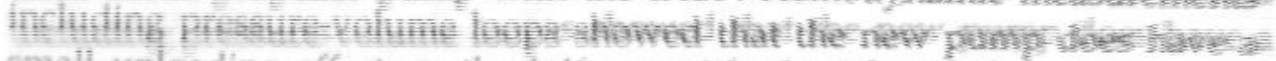

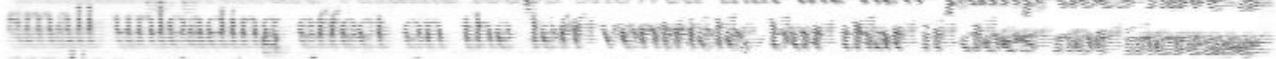

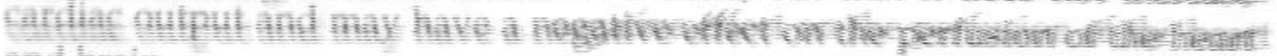
and hrain.

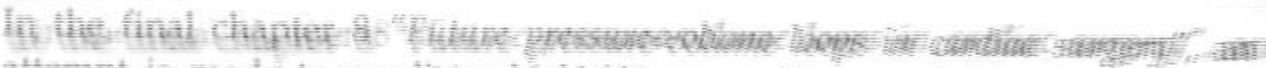

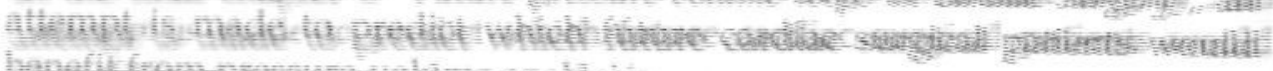

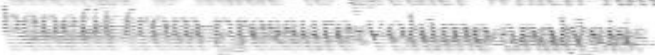




\subsection{References}

1 Klein MJ. Thermodynamics in Einstein's thought. Science 1967;157:509-516.

2 Denslow S. Relationship between PVA and myocardial oxygen consumption can be derived from thermodynamics. Am J Physiol 1996;270:H730-740.

3 Suga H. Ventricular energetics. Physiol Rev 1990;70:247-277.

4 ten Velden $\mathrm{GH}$, Elzinga G, Westerhof $\mathrm{N}$. Left ventricular energetics. Heat loss and temperature distribution of canine myocardium. Circ Res 1982;50:63-73.

5 Westerhof N. Cardiac work and efficiency. Cardiovasc Res 2000;48:4-7.

6 Takaoka H, Takeuchi M, Odake M, Hayashi Y, Hata K, Mori M, Yokoyama M. Comparison of hemodynamic determinants for myocardial oxygen consumption under different contractile states in human ventricle. Circulation 1993;87:59-69.

7 Ishihara $\mathrm{H}$, Yokota $\mathrm{M}$, Sobue $\mathrm{T}$, Saito $\mathrm{H}$. Relation between ventriculoarterial coupling and myocardial energetics in patients with idiopathic dilated cardiomyopathy. J Am Coll Cardiol 1994;23:406-416.

8 Katz AM. Influence of altered inotropy and lusitropy on ventricular pressurevolume loops. J Am Coll Cardiol 1988;11:438-445.

9 Tanoue Y, Herijgers P, Meuris B, Verbeken E, Leunens V, Lox M, Flameng W. Ischemic preconditioning reduces unloaded myocardial oxygen consumption in an in-vivo sheep model. Cardiovasc Res 2002;55:633.

10 Korvald C, Elvenes OP, Aghajani E, Myhre ES, Myrmel T. Postischemic mechanoenergetic inefficiency is related to contractile dysfunction and not altered metabolism. Am J Physiol Heart Circ Physiol 2001;281:H2645-2653.

11 Hayashi Y, Takeuchi M, Takaoka H, Hata K, Mori M, Yokoyama M. Alteration in energetics in patients with left ventricular dysfunction after myocardial infarction: increased oxygen cost of contractility. Circulation 1996;93:932-939.

12 Takaoka H, Takeuchi M, Odake M, Hata K, Hayashi Y, Mori M, Yokoyama M. Depressed contractile state and increased myocardial consumption for nonmechanical work in patients with heart failure due to old myocardial infarction. Cardiovasc Res 1994;28:1251-1257.

13 Asanoi H, Kameyama T, Ishizaka S, Nozawa T, Inoue H. Energetically optimal left ventricular pressure for the failing human heart. Circulation 1996;93:67-73.

14 Starling MR. Effects of valve surgery on left ventricular contractile function in patients with long-term mitral regurgitation. Circulation 1995;92:811-818.

15 Kameyama T, Asanoi H, Ishizaka S, Sasayama S. Ventricular load optimization by unloading therapy in patients with heart failure. J Am Coll Cardiol 1991;17:199-207.

16 Nelson GS, Berger RD, Fetics BJ, Talbot M, Spinelli JC, Hare JM, Kass DA. Left ventricular or biventricular pacing improves cardiac function at diminished energy cost in patients with dilated cardiomyopathy and left bundle-branch block. Circulation 2000;102:3053-3059.

17 Guyton AC. Textbook of medical physiology. Saunders, Philadelphia, 1991.

18 Brutsaert DL, Sys SU. Relaxation and diastole of the heart. Physiol Rev 1989;69:1228-1315.

19 Grossman W. Evaluation of systolic and diastolic function of the myocardium. In: D.S. Baim WG. Cardiac catheterization, angiography, and intervention. William \& Wilkins, Baltimore, MD, 1996:339-341. 
20 How to diagnose diastolic heart failure. European Study Group on Diastolic Heart Failure. Eur Heart J 1998;19:990-1003.

21 Murakami T, Hess OM, Gage JE, Grimm J, Krayenbuehl HP. Diastolic filling dynamics in patients with aortic stenosis. Circulation 1986;73:1162-1174.

22 Villari B, Hess OM, Kaufmann P, Krogmann ON, Grimm J, Krayenbuehl HP. Effect of aortic valve stenosis (pressure overload) and regurgitation (volume overload) on left ventricular systolic and diastolic function. Am J Cardiol 1992;69:927-934.

23 Little WC. Assessment of normal and abnormal ventricular function. In: Braunwald E, Zipes DP and Libby P. Heart disease: a textbook of cardiovascular medicine. W.B. Saunders Company, Philadelphia, 2001:479-502.

24 Fifer MA, Grossman W. Measurement of ventricular volume, ejection fraction, mass, wall stress, and regional wall motion. In: Baim DS and Grossman W. Cardiac catheterization, angiography, and intervention. Williams \& Wilkins, Baltimore, 1991:315-331.

25 Iskandrian AS, Hakki AH, Kane-Marsch S. Left ventricular pressure/volume relationship in aortic regurgitation. Am Heart J 1985;110:1026-1032.

26 Osbakken M, Bove AA, Spann JF. Left ventricular function in chronic aortic regurgitation with reference to end-systolic pressure, volume and stress relations. Am J Cardiol 1981;47:193-198.

27 Davidson CJ, Bonow RO. Cardiac catheterization. In: Braunwald E, Zipes DP and Libby P. Heart disease: a textbook of cardiovascular medicine. W.B. Saunders Company, Philadelphia, 2001:359-386.

28 Mehmel HC, Schwarz F, Ruffmann K, Manthey J, von Olshausen K, Kubler W. End-systolic pressure-volume and end-systolic stress-volume relationships in patients with aortic stenosis and with normal valvular function. Basic Res Cardiol 1983;78:338-350.

29 Rumberger JA. Use of electron beam tomography to quantify cardiac diastolic function. Cardiol Clin 2000;18:547-556.

30 Lorenz CH, Flacke S, Fischer SE. Noninvasive modalities. Cardiac MR imaging. Cardiol Clin 2000;18:557-570.

31 Hayward CS, Kalnins WV, Kelly RP. Gender-related differences in left ventricular chamber function. Cardiovasc Res 2001;49:340-350.

32 Wallace AW, Ratcliffe MB, Nose PS, Bellows W, Moores W, McEnany MT, Flachsbart K, Mangano DT. Effect of induction and reperfusion with warm substrate-enriched cardioplegia on ventricular function. Ann Thorac Surg 2000;70:1301-1307.

33 Schreuder J, Biervliet JD, van der Velde ET, ten Have K, van Dijk AD, Meyne NG, Baan J. Systolic and diastolic pressure-volume relationships during cardiac surgery. J Cardiothorac Vasc Anesth 1991;5:539-545.

34 Little WC. The left ventricular $\mathrm{dP} / \mathrm{dtmax}$-end-diastolic volume relation in closed-chest dogs. Circ Res 1985;56:808-815.

35 Wallace A, Lam HW, Mangano DT. Linearity, load dependence, hysteresis, and clinical associations of systolic and diastolic indices of left ventricular function in man. Multicenter Study of Perioperative Ischemia (McSPI) Research Group. J Card Surg 1995;10:460-467.

36 Norton JM. Toward consistent definitions for preload and afterload. Adv Physiol Educ 2001;25:53-61. 
37 Kass DA, Midei M, Graves W, Brinker JA, Maughan WL. Use of a conductance (volume) catheter and transient inferior vena caval occlusion for rapid determination of pressure-volume relationships in man. Cathet Cardiovasc Diagn 1988;15:192-202.

38 Korvald C, Elvenes OP, Myrmel T, Sorlie DG. Cardiac dysfunction and inefficiency after substrate-enriched warm blood cardioplegia. Eur J Cardiothorac Surg 2001;20:555-562; discussion 562-554.

39 Bishop A, White P, Oldershaw P, Chaturvedi R, Brookes C, Redington A. Clinical application of the conductance catheter technique in the adult human right ventricle. Int J Cardiol 1997;58:211-221.

40 Guyton AC, Coleman TG, Granger HJ. Circulation: overall regulation. Annu Rev Physiol 1972;34:13-46.

41 Kass DA, Midei M, Brinker J, Maughan WL. Influence of coronary occlusion during PTCA on end-systolic and end-diastolic pressure-volume relations in humans. Circulation 1990;81:447-460.

42 Gorcsan J, 3rd. Load-Independent Indices of Left Ventricular Function Using Automated Border Detection. Echocardiography 1999;16:63-76.

43 Deneault LG, Kancel MJ, Denault A, Mandarino WA, Gasior TA, Gorcsan J, Pinsky MR. A system for the on-line acquisition, visualization, and analysis of pressure-area loops. Comput Biomed Res 1994;27:61-67.

44 Nichols WW, Pepine CJ, Conti CR. Catheter tip manometer system: Pressure and velocity measurement. Adv Cardiovasc Phys 1983;5(Part II):144-176.

45 Millar HD, Baker LE. A stable ultraminiature catheter-tip pressure transducer. Med Biol Eng 1973;11:86-89.

46 Reesink KD, van der Nagel T, Bovelander J, Jansen JR, van der Veen FH, Schreuder JJ. Feasibility study of a fiber-optic system for invasive blood pressure measurements. Catheter Cardiovasc Interv 2002;57:272-276.

47 Chen $\mathrm{CH}$, Nevo E, Fetics B, Nakayama M, Pak PH, Maughan WL, Kass DA. Comparison of continuous left ventricular volumes by transthoracic twodimensional digital echo quantification with simultaneous conductance catheter measurements in patients with cardiac diseases. Am J Cardiol 1997;80:756-761.

48 Schmidlin D, Aschkenasy S, Vogt PR, Schmidli J, Jenni R, Schmid ER. Left ventricular pressure-area relations as assessed by transoesophageal echocardiographic automated border detection: comparison with conductance catheter technique in cardiac surgical patients. Br J Anaesth 2000;85:379-388.

49 Amirhamzeh MM, Dean DA, Jia CX, Cabreriza SE, Yano OJ, Burkhoff D, Spotnitz HM. Validation of right and left ventricular conductance and echocardiography for cardiac function studies. Ann Thorac Surg 1996;62:11041109.

50 Raff U, Culclasure TF, Clark C, Overturf L, Groves BM. Computerized left ventricular pressure-volume relationships (pV-loops) using disposable angiographic tip transducer pigtail catheters. Int J Card Imaging 2000;16:13-21.

51 Harpole DH, Skelton TN, Davidson CJ, Jones RH, Bashore TM. Validation of pressure-volume data obtained in patients by initial transit radionuclide angiocardiography. Am Heart J 1989;118:983-989.

52 Gepstein L, Hayam G, Ben-Haim SA. A novel method for nonfluoroscopic catheter-based electroanatomical mapping of the heart. In vitro and in vivo accuracy results. Circulation 1997;95:1611-1622. 
53 Staal EM, Steendijk P, Koning G, Dijkstra J, Jukema JW, Baan J. Continuous online measurement of absolute left ventricular volume by transcardiac conductance: angiographic validation in sheep. Crit Care Med 2002;30:13011305.

54 Steendijk P, Lardenoye JW, van der Velde ET, Schalij MJ, Baan J. Evaluation of a new transcardiac conductance method for continuous on-line measurement of left ventricular volume. Crit Care Med 2000;28:1599-1606.

55 Baan J, van der Velde ET, de Bruin HG, Smeenk GJ, Koops J, van Dijk AD, Temmerman D, Senden J, Buis B. Continuous measurement of left ventricular volume in animals and humans by conductance catheter. Circulation $1984 ; 70: 812-823$.

56 Szwarc RS, Ball HA. Simultaneous LV and RV volumes by conductance catheter: effects of lung insufflation on parallel conductance. Am J Physiol 1998;275:H653-661.

57 Steendijk P, Staal E, Jukema JW, Baan J. Hypertonic saline method accurately determines parallel conductance for dual-field conductance catheter. Am J Physiol Heart Circ Physiol 2001;281:H755-763.

58 Hettrick DA, Battocletti JH, Ackmann JJ, Linehan JH, Warltier DC. Effects of physical parameters on the cylindrical model for volume measurement by conductance. Ann Biomed Eng 1997;25:126-134.

59 Steendijk P, van der Velde ET, Baan J. Single and dual excitation of the conductance-volume catheter analysed in a spheroidal mathematical model of the canine left ventricle. Eur Heart J 1992;13 Suppl E:28-34.

60 Lewis ME, Al-Khalidi AH, Townend JN, Coote J, Bonser RS. The effects of hypothermia on human left ventricular contractile function during cardiac surgery. J Am Coll Cardiol 2002;39:102-108.

61 Brookes Cl, White PA, Bishop AJ, Oldershaw PJ, Redington AN, Moat NE. Validation of a new intraoperative technique to evaluate load-independent indices of right ventricular performance in patients undergoing cardiac operations. J Thorac Cardiovasc Surg 1998;116:468-476.

62 Woodard JC, Bertram CD, Gow BS. Detecting right ventricular volume changes using the conductance catheter. Pacing Clin Electrophysiol 1992;15:2283-2294.

63 Chaturvedi RR, Lincoln C, Gothard JW, Scallan MH, White PA, Redington AN, Shore DF. Left ventricular dysfunction after open repair of simple congenital heart defects in infants and children: quantitation with the use of a conductance catheter immediately after bypass. J Thorac Cardiovasc Surg 1998;115:77-83.

64 Al-Khalidi AH, Townend JN, Bonser RS, Coote JH. Validation of the conductance catheter method for measurement of ventricular volumes under varying conditions relevant to cardiac surgery. Am J Cardiol 1998;82:1248-1252.

65 Steendijk P, Baan J. Comparison of intravenous and pulmonary artery injections of hypertonic saline for the assessment of conductance catheter parallel conductance. Cardiovasc Res 2000;46:82-89.

66 Caputo M, Schreuder J, Fino C, Baan J, Alfieri O. Assessment of myocardial performance with ventricular pressure-volume relations: clinical applications in cardiac surgery. Ital Heart J 2000;1:269-274.

67 Ericsson AB, Kawakami T, Vaage J. Intermittent warm blood cardioplegia does not provide adequate myocardial resuscitation after global ischaemia. Eur J Cardiothorac Surg 1999;16:233-239. 
68 Chaturvedi RR, Shore DF, White PA, Scallan MH, Gothard JW, Redington AN, Lincoln C. Modified ultrafiltration improves global left ventricular systolic function after open-heart surgery in infants and children. Eur J Cardiothorac Surg 1999;15:742-746.

69 Tatebe S, Davies MJ, Tsang VT, Elliott MJ. Perioperative monitoring of left ventricular contractility. J Thorac Cardiovasc Surg 2001;122:1036-1038.

70 Harpole DH, Rankin JS, Wolfe WG, Smith LR, Young WG, Clements FM, Jones RH. Assessment of left ventricular functional preservation during isolated cardiac valve operations. Circulation 1989;80:III1-9.

71 Schreuder JJ, van der Veen FH, van der Velde ET, Delahaye F, Alfieri O, Jegaden O, Lorusso R, Jansen JR, Hoeksel SA, Finet G, Volterrani M, Kaulbach HG, Baan J, Wellens HJ. Left ventricular pressure-volume relationships before and after cardiomyoplasty in patients with heart failure. Circulation 1997;96:2978-2986.

72 Schreuder JJ, van der Veen FH, van der Velde ET, Delahaye F, Alfieri O, Jegaden O, Lorusso R, Jansen JR, van Ommen V, Finet G, et al. Beat-to-beat analysis of left ventricular pressure-volume relation and stroke volume by conductance catheter and aortic Modelflow in cardiomyoplasty patients. Circulation 1995;91:2010-2017.

73 Kass DA, Baughman KL, Pak PH, Cho PW, Levin HR, Gardner TJ, Halperin HR, Tsitlik JE, Acker MA. Reverse remodeling from cardiomyoplasty in human heart failure. External constraint versus active assist. Circulation 1995;91:23142318.

74 Derrick GP, Narang I, White PA, Kelleher A, Bush A, Penny DJ, Redington AN. Failure of stroke volume augmentation during exercise and dobutamine stress is unrelated to load-independent indexes of right ventricular performance after the Mustard operation. Circulation 2000;102:III154-159.

75 Chaturvedi RR, Kilner PJ, White PA, Bishop A, Szwarc R, Redington AN. Increased airway pressure and simulated branch pulmonary artery stenosis increase pulmonary regurgitation after repair of tetralogy of Fallot. Real-time analysis with a conductance catheter technique. Circulation 1997;95:643-649.

76 Tanoue Y, Sese A, Ueno Y, Joh K, Hijii T. Bidirectional Glenn procedure improves the mechanical efficiency of a total cavopulmonary connection in high-risk fontan candidates. Circulation 2001;103:2176-2180.

77 Popovic Z, Miric M, Gradinac S, Neskovic AN, Bojic M, Popovic AD. Partial left ventriculectomy improves left ventricular end systolic elastance in patients with idiopathic dilated cardiomyopathy. Heart 2000;83:316-319.

78 Schreuder JJ, Steendijk P, van der Veen FH, Alfieri O, van der Nagel T, Lorusso $\mathrm{R}$, van Dantzig JM, Prenger KB, Baan J, Wellens HJ, Batista RJ. Acute and shortterm effects of partial left ventriculectomy in dilated cardiomyopathy: assessment by pressure-volume loops. J Am Coll Cardiol 2000;36:2104-2114.

79 Schreuder JJ, Steendijk P, Baan J, Alfieri O. Batista's operation: what have we learned? J Am Coll Cardiol 2001;38:286.

80 Burkhoff D. New heart failure therapy: the shape of things to come? J Thorac Cardiovasc Surg 2001;122:421-423.

81 Ratcliffe MB, Wallace AW, Salahieh A, Hong J, Ruch S, Hall TS. Ventricular volume, chamber stiffness, and function after anteroapical aneurysm plication in the sheep. J Thorac Cardiovasc Surg 2000;119:115-124. 
82 Castiglioni A, Quarti A, Schreuder J, Blasio A, Benussi S, Torracca L, Maisano F, Alfieri O. Surgical restoration of the left ventricle for postinfarction aneurysm. Ital Heart J 2002;3:370-374.

83 Bonow RO, Carabello B, de Leon AC, Jr., Edmunds LH, Jr., Fedderly BJ, Freed MD, Gaasch WH, McKay CR, Nishimura RA, O'Gara PT, O'Rourke RA, Rahimtoola SH, Ritchie JL, Cheitlin MD, Eagle KA, Gardner TJ, Garson A, Jr., Gibbons RJ, Russell RO, Ryan TJ, Smith SC, Jr. Guidelines for the management of patients with valvular heart disease: executive summary. A report of the American College of Cardiology/American Heart Association Task Force on Practice Guidelines (Committee on Management of Patients with Valvular Heart Disease). Circulation 1998;98:1949-1984.

84 Abu-Omar Y, Taggart DP. Off-pump coronary artery bypass grafting. Lancet 2002;360:327-330.

85 Jansen EW, Lahpor JR, Borst C, Grundeman PF, Bredee JJ. Off-pump coronary bypass grafting: how to use the Octopus Tissue Stabilizer. Ann Thorac Surg 1998;66:576-579.

86 Grundeman PF, Borst C, van Herwaarden JA, Mansvelt Beck HJ, Jansen EW. Hemodynamic changes during displacement of the beating heart by the Utrecht Octopus method. Ann Thorac Surg 1997;63:S88-92.

87 Mueller XM, von Segesser LK. Circulatory support for OPCAB procedures. Perfusion 2002;17:305-312.

88 Torracca L, Schreuder J, Quarti A, Ismeno G, Franze V, Alfieri O. Acute effects of beating heart coronary surgery on left ventricular performance. Ann Thorac Surg 2002;74:S1348-1352.

89 Grundeman P, Verlaan C, Boven V, Borst C. Ninety degrees anterior cardiac displacement in off-pump CABG: The Starfish ${ }^{\mathrm{TM}}$ cardiac positioner preserves stroke volume [Abstract]. Heart Surg Forum 2002;5 [suppl 2]:S181.

90 Lima LE, Jatene F, Buffolo E, Vanky F, Casimir-Ahn E, Lohn U, Leprince P, Pavie A, Laczkovics AM, Reichenspurner H, Calafiore A, Nataf P, Mack M. A multicenter initial clinical experience with right heart support and beating heart coronary surgery. Heart Surg Forum 2001;4:60-64.

91 Meyns B, Autschbach R, Boning A, Konertz W, Matschke K, Schondube F, Wiebe K, Fischer E. Coronary artery bypass grafting supported with intracardiac microaxial pumps versus normothermic cardiopulmonary bypass: a prospective randomized trial. Eur J Cardiothorac Surg 2002;22:112-117.

92 Ryan TJ, Antman EM, Brooks NH, Califf RM, Hillis LD, Hiratzka LF, Rapaport E, Riegel B, Russell RO, Smith EE, 3rd, Weaver WD, Gibbons RJ, Alpert JS, Eagle KA, Gardner TJ, Garson A, Jr., Gregoratos G, Smith SC, Jr. 1999 update: ACC/AHA guidelines for the management of patients with acute myocardial infarction. A report of the American College of Cardiology/American Heart Association Task Force on Practice Guidelines (Committee on Management of Acute Myocardial Infarction). J Am Coll Cardiol 1999;34:890-911.

93 Phillips SJ, Zeff RH, Kongtahworn C, Grignon A, Barker L, Iannone LA, Tannenbaum M, Verhey MH, Wickemeyer WJ, Ghali MG, et al. Benefits of combined balloon pumping and percutaneous cardiopulmonary bypass. Ann Thorac Surg 1992;54:908-910.

94 Anderson RD, Ohman EM, Holmes DR, Jr., Col I, Stebbins AL, Bates ER, Stomel RJ, Granger CB, Topol EJ, Califf RM. Use of intraaortic balloon counterpulsation in patients presenting with cardiogenic shock: observations from the GUSTO-I 
Study. Global Utilization of Streptokinase and TPA for Occluded Coronary Arteries. J Am Coll Cardiol 1997;30:708-715.

95 Delgado DH, Rao V, Ross HJ, Verma S, Smedira NG. Mechanical circulatory assistance: state of art. Circulation 2002;106:2046-2050.

96 Kolla S, Lee WA, Hirschl RB, Bartlett RH. Extracorporeal life support for cardiovascular support in adults. Asaio J 1996;42:M809-819. 


\section{Chapter 2}

\section{Aortic stenosis}

Published as:

Dekker ALAJ, Barenbrug PJC, van der Veen FH, Roekaerts P, Mochtar B, Maessen JG. Pressure-volume loops in patients with aortic stenosis. J Heart Valve Dis 2003;12:325-332. 


\subsection{Abstract}

\section{Background}

Pre-operative left ventricular function is the strongest predictor of outcome after valve replacement for aortic stenosis. Although pressure-volume analysis with the conductance catheter technique can provide detailed information on left ventricular systolic and diastolic function, this technique has not yet been used in aortic stenosis patients. This study examined the potential use of left ventricular function measurements using pressurevolume analysis with a conductance catheter during surgery for aortic stenosis.

\section{Methods}

In six patients with severe symptomatic aortic stenosis, a conductance catheter was placed under trans esophageal echocardiographic guidance in the left ventricle via the right superior pulmonary vein.

\section{Results}

The procedure was successful in all patients and lengthened the operation by less than 30 minutes with no increase in bypass or aortic cross-clamping time. Pressure-volume analysis showed that systolic function was normal in all patients (EF $42-59 \%$, end-systolic elastance $1.6-4.5 \mathrm{mmHg} / \mathrm{ml}$ ) while diastolic dysfunction was found in all patients (Tau $32-96 \mathrm{~ms}$, LV enddiastolic pressure $7-42 \mathrm{mmHg}$, atrial kick $25-60 \%$ ). After valve replacement, systolic function improved but diastolic function did not.

\section{Conclusions}

The conductance catheter placed via the pulmonary vein can determine left ventricular systolic and diastolic dysfunction in detail in an individual patient with aortic stenosis before and after valve replacement. The technique may be used to extend diagnostic data from less-invasive modalities and to determine prognosis in the individual patient. 


\subsection{Introduction}

Analysis of left ventricular pressure-volume loops has been accepted as the gold standard to study left ventricular function ${ }^{1-3}$. With the introduction of the conductance catheter and by interventions such as preload reduction by caval vein occlusion 4 , detailed and load-independent indices for systolic and diastolic function have been obtained in surgical patients at our institution ${ }^{5-7}$ and by other investigators ${ }^{8,9}$.

Pressure-volume analysis has rarely been used in aortic stenosis patients for mainly three reasons. First, retrograde catheterization through the stenotic valve is associated with a high complication rate ${ }^{10}$. Second, catheterization through the stenotic valve affects cardiac function, probably by decreasing the aortic valve area ${ }^{11}$. Third, since the aortic valvular gradient and area are still the diagnostic hallmarks for clinical decision making and can be easily obtained by echocardiography, there has been no need for invasive diagnostics. However, timing of aortic valve replacement solely based on the severity of the gradient and symptoms can be disputed: The state of myocardial adaptation to chronic pressure volume overload is also prognostically relevant ${ }^{12-14}$. Consequently, a number of patients do not show regression of left ventricular hypertrophy and develop heart failure despite aortic valve replacement.

Pressure-volume analysis in aortic stenosis patients has been limited to radionuclide angiocardiography or ventriculography using a transseptal approach ${ }^{15-18}$, and some investigators reported successful retrograde catheterization studies ${ }^{19,20}$. However, no study has reported the use of the conductance catheter in these patients although it has clear advantages (continuous volume and pressure measurement, beat-to-beat interventions, relative ease of use) compared to the previously applied methods.

It has been shown by our institution and other investigators that the conductance catheter can be placed via the pulmonary vein in surgical patients ${ }^{7.9}$. In this study we tested the feasibility of measuring pressurevolume loops in patients with aortic stenosis by inserting a conductance catheter in the left ventricle via the pulmonary vein before and after aortic valve replacement surgery. 


\subsection{Methods}

\subsubsection{Patient population}

Six male patients (age 60-76 years) with symptomatic severe aortic valve stenosis (AVA $\left.<1.0 \mathrm{~cm}^{2}\right)^{21}$, were operated on for aortic valve replacement (Table 2-1). All patients had severely calcified, in origin tricuspid, aortic valves resulting in a significant gradient $(42-90 \mathrm{mmHg}$ ) and increased left ventricular mass (122-160 $\left.\mathrm{g} \mathrm{m}^{-2}\right)$. Aortic regurgitation existed in one patient (nr. 3) but echocardiography could not detect any other important valve disease (grade 1 or less). Two types of mechanical valves were used for the replacement and patient nr. 4 had simultaneous bypass surgery of the right coronary artery. All patients gave informed consent and the study was approved on February 15, 1998 by the institutional review committee.

\subsubsection{Intraoperative Patient Management}

The anesthetic technique was standardized (total intravenous anesthesia with propofol and an opioid). Intravenous fluids were administered to maintain cardiac filling pressures at their normal values (central venous pressure $8-14 \mathrm{mmHg}$ and pulmonary capillary wedge pressure 8-16 $\mathrm{mmHg}$ ). If hypotension occurred, defined as a mean arterial pressure below $60 \mathrm{mmHg}$, it was treated using standard hospital procedures: intravenous fluids and, when indicated, incremental intravenous doses of $2.5 \mathrm{mg}$ epinefrin and a dobutamin infusion whenever cardiac index decreased below $21 / \mathrm{min} / \mathrm{m}^{2}$.

\subsubsection{Instrumentation}

Pressure-volume loops were obtained by placing a conductance catheter with an integrated pressure sensor (Sentron ANP-223N, Roden, the Netherlands) into the left ventricle through an $18 \mathrm{Fr}$ atrial vent catheter (Terumo, Ann Arbor, MI) which was placed via an incision in the right superior pulmonary vein. The conductance catheter was connected to a Leycom Sigma 5DF system (CD Leycom, Zoetermeer, the Netherlands), that was used in dual frequency mode.

For aortic pressure measurements, a pressure tip catheter (Sentron ANP$530 \mathrm{~N}$, Roden, the Netherlands) was placed in the aortic root, just above the aortic valve. Finally, a pulmonary artery thermodilution catheter (Baxter, Deerfield, IL) was used to determine cardiac output and calibrate the conductance catheter.

\subsubsection{Measurement protocol}

Measurements were performed before and 15 minutes after the successful weaning of cardiopulmonary bypass when the patient was hemodyna- 
mically stable. To evaluate the atrial contribution to ventricular filling, the start of the atrial contraction was defined as $50 \mathrm{~ms}$ after the P-wave on the ECG. The time constant of relaxation, Tau, was calculated by the method of Villari ${ }^{18}$.

To estimate myocardial contractility, measurements were obtained during inferior caval vein occlusion which results in estimation of the slope Ees of the end-systolic pressure-volume relation (Figure 2-1) 4 . In two patients the occlusion produced ectopic beats, and Ees could not be determined preoperatively. All measurements were done at end-expiration breath hold to eliminate the effect of ventilation on the conductance measurements.

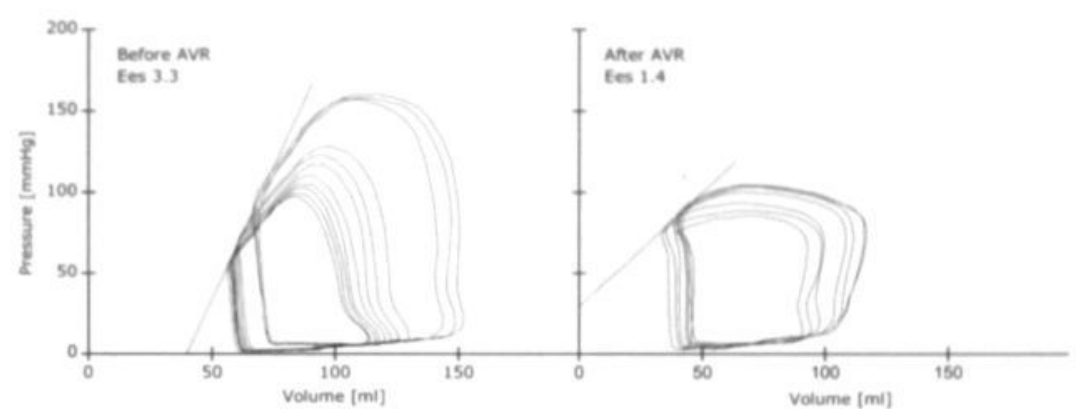

Figure 2-1: Pressure-volume loops during inferior caval vein occlusion (Patient 4) before (left) and after aortic valve replacement (right). The end-systolic pressure volume relation is drawn in. The slope of this relation, end systolic elastance Ees, is given in the upper left corner of each graph.

\subsubsection{Conductance catheter position and calibration}

The conductance catheter contains metal rings that can clearly be seen with ultrasound (Figure 2-2). Therefore, the correct position of the catheter, along the long axis of the ventricle with its pigtail in the apex, could be validated using trans-esophageal echocardiography. Care was taken to avoid catheter-wall contact and kinking or bending of the catheter.

The conductance catheter measures ventricular volume in five $1 \mathrm{~cm}$ segments. With the pulmonary vein approach, the upper segments of the catheter may measure atrial volume instead of ventricular volume. Any atrial segments could easily be excluded by observing the volume segmental signals on the display of the conductance console: An atrial segment is out-of-phase with a ventricular segment as the atrium fills during systole and empties during diastole, exactly the opposite to a ventricular volume segment. An example of such an out-of-phase segment 
is given in Figure 2-2. After achieving the correct position, measurements were immediately performed so no fixation of the catheter was necessary. Positioning of the conductance catheter took less than ten minutes in all patients. During aortic valve replacement the catheter was left in place, so no re-catheterization was necessary for the post-operative measurements.

Conductance calibration in this open-heart setting was done in the standard manner by comparing conductance with thermodilution derived stroke volumes. Parallel conductance was determined by injecting $7.5 \mathrm{ml} 6.5 \%$ hypertonic saline into the pulmonary artery ${ }^{5}$. The average time necessary to perform all conductance measurements (incl. calibration) was 9 minutes (range 6-15) pre-operatively and 6 minutes (range 4-7) post-operatively.
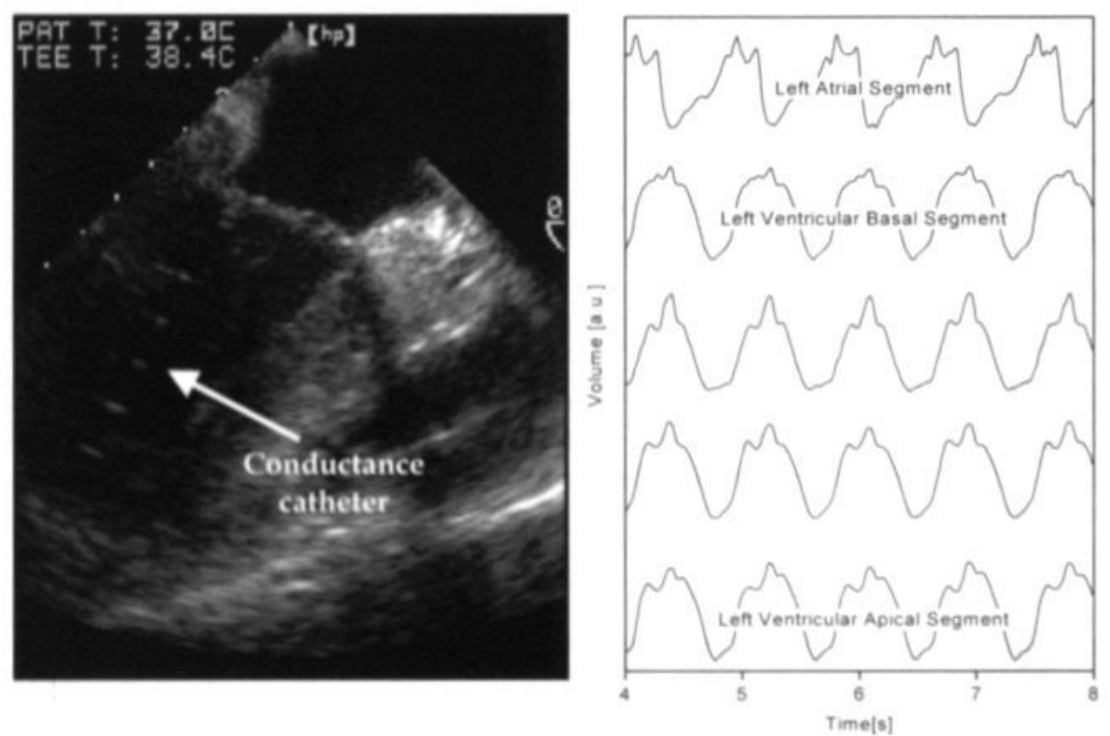

Figure 2-2: Left: TEE image of the conductance catheter inside the left ventricle. The metal rings on the conductance catheter can be clearly seen. Right: Volume segments of a conductance catheter correctly placed in the left ventricle. The ventricular long axis is too short to include all five volume segments, so only the bottom four segments are used to record ventricular volume. The top segment is an atrial volume segment and is out-ofphase with the ventricular segments as the atrium fills during systole and empties during diastole. 


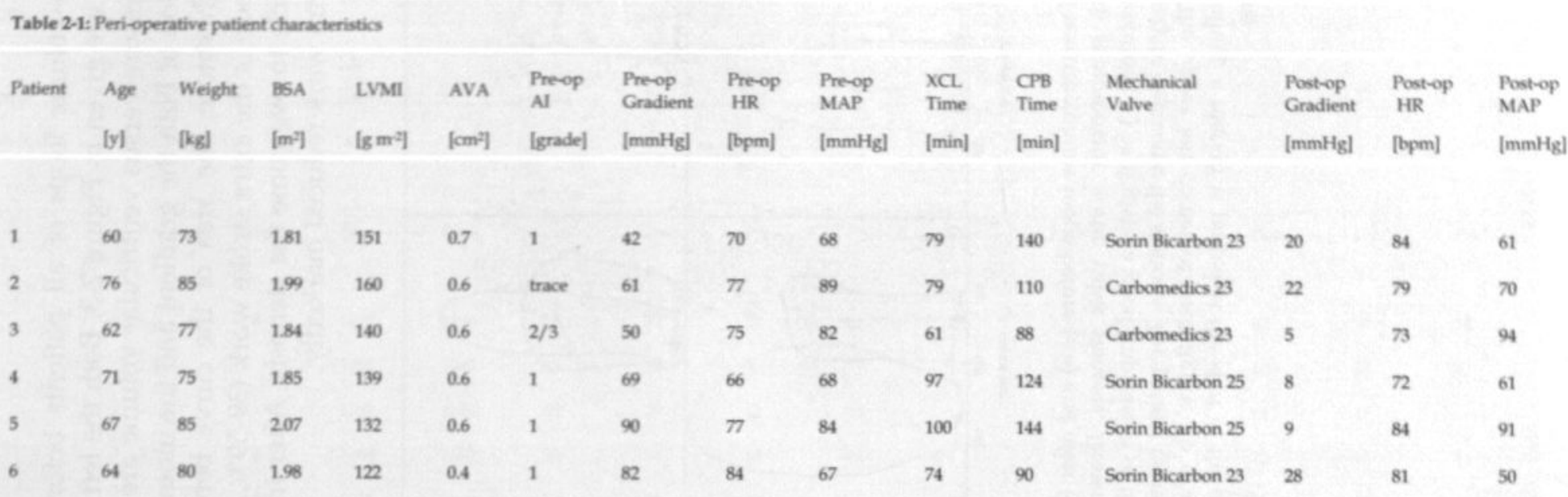

BSA: body surface areac LVMI: left ventricular mass index; AVA: aortic valve area (Gorlin formula); Pre-op Al: aortic insufficiency of the native valve determined by echocardiography; Pre-op Gradient: peak-to-peak gradient of the native valve; HR: Heart Rate; MAP: Mean Arterial Pressure; Mechanical valve: valve used for aortic valve replacement; Post-op Gradient: peak-to-peak gradient of the mechanical valve in situ; XCL: Cross-clamping CPB: Cardiopulmonary Bypass 


\subsection{Results}

The pressure-volume loops of all patients before and after aortic valve replacement, are given in Figure 2-3. Both the left ventricular pressure and the aortic pressure versus ventricular volume are plotted as this gives the best impression of both the gradient and the moment of valve opening and closure. Furthermore, the area of the curve between the aortic and the ventricular loop is the extra stroke work (39-59\%, see Table 2-2) performed by the ventricle to overcome the stenosis. After implanting the mechanical valve, this extra work reduced markedly.

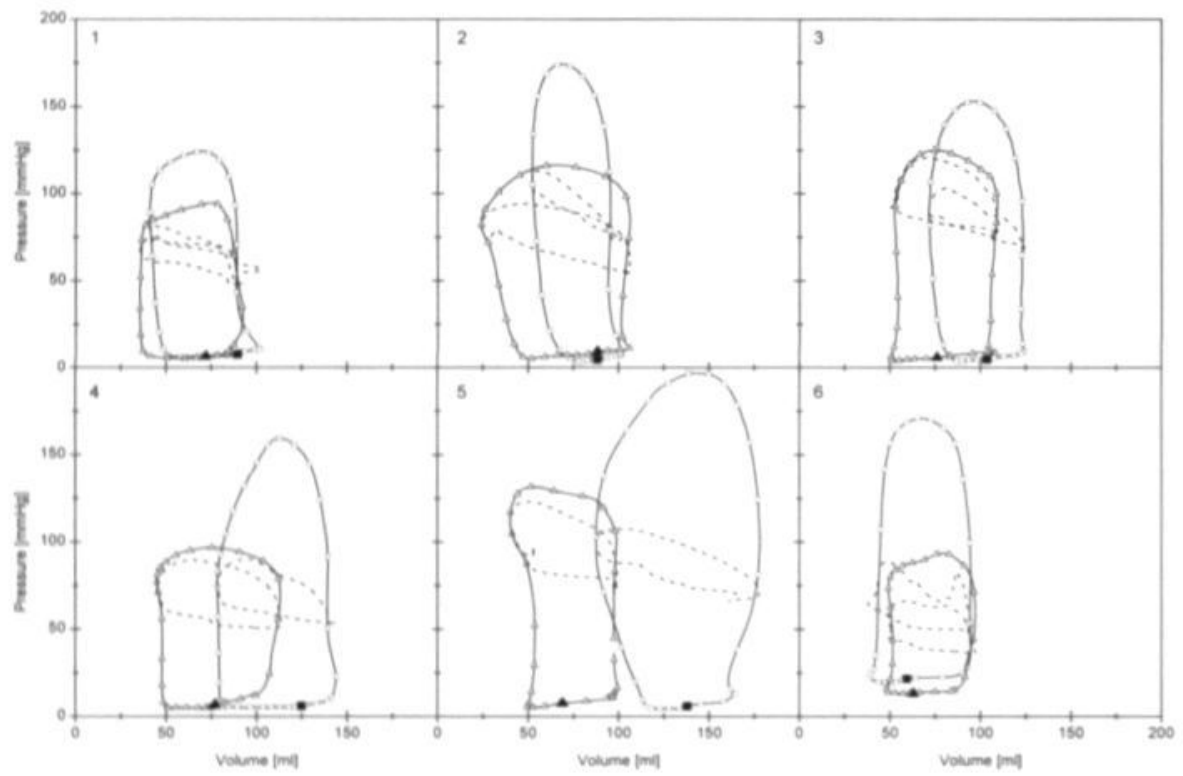

Figure 2-3: Pressure-volume loops before (-口-) and after (- $-\Delta-)$ aortic valve replacement of patients with symptomatic aortic valve stenosis. Drawn in is the aortic pressure vs. ventricular volume (- -) as it gives a good impression of the gradient and the extra stroke work necessary to overcome the stenosis. The patient number, corresponding to the tables, is given in the upper left corner of each figure. To evaluate the atrial contribution to ventricular filling, a marker is placed at the start of the atrial contraction. Time between points is $28 \mathrm{~ms}$. 
Table 2-2:Systolic function indices before and after aortic valve replacement for aortic stenosis

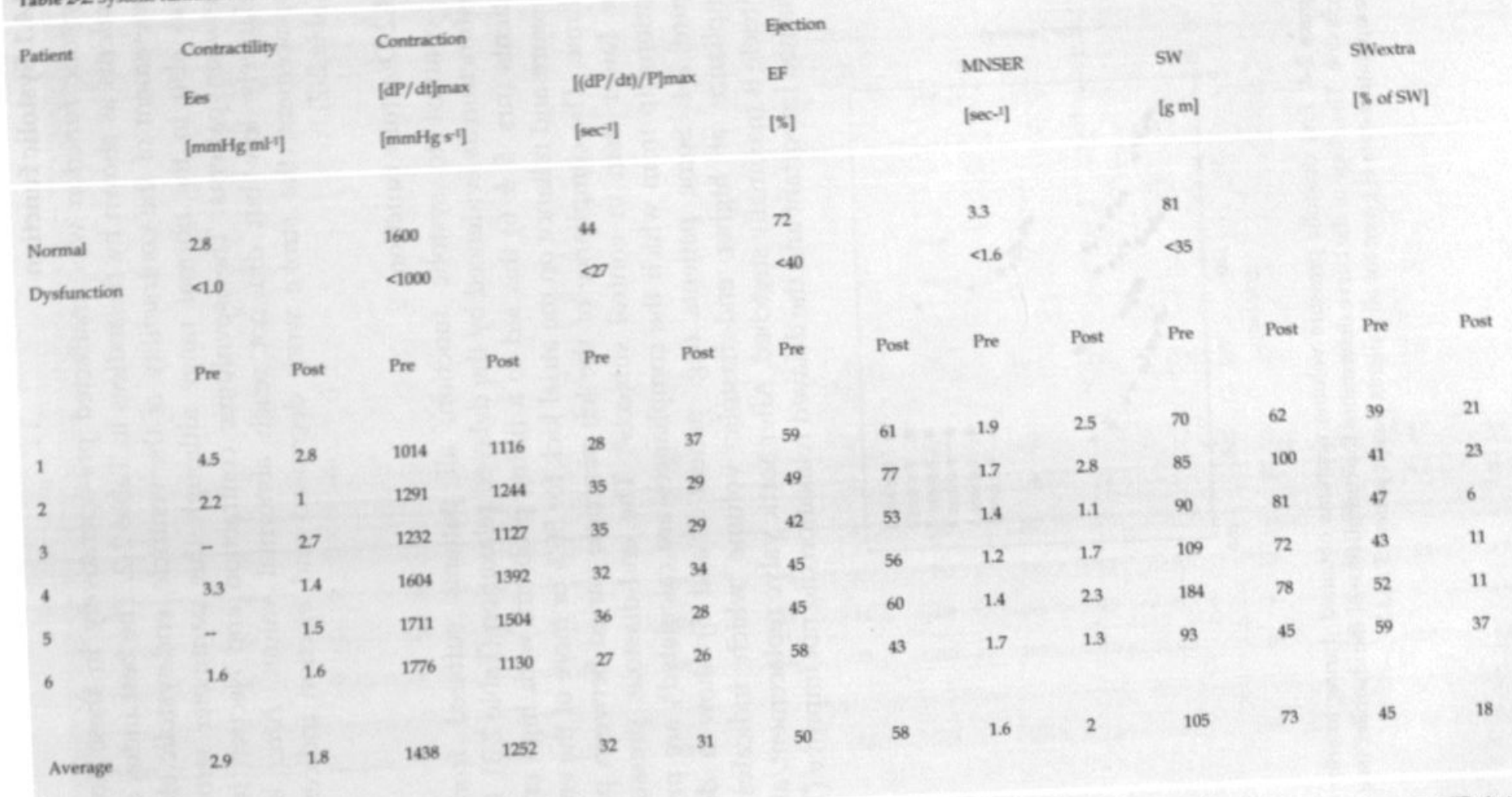

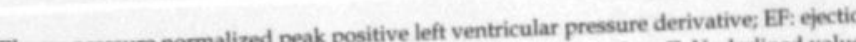

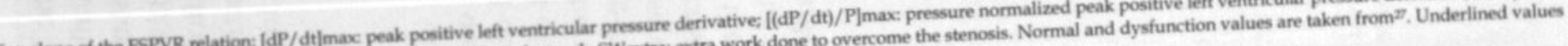

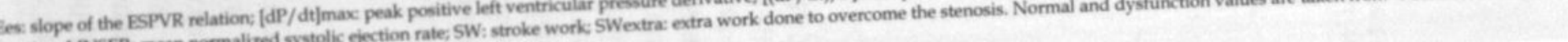
fraction: MNSER: mean norm 


\subsubsection{Systolic function}

Systolic function was unaffected pre-operatively in these aortic stenosis patients as shown by the indices in Table 2-2. The best index available for assessment of the contractility of the ventricle, end-systolic elastance Ees, was also in the normal range although this parameter strongly varied between patients. The isovolumic contraction and ejection indices were relatively low but did not reach abnormal values. After aortic valve replacement, the stroke work decreased and ejection indices improved (Table 2-2).

\subsubsection{Diastolic function}

In contrast to systolic function, all patients suffered from diastolic dysfunction as evidenced by the delayed relaxation (Table 2-3). In only two patients (nrs. 5 \& 6) this led to a filling problem, with high end-diastolic pressure and reliance on the atrial kick for $50 \%$ or more of the end-diastolic volume. The compliance of the left ventricle varied between patients but was lower than in control subjects ${ }^{3}$. The end-diastolic pressure-volume relationship from which the compliances are calculated ${ }^{3}$, are presented in Figure 2-4: Some patients (e.g. patient 5 and 6) show a decrease in compliance at higher end-diastolic volume which indicates that the ventricle is maximally stretched. After aortic valve replacement, atrial filling remained important and the delayed relaxation did not improve (Table 2-3).

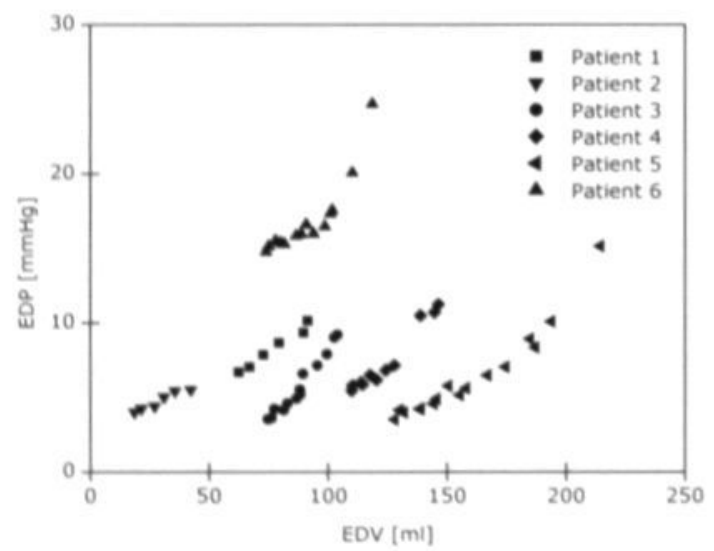

Figure 2-4: End diastolic pressure volume relations obtained during inferior caval vein occlusion. The slope of the curve determines the compliance of the chamber (see Table 2-3). Pre-operative data is given for all patients except patient 3 and 5. 
Table 2.3. Diastolic function indices before and after aortic valve replacement for aortic stenosis

\begin{tabular}{|c|c|c|c|c|c|c|c|c|c|c|c|c|c|c|c|c|}
\hline \multirow[t]{3}{*}{ Patient } & \multicolumn{6}{|c|}{ Relaxation } & \multicolumn{10}{|c|}{ Filling } \\
\hline & \multicolumn{2}{|l|}{ Tau } & \multicolumn{2}{|l|}{ IVRT } & \multicolumn{2}{|c|}{$[\mathrm{dP} / \mathrm{d} t]=$} & \multicolumn{2}{|c|}{ LVEDP } & \multicolumn{2}{|c|}{ PFRerr } & \multicolumn{2}{|c|}{$E / A$} & \multicolumn{2}{|l|}{ AF } & \multicolumn{2}{|c|}{$\mathrm{Cou}$} \\
\hline & \multicolumn{2}{|l|}{ [ms] } & \multicolumn{2}{|l|}{ [ms] } & \multicolumn{2}{|c|}{ [mmHigs] } & \multicolumn{2}{|c|}{ [mmHg] } & \multicolumn{2}{|c|}{$\left[\mathrm{ml} \mathrm{s}^{-1}\right]$} & \multicolumn{2}{|l|}{$\mathrm{H}$} & \multicolumn{2}{|l|}{$[\mathbf{F}]$} & \multicolumn{2}{|c|}{$\left[\mathrm{ml} \mathrm{mmH} \mathrm{mg}^{-1}\right]$} \\
\hline Dysfunction & $>48$ & & $>105$ & & 41100 & & $>16$ & & $<160$ & & $<0.5$ & & & & & \\
\hline \multirow[t]{2}{*}{ Normal } & 36 & & 84 & & 1864 & & 8 & & 300 & & 1.2 & & 15 & & 10 & \\
\hline & Pre & Post & Pre & Post & Pre & Post & Pre & Post & Pre & Post & Pre & Post & Pre & Post & Pre & Post \\
\hline 1 & 56 & 98 & 116 & 108 & 1145 & 999 & 12 & 8 & 435 & 424 & 2 & 1.7 & 25 & 29 & 8.7 & 6.4 \\
\hline 2 & 63 & 93 & 12 & 110 & 1310 & 1071 & 7 & 11 & 250 & 284 & 1.6 & 1 & 36 & 27 & 9.1 & 14.1 \\
\hline 3 & 61 & 63 & 120 & 144 & 1153 & 1370 & 8 & 8 & 243 & 267 & 0.9 & 0.5 & 44 & 58 & - & 5.1 \\
\hline 4 & 96 & 73 & 128 & 116 & 813 & 1203 & 11 & 13 & 283 & 246 & 1.1 & 0.6 & 26 & 43 & 6.3 & 2.7 \\
\hline 5 & 56 & 61 & 128 & 105 & 1310 & 1956 & 19 & 14 & 228 & 246 & 0.5 & 3.3 & 50 & 62 & - & 8.9 \\
\hline 6 & 32 & 75 & 120 & 122 & 1853 & 908 & 24 & 15 & 203 & 168 & 0.3 & 0.5 & 60 & 59 & 5.9 & 6.3 \\
\hline Average & 61 & 77 & 123 & 118 & 1264 & 1251 & 14 & 12 & 274 & 331 & 1.1 & 1.3 & 38 & 44 & 7.5 & 3 \\
\hline
\end{tabular}

Tau: Time constant of isovolumic left ventricular pressure; IVRT: Isovolumic relaxation time, the time from aortic valve closure to mitral valve opening [dP/dt]ma: Peak negative left ventricular pressure derivative; LVEDP: Left ventricular end-diastolic pressure; PFRers Peak filling rate during the early, rapid filling phase; E/A ratio: The ratio of PFRerp and PFR during atrial contraction; AF: Percentage of end-diastolic volume resulting after atrial contraction. CDis: Diastolic chamber compliances. Normal and dysfunction values taken from. Underlined values indicate diastolic dysfunction. 
56 | Chapter 2

\subsubsection{Intra-operative hemodynamic management}

As can be seen in Table 2-1, filling pressures were maintained within normal limits in all patients, weaning from bypass was uneventful in all patients and no patient required inotropic support. Mean arterial pressure and heart rate were recorded to compare pre- and post-operative hemodynamic state. In all these were similar, except in patient 6 who experienced a decline in mean arterial pressure of more than $25 \%$ after valve replacement. 


\subsection{Discussion}

\subsubsection{Pressure-volume analysis in aortic stenosis patients}

In this study, we presented a new method to perform pressure volumeanalysis in patients with aortic stenosis during surgery for aortic valve replacement. We placed a conductance catheter via the right superior pulmonary vein and advanced it to the correct position in the left ventricle under echocardiographic guidance and by checking the volumetric segments of the conductance catheter 7.9 .

The procedure, including catheter placement, calibration and measurements before and after aortic valve replacement, lengthened the operation by less than 30 minutes with no increase in bypass or cross clamping time.

There are clear benefits from the two other proposed methods to record pressure-volume loops in these patients i.e. ventriculography and radionuclide angiocardiography. Both have the drawback that they can only sample every $20 \mathrm{~ms}$ and do not measure beat-to-beat ventricular volume. This limits their ability to determine load-independent measures of systolic and diastolic function as preload manipulation by caval vein occlusion is impossible (during surgery this problem can be overcome by using the cardiopulmonary bypass to reach a certain reduction of preload by withdrawal of blood ${ }^{17}$ ). Furthermore, both methods still require catheterization for the pressure measurement by the transseptal or retrograde approach which entails risk ${ }^{10}$.

The method proposed in this study does not have these limitations. It only requires pulmonary vein catheterization and measures volume and pressure continuously. The pulmonary vein catheterization is a routine procedure for any cardiac surgeon and is similar to introducing a left ventricular vent. Preload manipulation by external caval vein occlusion (Figure 2-1) was successful in 10 of 12 cases, with the only problem being extra systolic beats.

It was observed that these extra systolic beats tended to occur during caval vein occlusion but not so much when the occlusion was released. It may be possible to determine the end-systolic and diastolic pressure volume relation by performing measurements during the release of the occlusion (which was not done in this study).

The main drawback of the proposed method is that it can only be performed during surgery. The same holds for ventriculography and radionuclide cardiography if load independent indices need to be determined ${ }^{17}$. At present, this excludes the use of pressure-volume loops as 
a pre-operative diagnostic tool in the decision making for aortic valve replacement. In future, it may be possible to obtain pre-operative pressurevolume loops with new techniques such as transthoracic conductance ${ }^{22}$ or echocardiography ${ }^{23}$ in combination with a very small pressure catheter, but these methods have not yet been extensively validated.

However, pressure-volume loops may be of value to confirm pre-operative diagnostic methods and may be used to determine the prognosis and postoperative treatment of the individual patient as pre-operative systolic and diastolic dysfunction are the most powerful predictors of outcome after valve replacement ${ }^{13,14}$

\subsubsection{Pressure-volume analysis in the individual patient}

In this highly selective group of aortic valve stenosis patients, systolic function is not affected, and none of the patients are in heart failure as evidenced by the high Ees compared to heart failure patients ${ }^{24}$. In contrast, diastolic dysfunction is present in all patients and two have a filling problem which can eventually lead to diastolic heart failure ${ }^{21}$. So, if the natural history of the disease is first left ventricular hypertrophy, then diastolic dysfunction, then systolic dysfunction and finally heart failure ${ }^{13}$, all these patients can be ranked in a state between diastolic and systolic ventricular dysfunction.

\subsubsection{Systolic and diastolic function}

Systolic function, represented by the ejection and contraction phase, is preserved in these aortic stenosis patients, although in the low-normal range. The ejection phase is primarily affected because the ventricle has to eject through the stenotic valve. Thus, ejection fraction and the related index mean normalized systolic ejection rate are decreased before the valve replacement but improve immediately after the new valve is placed.

The cardiac muscle itself is not affected as seen by the normal contraction phase and contractility index Ees, which shows that none of the patients were in systolic heart failure. The ventricle can therefore still perform the extremely high stroke work, of which almost half is used to overcome the stenosis. After the valve replacement, the contractility seems to decrease somewhat. It is known that the cardiopulmonary bypass has a negative influence on the contractility of the right ventricle ${ }^{25}$ and the observed decrease in left ventricular contractility may have a similar cause.

In contrast, the pressure-volume analysis clearly confirms that diastolic dysfunction is present in all aortic stenosis patients as relaxation is delayed and patients rely heavily on the atrial kick for their filling ${ }^{13.15}$. Furthermore, Fig. 2-5 and Table 2-3 illustrate that left ventricular compliance is decreased which is known to be caused by the increased stiffness due to hyper- 
trophy ${ }^{16}$. Fig. 2-5 also shows that in some patients (e.g. patient 5 and 6) compliance increases strongly when preload is reduced, indicating that these patients have minimal preload-reserve.

The varying degree of diastolic dysfunction between aortic stenosis patients has been observed by other investigators ${ }^{15}$ and is important for the prognosis of the individual patient ${ }^{13}$. The diastolic dysfunction is known to be caused by hypertrophy and it does not improve immediately after aortic valve replacement ${ }^{18}$.

\subsubsection{Clinical relevance}

This study shows that a single conductance measurement can provide the clinician several load independent indices of systolic and diastolic function in the individual patient with aortic stenosis. In our opinion catheterization through the stenotic aortic valve is currently not indicated in the symptomatic patient with severe aortic stenosis. However, we can envisage that the technique may be of use in the timing of aortic valve replacement in asymptomatic patients and in patients with moderate stenosis. In these patients, the quantitative diagnosis of heart failure and diastolic dysfunction is limited with non-invasive modalities such as echocardiography especially in the presence of normal systolic function ${ }^{26}$. The conductance method may then be used to validate and extend the accuracy of echocardiographic data. Finally, this study again shows that intra-operative conductance measurements are feasible and relatively easy and quick to perform, possibly expanding its use to other interventions in the setting of open heart surgery. 


\subsection{References}

1. Foex P and Leone BJ. Pressure-volume loops: a dynamic approach to the assessment of ventricular function. J Cardiothorac Vasc Anesth 1994;8:84-96.

2. Modersohn D, Walde T and Bruch L. Diastolic heart function--pathophysiology, characterization, and therapeutic approaches. Clin Cardiol 1993;16:850-8.

3. Hayward CS, Kalnins WV and Kelly RP. Gender-related differences in left ventricular chamber function. Cardiovasc Res 2001;49:340-50.

4. Kass DA, Midei M, Graves W, Brinker JA and Maughan WL. Use of a conductance (volume) catheter and transient inferior vena caval occlusion for rapid determination of pressure-volume relationships in man. Cathet Cardiovasc Diagn 1988;15:192-202.

5. Schreuder J, van der Veen FH, van der Velde ET, et al. Left ventricular pressure-volume relationships before and after cardiomyoplasty in patients with heart failure. Circulation 1997;96:2978-86.

6. Schreuder JJ, Steendijk P, van der Veen FH, et al. Acute and short-term effects of partial left ventriculectomy in dilated cardiomyopathy: assessment by pressurevolume loops. J Am Coll Cardiol 2000;36:2104-14.

7. Schreuder JJ, Biervliet JD, van der Velde ET, et al. Systolic and diastolic pressure-volume relationships during cardiac surgery. J Cardiothorac Vasc Anesth 1991;5:539-45.

8. Brookes CI, White PA, Bishop AJ, et al. Validation of a new intraoperative technique to evaluate load-independent indices of right ventricular performance in patients undergoing cardiac operations. J Thorac Cardiovasc Surg 1998;116:468-76.

9. Wallace A, Lam HW and Mangano DT. Linearity, load dependence, hysteresis, and clinical associations of systolic and diastolic indices of left ventricular function in man. Multicenter Study of Perioperative Ischemia (McSPI) Research Group. J Card Surg 1995;10:460-7.

10. Folland ED, Oprian C, Giacomini J, et al. Complications of cardiac catheterization and angiography in patients with valvular heart disease. VA Cooperative Study on Valvular Heart Disease. Cathet Cardiovasc Diagn $1989 ; 17: 15-21$.

11. Tamari I, Borer JS, Goldberg HL, et al. Hemodynamic changes during retrograde left-heart catheterization in patients with aortic stenosis. Cardiology 1991;78:171-8.

12. Powell DE, Tunick PA, Rosenzweig BP, et al. Aortic valve replacement in patients with aortic stenosis and severe left ventricular dysfunction. Arch Intern Med 2000;160:1337-41.

13. Lund O, Flo C, Jensen FT, et al. Left ventricular systolic and diastolic function in aortic stenosis. Prognostic value after valve replacement and underlying mechanisms. Eur Heart J 1997;18:1977-87.

14. Hwang $\mathrm{MH}$, Hammermeister KE, Oprian C, et al. Preoperative identification of patients likely to have left ventricular dysfunction after aortic valve replacement. Participants in the Veterans Administration Cooperative Study on Valvular Heart Disease. Circulation 1989;80:165-76.

15. Murakami T, Hess OM, Gage JE, Grimm J and Krayenbuehl HP. Diastolic filling dynamics in patients with aortic stenosis. Circulation 1986;73:1162-74. 
16. Villari B, Hess OM, Kaufmann P, et al. Effect of aortic valve stenosis (pressure overload) and regurgitation (volume overload) on left ventricular systolic and diastolic function. Am J Cardiol 1992;69:927-34.

17. Harpole DH, Jr., Gall SA, Jr., Wolfe WG, Rankin JS and Jones RH. Effects of valve replacement on ventricular mechanics in mitral regurgitation and aortic stenosis. Ann Thorac Surg 1996;62:756-61.

18. Villari B, Vassalli G, Monrad ES, et al. Normalization of diastolic dysfunction in aortic stenosis late after valve replacement. Circulation 1995;91:2353-8.

19. Friedrich SP, Lorell $\mathrm{BH}$, Rousseau MF, et al. Intracardiac angiotensin-converting enzyme inhibition improves diastolic function in patients with left ventricular hypertrophy due to aortic stenosis. Circulation 1994;90:2761-71.

20. Harpole DH, Davidson CJ, Skelton TN, et al. Changes in left ventricular systolic performance immediately after percutaneous aortic balloon valvuloplasty. Am J Cardiol 1990;65:1213-8.

21. Bonow RO, Carabello B, de Leon AC, Jr., et al. Guidelines for the management of patients with valvular heart disease: executive summary. A report of the American College of Cardiology/American Heart Association Task Force on Practice Guidelines (Committee on Management of Patients with Valvular Heart Disease). Circulation 1998;98:1949-84.

22. Steendijk P, Lardenoye JW, van der Velde ET, Schalij MJ, Baan J. Evaluation of a new transcardiac conductance method for continuous on-line measurement of left ventricular volume. Crit Care Med 2000;28:1599-1606.

23. Schmidlin D, Aschkenasy S, Vogt PR, Schmidli J, Jenni R, Schmid ER. Left ventricular pressure-area relations as assessed by transoesophageal echocardiographic automated border detection: comparison with conductance catheter technique in cardiac surgical patients. Br J Anaesth 2000;85:379-388.

24. Popovic Z, Miric M, Gradinac S, et al. Partial left ventriculectomy improves left ventricular end systolic elastance in patients with idiopathic dilated cardiomyopathy. Heart 2000;83:316-9.

25. Brookes CIO, White PA, Bishop AJ, Oldershaw PJ, Redington AN, Moat NE. Validation of a new intraoperative technique to evaluate load-independent indices of right ventricular performance in patients undergoing cardiac operations. J Thorac Cardiovasc Surg 1998;116:468-76.

26. Ommen SR. Echocardiographic assessment of diastolic function. Curr Opin Cardiol 2001; 16:240-5.

27. Grossman W. Evaluation of systolic and diastolic function of the myocardium. In D.S. Baim W G, ed. Cardiac catheterization, angiography, and intervention. Baltimore, MD: William \& Wilkins,1996:339-41.

28. European Study Group on Diastolic Heart Failure. How to diagnose diastolic heart failure. Eur Heart J 1998;19:990-1003. 


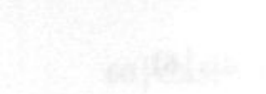

?

is

.

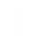




\section{Chapter 3}

\section{Aortic regurgitation}

Submitted for publication as:

Dekker ALAJ, Barenbrug PJC, van der Nagel T, van der Veen FH, Maessen JG. Diagnosis of aortic regurgitation with pressure-volume loops. 


\subsection{Abstract}

\section{Background}

Calibration of pressure-volume loops via a conductance catheter requires knowledge of left ventricular stroke volume. Usually this stroke volume is derived by thermodilution, but this method underestimates left ventricular stroke volume if aortic regurgitation is present. The presence and severity of aortic regurgitation might be determined in a pressure-volume loop itself as a volume increase in the relaxation phase. This hypothesis is tested in a comparative study with echocardiography in patients.

\section{Methods}

In 36 consecutive patients ( 26 aortic stenosis; 10 heart failure) with aortic regurgitation ranging from none to severe, pressure-volume loops were obtained during surgery and compared to echocardiography. Aortic regurgitation was quantified from the pressure-volume loops as the volume increase during relaxation. The relaxation phase was defined as starting at $\mathrm{dP} / \mathrm{dt}_{\min }$ or minimal left ventricular volume, and ending at minimal left ventricular pressure or the moment where left ventricular pressure declines below end-diastolic pressure.

\section{Results}

No correlation could be found between the degree of aortic regurgitation by echocardiography and the quantification of aortic regurgitation via pressure-volume loops. However, the amount of aortic regurgitation measured with pressure-volume loops decreased significantly after aortic valve replacement.

\section{Conclusions}

The increase in left ventricular volume during the relaxation phase of a pressure-volume loop does not correlate with the severity of aortic regurgitation. Therefore, aortic regurgitation cannot be quantified in a pressure-volume loop and should be quantified by other methods when calibration of the conductance catheter is done with thermodilution. 


\subsection{Introduction}

Analysis of left ventricular pressure-volume loops (PV-loops) is the gold standard to study left ventricular function ${ }^{1-3}$. With the introduction of the conductance cathetert, the measurement of beat-to-beat PV-loops became feasible and since then, we and others have successfully applied this technique in surgical patients ${ }^{5-9}$.

The conductance catheter is calibrated by comparing conductance derived left ventricular stroke volume to the stroke volume measured via thermodilution 4 . However, if severe valvular regurgitation is present, the left ventricular stroke volume is much higher than thermodilution derived stroke volume. Ignoring this difference and calibrating the conductance catheter with thermodilution, will lead to an underestimation of the absolute volume value if valvular regurgitation is present. Valvular regurgitation is usually determined by echocardiography ${ }^{10}$ but in light of the above it would also be beneficial to detect valvular regurgitation in a pressure-volume loop.

The corners of a pressure-volume loop are determined by valvular opening and closure (Figure 3-1). For instance, it can be assumed that aortic regurgitation is visible as an increase of volume in the relaxation phase, and that the amount of volume increase in that phase is related to the amount of valvular regurgitation. However, studies on aortic regurgitation with PVloops have not yet been reported.

In this study, we test the hypothesis that aortic regurgitation can be diagnosed in a pressure-volume loop as an increase in volume in the relaxation phase. It is the goal of this study to compare this new method of detecting aortic regurgitation with echocardiography.

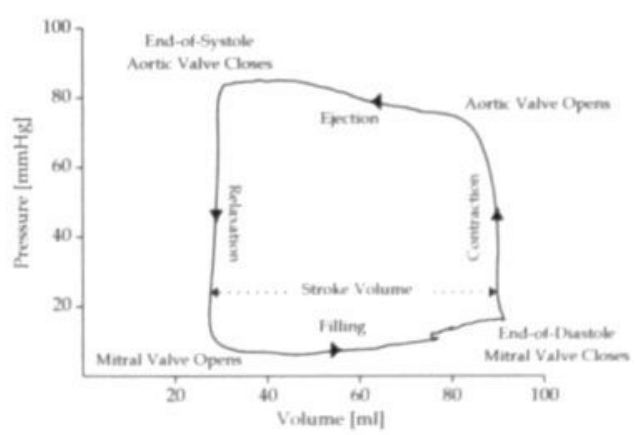

Figure 3-1: A normal left ventricular pressure-volume loop 


\subsection{Methods}

\subsubsection{Patients and Anesthesia}

In this retrospective study, thirty-six patients were included with the only criteria being the availability of both PV-loops and echocardiographic data. In twenty-six patients, PV-loops were recorded during surgery for aortic valve replacement due to symptomatic aortic valve stenosis. In ten patients with heart failure and left bundle branch block, PV-loops were recorded during surgery for epicardial left ventricular pacing lead placement. A trans-thoracic echocardiography (Doppler color flow mapping and vena contracta imaging) was performed in all patients as part of the normal clinical evaluation before surgery. The aortic regurgitation was graded none, mild, moderate or severe, and was used as a gold standard to compare to aortic regurgitation detection with PV-loops.

The anesthetic technique was standardized (total intravenous anesthesia with propofol and an opioid). Intravenous fluids were administered to maintain cardiac filling pressures at their normal values (central venous pressure 8-14 $\mathrm{mmHg}$ and pulmonary capillary wedge pressure 8-16 $\mathrm{mmHg}$ ). If hypotension occurred, defined as a mean arterial pressure below $60 \mathrm{mmHg}$, it was treated using standard hospital procedures: intravenous fluids and, when indicated, incremental intravenous doses of $2.5 \mathrm{mg}$ epinefrin and a dobutamin infusion whenever cardiac index decreased below $21 / \mathrm{min} / \mathrm{m}^{2}$.

\subsubsection{Conductance catheter}

In the aortic stenosis patients, PV-loops were obtained by placing a conductance catheter (CDLeycom, Zoetermeer, The Netherlands) into the left ventricle through an $18 \mathrm{Fr}$ atrial vent catheter (Terumo, Ann Arbor, MI) which was placed via an incision in the right superior pulmonary vein. In the heart failure patients, the conductance catheter was placed via the femoral artery under fluoroscopy. The conductance catheter was connected to a CDLeycom CFL conductance system (CDLeycom, Zoetermeer, The Netherlands).

\subsubsection{Relaxation phase definition}

It is the hypothesis of this study that aortic regurgitation is visible as an increase in ventricular volume in the (usually isovolumic) relaxation phase. This phase can be said to begin at aortic valve closure and to end at mitral valve opening. However, aortic valve closure and mitral valve opening are not always evident in a pressure-volume loop. To overcome this problem, we used the following four definitions for the relaxation phase: 
1. From maximum negative left ventricular pressure derivative $\left(\mathrm{dPdt}_{\min }\right)$ to minimal left ventricular pressure $\left(\mathrm{LVP}_{\min }\right)$

2. From maximum negative left ventricular pressure derivative $\left(\mathrm{dPdt}_{\min }\right)$ to the point were left ventricular pressure declines below left ventricular end-diastolic pressure (LVP<EDP).

3. From minimal left ventricular volume $\left(\mathrm{LVV}_{\min }\right)$ to minimal left ventricular pressure $\left(\mathrm{LVP}_{\min }\right)$

4. From minimal left ventricular volume $\left(\mathrm{LVV}_{\min }\right)$ to the point were left ventricular pressure declines below left ventricular end-diastolic pressure (LVP<EDP).

All these points are readily detected in a pressure-volume measurement and will be operator-independent.

\subsubsection{Quantification of aortic regurgitation in PV-loops}

With these definitions of the relaxation phase, the amount of aortic regurgitation in that phase can be quantified as the left ventricular volume at the end of the relaxation phase minus the volume at the start of the phase divided by the stroke volume. Thus defined, this "regurgitant fraction" indicates how much blood enters the ventricle in the relaxation phase as a fraction of the total stroke volume. With the aforementioned four definitions of the relaxation phase, four values of the regurgitant fraction are obtained.

\subsubsection{Statistical Analysis}

Measurements done before and after aortic valve replacement were compared via a paired t-test. Significance was assumed if the p-value was less than 0.05 . 


\subsection{Results}

Patient data are summarized in Table 3-1 and Figure 3-2. There was no correlation between echocardiography and any of the PV-loops derived indices for aortic regurgitation. In the aortic stenosis patients that had PVloops derived aortic regurgitation of $5 \%$ or more before the aortic valve replacement, this regurgitation reduced significantly after the aortic valve was replaced (Figure 3-3).

Table 3-1: Aortic regurgitation by echocardiography and pressure-volume loops

\begin{tabular}{|c|c|c|c|c|c|c|}
\hline Patient & Primary Disease & $\begin{array}{l}\text { ARecono } \\
\text { [grade] }\end{array}$ & $\begin{array}{l}\text { AR, } \\
\text { [\%SV] }\end{array}$ & $\begin{array}{l}\mathrm{AR}_{2} \\
\text { [\%SV] }\end{array}$ & $\begin{array}{l}\text { ARs } \\
\text { [\%SV] }\end{array}$ & $\begin{array}{l}\mathrm{AR}_{\mathbf{4}} \\
{[\% \mathrm{SV}]}\end{array}$ \\
\hline 1 & Heart Failure & none & 0 & 0 & 5 & 0 \\
\hline 2 & Heart Failure & none & 0 & 0 & 5 & 11 \\
\hline 3 & Aortic Stenosis & none & 0 & $\mathbf{0}$ & 25 & 0 \\
\hline 4 & Aortic Stenosis & none & 7 & 3 & 7 & 3 \\
\hline 5 & Aortic Stenosis & none & 12 & $\mathbf{0}$ & 16 & 3 \\
\hline 6 & Aortic Stenosis & none & 14 & 5 & 15 & 6 \\
\hline 7 & Heart Failure & none & 15 & 6 & 17 & 9 \\
\hline 8 & Aortic Stenosis & none & 15 & 49 & 20 & 50 \\
\hline 9 & Heart Failure & none & 25 & 0 & 35 & 1 \\
\hline 10 & Heart Failure & none & 50 & 22 & 50 & 32 \\
\hline 11 & Heart Failure & trace & 37 & 5 & 41 & 9 \\
\hline 12 & Aortic Stenosis & trace & 40 & 30 & 47 & 38 \\
\hline 13 & Heart Failure & mild & 3 & 2 & 4 & 3 \\
\hline 14 & Aortic Stenosis & mild & 5 & 5 & 6 & 6 \\
\hline 15 & Aortic Stenosis & mild & 7 & 0 & 17 & 1 \\
\hline 16 & Aortic Stenosis & mild & 7 & 4 & 11 & 7 \\
\hline 17 & Aortic Stenosis & mild & 10 & 6 & 12 & 7 \\
\hline 18 & Heart Failure & mild & 12 & 6 & 15 & 9 \\
\hline 19 & Aortic Stenosis & mild & 36 & 24 & 37 & 25 \\
\hline 20 & Aortic Stenosis & mild & 37 & 9 & 41 & 13 \\
\hline 21 & Aortic Stenosis & mild & 37 & 12 & 40 & 15 \\
\hline 22 & Aortic Stenosis & mild & 50 & 24 & 50 & 29 \\
\hline 23 & Aortic Stenosis & mild to moderate & 13 & 0 & 23 & 8 \\
\hline 24 & Aortic Stenosis & mild to moderate & 15 & 3 & 15 & 4 \\
\hline 25 & Aortic Stenosis & mild to moderate & 18 & 0 & 30 & 0 \\
\hline 26 & Aortic Stenosis & mild to moderate & 19 & 11 & 23 & 16 \\
\hline 27 & Aortic Stenosis & mild to moderate & 26 & 0 & 33 & 0 \\
\hline 28 & Aortic Stenosis & mild to moderate & 39 & 9 & 40 & 10 \\
\hline 29 & Aortic Stenosis & moderate & 0 & 0 & 4 & 0 \\
\hline 30 & Aortic Stenosis & moderate & 20 & 4 & 26 & 10 \\
\hline 31 & Aortic Stenosis & moderate & 48 & 7 & 50 & 9 \\
\hline 32 & Aortic Stenosis & moderate & 50 & 50 & 50 & 50 \\
\hline 33 & Aortic Stenosis & moderate to severe & 0 & 0 & 8 & 0 \\
\hline 34 & Heart Failure & moderate to severe & 21 & 10 & 24 & 14 \\
\hline 35 & Heart Failure & moderate to severe & 27 & 17 & 29 & 18 \\
\hline 36 & Aortic Stenosis & moderate to severe & 32 & 12 & 34 & 15 \\
\hline
\end{tabular}

AReso: Aortic regurgitation determined by echocardiography: ARs: Left ventricular volume increase from dP/dt-m to LVPmi ARs Left ventricular volume increase from dP/dtm to the moment were LVPCLVPw ; ARs Left ventricular volume increase from $L V V_{m}$ to $L V P=i R_{4}$ : Left ventricular volume increase from $L V V=$ to the moment were LVP×LVPrns SV: Stroke volume 


\subsection{Discussion}

It was the aim of this study to assess whether aortic regurgitation can be detected in PV-loops obtained with a conductance catheter. The hypothesis was that aortic regurgitation would manifest itself in PV-loops as a left ventricular volume increase in the relaxation phase. The results of this study are disappointing: No correlation was found between echocardiography and PV-loops in the quantification of aortic regurgitation. However, in the subset of patients that underwent an aortic valve replacement, significantly less volume increase was seen in the relaxation phase after the valve was replaced. A number of explanations are possible for these observations.
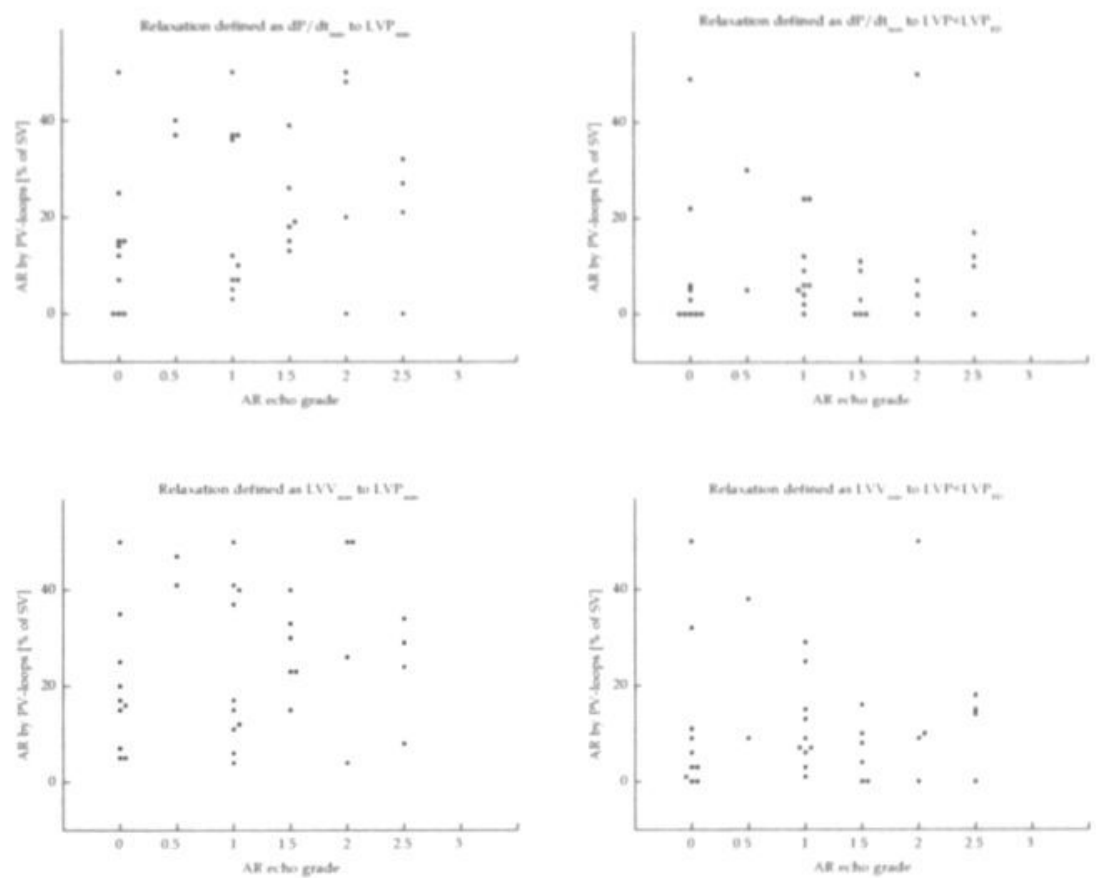

Figure 3-2: Comparison of the diagnosis aortic regurgitation by echocardiography and by pressure-volume loops in 36 patients. Aortic regurgitation is quantified by pressurevolume loops as the volume increase during the relaxation phase as a percentage of the stroke volume. The relaxation phase is defined as (see also Methods section): Top left: from $\mathrm{dPdt}_{\min }$ to $\mathrm{LVP}_{\min }$ Top right: from $\mathrm{dPdt}_{\min }$ to $\mathrm{LVP}<\mathrm{EDP}$; Bottom left: from $\mathrm{LVV}_{\min }$ to $\mathrm{LVP}_{\min }$ Bottom right: from $L V V_{\min }$ to $L V P<E D P$.

Echo grading of aortic regurgitation: $0=$ none, $0.5=$ trace, $1=$ mild, $1.5=$ mild to moderate, $2=$ moderate, $2.5=$ moderate to severe, $3=$ severe. 


\subsubsection{Aortic regurgitation: A holo-diastolic disease}

The severity of aortic regurgitation depends on the pressure gradient and the regurgitant orifice area ${ }^{11}$. The pressure gradient across the valve increases rapidly in the relaxation phase but stays fairly constant for the remainder of diastole. On the other hand, the regurgitant orifice may also depend on the pressure gradient and thus may increase, decrease or remain constant during the relaxation phase and the rest of diastole 11,12 . For instance, if the regurgitant orifice becomes smaller at high pressure gradients than much more regurgitation occurs in the relaxation phase compared to the situation were the regurgitant orifice increases with the pressure gradient.
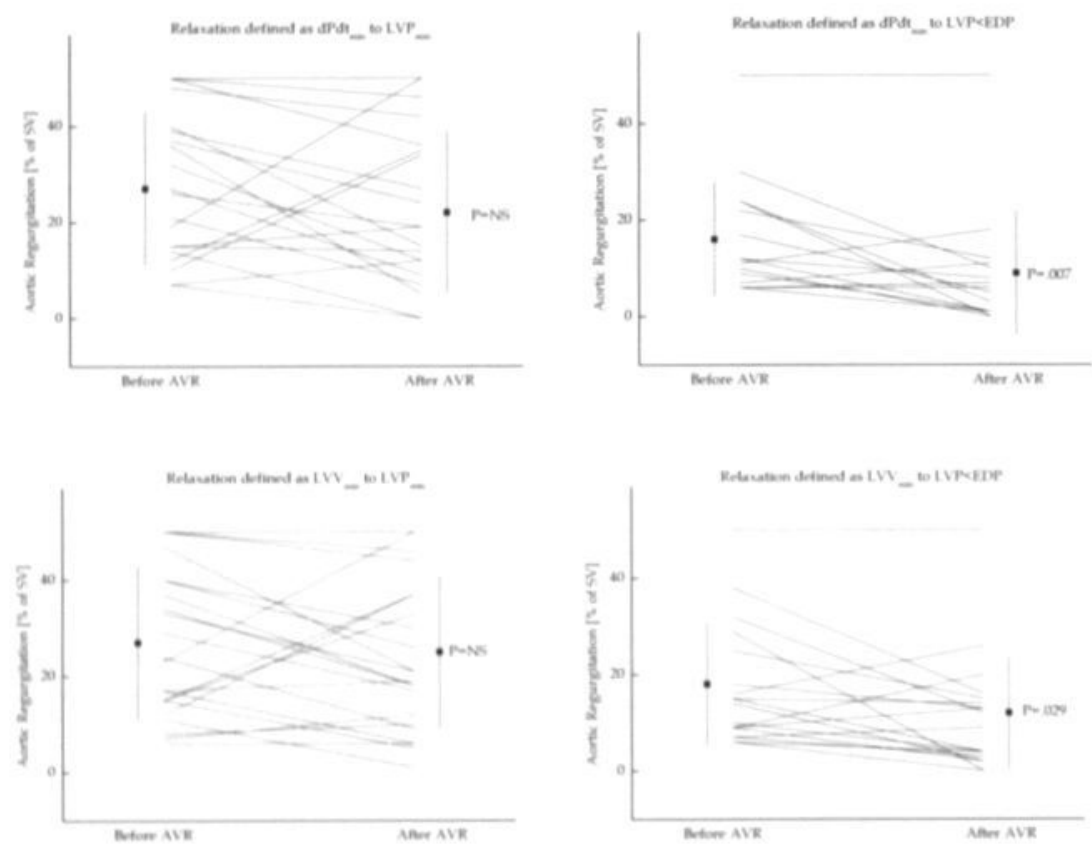

Figure 3-3: Aortic regurgitation with pressure-volume loops before and after AVR in patients with pre-AVR aortic regurgitation of $5 \%$ or more. Aortic regurgitation is quantified by pressure-volume loops as the volume increase during the relaxation phase as a percentage of the stroke volume. The relaxation phase is defined as (see also Methods section):

Top left: from dP/dtmin to $\mathrm{LVP}_{\min }$ Top right: from $\mathrm{dPdt}_{\min }$ to $\mathrm{LVP}<\mathrm{LVP} \mathrm{ED}_{\mathrm{i}}$; Bottom left: from $L V V_{\min }$ to $L V P_{\min }$; Bottom right: from $L V V_{\min }$ to $L V P<L V P_{E D}$.

In light of the above, it is important to realize that echocardiography and PV-loops measure a different variable at different time points during diastole. With echocardiography, the peak regurgitant jet in diastole is 
measured. In the proposed PV-loops method however, the volume increase during the relaxation phase is taken as a measure for aortic regurgitation.

This difference in variable and timepoint may explain the bad correlation between echocardiography and PV-loops despite the observed decrease in aortic regurgitation in the relaxation phase upon valve replacement

\subsubsection{Definition of the relaxation phase}

The method proposed in this study to quantify aortic regurgitation in a pressure-volume loop, depends on the correct identification of the relaxation phase. The (usually isovolumic) relaxation phase is defined as starting at aortic valve closure and ending at mitral valve opening. Both are not always evident in a pressure-volume loop. As a substitute, we used $\mathrm{dP} / \mathrm{dt}_{\min }$ and $\mathrm{LVV}_{\min }$ as starting points, and $L V P_{\min }$ and $L V P<L V P_{E D}$ as endpoints of the relaxation phase. Especially the latter two are questionable. For instance, other investigators have shown that minimal left ventricular pressure sometimes occurs long after the mitral valve is open, leading to a $20 \%$ mean volume increase in the relaxation phase, although that study did not exclude the presence of aortic regurgitation ${ }^{13}$. Delayed relaxation, which is often encountered in aortic stenosis patients, will lead to an even later occurrence of minimal left ventricular pressure. This is a possible explanation why a relaxation phase definition incorporating $L V P_{\min }$ leads to such a wide variation in values of aortic regurgitation (Figure 3-2 and Figure 3-3). The definition of the relaxation phase from $\mathrm{dP} / \mathrm{dt}_{\min }$ to $L V P<L V P_{E D}$ seems to be more appropriate based on our results (Figure 3-3).

\subsubsection{Aortic regurgitation due to the conductance catheter}

In the heart failure patients that were catheterized retrogradely, some additional aortic regurgitation may result from the presence of the conductance catheter across the aortic valve. However, whether this produces some non-physiological regurgitation, is still a matter of debate ${ }^{14}$.

\subsubsection{Calibration of the conductance catheter in aortic regurgitation}

Calibration of the conductance catheter depends on the correct identification of LV stroke volume. In aortic regurgitation patients, LV stroke volume can be determined by measuring forward stroke volume via thermodilution and by using echocardiography to determine the regurgitant fraction ${ }^{15,16}$. If regurgitant fraction and net stroke volume are known, then total left ventricular stroke volume can be calculated and used to calibrate the conductance catheter.

\subsubsection{Study limitations}

In this retrospective analysis patients were studied that had specific diseases and do not represent the general patient population. More 
specifically, it can not be excluded that coexistence of aortic regurgitation with heart failure and aortic stenosis results in a variety of hemodynamic dysfunctions that may have influenced these results.

\subsubsection{Conclusion}

The increase in left ventricular volume during the relaxation phase of a pressure-volume loop does not correlate with the severity of aortic regurgitation. Therefore, aortic regurgitation can not be quantified in a pressure-volume and should be quantified by other methods when calibration of the conductance catheter is done with thermodilution. 


\subsection{References}

1. Foex P, Leone BJ. Pressure-volume loops: a dynamic approach to the assessment of ventricular function. J Cardiothorac Vasc Anesth 1994;8(1):84-96.

2. Modersohn D, Walde T, Bruch L. Diastolic heart function--pathophysiology, characterization, and therapeutic approaches. Clin Cardiol 1993;16(12):850-8.

3. Hayward CS, Kalnins WV, Kelly RP. Gender-related differences in left ventricular chamber function. Cardiovasc Res 2001;49(2):340-50.

4. Baan J, van der Velde ET, de Bruin HG, Smeenk GJ, Koops J, van Dijk AD, et al. Continuous measurement of left ventricular volume in animals and humans by conductance catheter. Circulation 1984;70(5):812-23.

5. Schreuder J, van der Veen FH, van der Velde ET, Delahaye F, Alfieri O, Jegaden $\mathrm{O}$, et al. Left ventricular pressure-volume relationships before and after cardiomyoplasty in patients with heart failure. Circulation 1997;96(9):2978-86.

6. Schreuder J, Steendijk P, van der Veen FH, Alfieri O, van der Nagel T, Lorusso $\mathrm{R}$, et al. Acute and short-term effects of partial left ventriculectomy in dilated cardiomyopathy: assessment by pressure-volume loops. J Am Coll Cardiol 2000;36(7):2104-14.

7. Schreuder JJ, Biervliet JD, van der Velde ET, ten Have K, van Dijk AD, Meyne NG, et al. Systolic and diastolic pressure-volume relationships during cardiac surgery. J Cardiothorac Vasc Anesth 1991;5(6):539-45.

8. Brookes CI, White PA, Bishop AJ, Oldershaw PJ, Redington AN, Moat NE. Validation of a new intraoperative technique to evaluate load-independent indices of right ventricular performance in patients undergoing cardiac operations. J Thorac Cardiovasc Surg 1998;116(3):468-76.

9. Wallace A, Lam HW, Mangano DT. Linearity, load dependence, hysteresis, and clinical associations of systolic and diastolic indices of left ventricular function in man. Multicenter Study of Perioperative Ischemia (McSPI) Research Group. J Card Surg 1995;10(4 Suppl):460-7.

10. Bonow RO, Carabello B, de Leon AC, Jr., Edmunds LH, Jr., Fedderly BJ, Freed $\mathrm{MD}$, et al. Guidelines for the management of patients with valvular heart disease: executive summary. A report of the American College of Cardiology/American Heart Association Task Force on Practice Guidelines (Committee on Management of Patients with Valvular Heart Disease). Circulation 1998;98(18):1949-84.

11. Gaasch WH, Sundaram M, Meyer TE. Managing asymptomatic patients with chronic aortic regurgitation. Chest 1997;111(6):1702-9.

12. Reimold SC, Maier SE, Fleischmann KE, Khatri M, Piwnica-Worms D, Kikinis R, et al. Dynamic nature of the aortic regurgitant orifice area during diastole in patients with chronic aortic regurgitation. Circulation 1994;89(5):2085-92.

13. Fioretti P, Brower RW, Meester GT, Serruys PW. Interaction of left ventricular relaxation and filling during early diastole in human subjects. Am J Cardiol 1980;46(2):197-203.

14. Shandling AH, Lehmann KG, Atwood JE, Andersh S, Gardin J. Prevalence of catheter-induced valvular regurgitation as determined by Doppler echocardiography. Am J Cardiol 1989;63(18):1369-74.

15. Willett DL, Hall SA, Jessen ME, Wait MA, Grayburn PA. Assessment of aortic regurgitation by transesophageal color Doppler imaging of the vena contracta: 
74|Chapter 3

validation against an intraoperative aortic flow probe. J Am Coll Cardiol 2001;37(5):1450-5.

16. Tribouilloy CM, Enriquez-Sarano M, Bailey KR, Seward JB, Tajik AJ. Assessment of severity of aortic regurgitation using the width of the vena contracta: A clinical color Doppler imaging study. Circulation 2000;102(5):55864 . 


\section{Chapter 4}

\section{Cardiac tilting}

Published as:

Dekker AL, Geskes GG, Cramers AA, Dassen WR, Maessen JG, Prenger KB, van der Veen FH. Right ventricular support for off-pump coronary artery bypass grafting studied with bi-ventricular pressure-volume loops in sheep. Eur J Cardiothorac Surg 2001;19:179-184. 


\subsection{Abstract}

\section{Objectives}

Tilting the heart during off-pump coronary artery bypass grafting (OPCABG) causes a strong decrease in cardiac output. It is hypothesized that this decrease is caused by reduced right ventricular filling and that right ventricular support is thus the best way to restore cardiac output. Simultaneous left and right ventricular pressure-volume loops were used to test this hypothesis.

\section{Methods}

In seven sheep, the heart was tilted with the use of an Octopus device. After unsupported tilting, a novel right ventricular support, the Enabler, was activated at a pulsatile flow of $1.6 \mathrm{l} / \mathrm{min}$. Pressure-volume loops of both ventricles were obtained using conductance catheters, and cardiac output was monitored with an aortic flow probe.

\section{Results}

Tilting reduced cardiac output by $31 \%(4.4-3.1 \mathrm{l} / \mathrm{min}, \mathrm{P}=0.001)$ and right ventricular end-diastolic volume by $44 \%(8651 \mathrm{ml}, \mathrm{P}=0.005)$, while right ventricular end-diastolic pressure did not decrease. Left ventricular systolic pressure was not significantly reduced upon tilting and even increased in two animals. During Enabler right ventricular support, the cardiac output remained $23 \%$ lower than pre-tilting values $(3.4 \mathrm{vs} .4 .4 \mathrm{l} / \mathrm{min}, \mathrm{P}=0.001)$.

\section{Conclusions}

Restricted right ventricular filling is the primary cause of the strong decrease in cardiac output during tilting. The Enabler right ventricular support can currently not restore cardiac output to pre-tilting values, mainly caused by its limited output and a decrease in right ventricular output upon Enabler activation. Constant monitoring of cardiac output is crucial during (unsupported or supported) tilting as blood pressure alone may not reflect the extent of the reduction in cardiac function. 


\subsection{Introduction}

Left ventricular pressure-volume loops measured by a conductance catheter are now commonly used to measure the effect of disease, new drugs, left heart assist and cardiomyoplasty on left ventricular function ${ }^{1.5}$. Right ventricular pressure.volume loops are less often used ${ }^{6,7}$, but also show good correlation with other techniques ${ }^{8}$.

Simultaneous left and right ventricular pressure-volume loops are necessary for an in-depth investigation of cardiac function, especially when studying interventions that affect both ventricles. One such intervention is cardiac tilting for multivessel off-pump coronary artery bypass grafting (OPCABG) $^{9,10}$.

OPCABG eliminates the use of the extracorporeal circulation with its wellknown complications ${ }^{11}$. In this procedure, the Octopus device (Medtronic Inc., Minneapolis, MI) is often used to stabilize the site of the anastomosis, but can also be used to lift and rotate the heart, thereby allowing multivessel OPCABG ${ }^{12}$. However, this so-called cardiac tilting is not without hemodynamic consequences; tilting the heart is reported to cause a $44 \%$ decrease in stroke volume in healthy pigs and to reduce systemic blood pressures with a concomitant higher right atrial pressure, suggesting right ventricular dysfunction 9.10 . The hemodynamic consequences of cardiac tilting limit the use of OPCABG in patients with poor cardiac function.

The Enabler (Hemodynamics Systems Ltd., Yoqneam, Israel) was developed to support the right ventricle during cardiac tilting, thereby making multivessel OPCABG possible in all patients. It consists of a $24 \mathrm{~F}$ catheter that is placed via surgical preparation of the femoral vein or via the right atrium and creates a pulsatile flow, 1:1 triggered to the ECG ${ }^{13,14}$.

The Hemopump (Medtronic Inc., Minneapolis, MI) is also used in beating heart $\mathrm{CABG}$, but only to support the left ventricle during CABG of single or easily accessible vessels ${ }^{15,16}$. One study compared right and left heart bypass with the Biomedicus device and concluded that only right heart bypass could restore cardiac function during $\mathrm{OPCABG}^{17}$.

It is hypothesized that (a) cardiac tilting reduces right ventricular filling which results in a decreased cardiac output and that (b) right ventricular support is thus the best way to counteract this effect. Because tilting and right ventricular support are interventions that affect both ventricles, simultaneous left and right ventricular pressure-volume loops were used to test these hypotheses. 


\subsection{Animals and methods}

\subsubsection{Animals and medication}

All animals received humane care in compliance with the Guide for the Care and Use of Laboratory Animals (NIH publication 86-23, revised 1985) and the study was approved by our institution's animal ethics committee.

Seven female Texelaar sheep with an average weight of $68 \mathrm{~kg}$ (range 61-76 $\mathrm{kg}$ ) were premedicated with atropine (s.c. $0.2 \mathrm{mg} / \mathrm{kg}$ ). Anesthesia was induced with sodium thiopental (i.v.-bolus $15 \mathrm{mg} / \mathrm{kg}$ ) and maintained with halothane $(2 \%)$. After administration of muscle relaxant suxamethonium (i.v.-bolus $0.1 \mathrm{mg} / \mathrm{kg}$ ) and analgetic buprenorfine (i.v.-bolus $0.01 \mathrm{mg} / \mathrm{kg}$ ), a midsternotomy was performed, the pericardial sac was opened and lidocaine (i.v.-bolus $100 \mathrm{mg}$ and i.v.-infusion $1 \mathrm{mg} / \mathrm{kg}$ per h) was given to prevent arrhythmia during heart manipulation. Heparin (i.v.-bolus 100 $\mathrm{IU} / \mathrm{kg}$ ) was administered and the activated clotting time was measured and kept above $400 \mathrm{~s}$ during the experiment. The animals were killed with an overdose of pentobarbital (i.v.-bolus $200 \mathrm{mg} / \mathrm{kg}$ ).

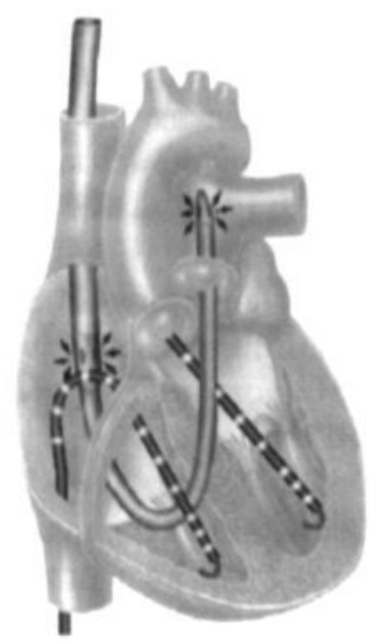

Figure 4-1: Cartoon showing the Enabler catheter positioned in the right heart. Conductance catheters are placed in both ventricles with their pigtail in the ventricular apex.

\subsubsection{Instrumentation}

A Doppler aortic flow probe (Transonic, Ithaca, NY) was placed on the descending aorta and compared to thermodilution-derived cardiac output to include flow to the coronary arteries and the upper body, which was assumed to be a fixed percentage for the remainder of the experiment. Two 
conductance catheters (ANP-223N, Sentron, Roden, The Netherlands) were placed under fluoroscopy in the left and right ventricles via the femoral artery and jugular vein, respectively, (Figure 4-1) and connected to two Leycom Sigma-5DF systems (Cardiodynamics, Leiden, The Netherlands).

The Enabler catheter was placed via the jugular vein (right atrium in one sheep) through the right ventricle into the pulmonary artery, so that the catheter's inlet valve was positioned in the right atrium and the outlet valve was positioned in the pulmonary artery (Figure 4-1).

\subsubsection{Measurements}

The measurement protocol started with cardiac tilting by the Octopus device to expose the inferior wall, as described elsewhere ${ }^{12}$. After $5 \mathrm{~min}$ of unsupported tilting, the right ventricular support was activated at its maximum flow of $1.6 \mathrm{l} / \mathrm{min}$ for $10 \mathrm{~min}$. In one sheep a posterior wall tilting procedure was performed ${ }^{12}$. The recorded hemodynamic signals included ECG, right and left ventricular pressure and volume, cardiac output and pump flow settings. Measurements were done at baseline, $5 \mathrm{~min}$ of cardiac tilting and $10 \mathrm{~min}$ of right ventricular support.

\subsubsection{Conductance calibration}

Parallel conductance was determined by the method described elsewhere 5 . Absolute volumes were determined by comparing conductance-derived stroke volume with the stroke volume measured by the aortic flow probe. Because the aortic flow probe measures the sum of both right ventricular support and right ventricular output, the right ventricular slope factor during activation of the right ventricular support was assumed to be the average of the slope factor before and after the activation.

\subsubsection{Data analysis}

All conductance measurements were analyzed with the Circlab 99 software package (Paul Steendijk, Leiden, The Netherlands). A non-parametric Friedman test with $\alpha=0.01$ was used to select those variables in which at least one stage (baseline, tilt or right ventricular support) was different from the other stages. In these selected variables, statistically significant differences between the baseline, tilted and right ventricular support stages were tested using a paired t-test with Bonferroni correction for three multiple measures. Significance was assumed if the corrected P value was less than 0.05 . 


\subsection{Results}

\subsubsection{Cardiac tilting}

In Table 4-1, hemodynamic data from the conductance measurements are summarized. They show that tilting caused a strong and significant reduction in cardiac output of $31 \%$. This reduction was accompanied by a decrease in right ventricular end-diastolic volume of $44 \%$, while enddiastolic pressure rose slightly but not significantly. These effects are also seen in the examples of pressure-volume loops given in Figure 4-2. Left ventricular pressure did not significantly decrease and even increased in two animals upon tilting.
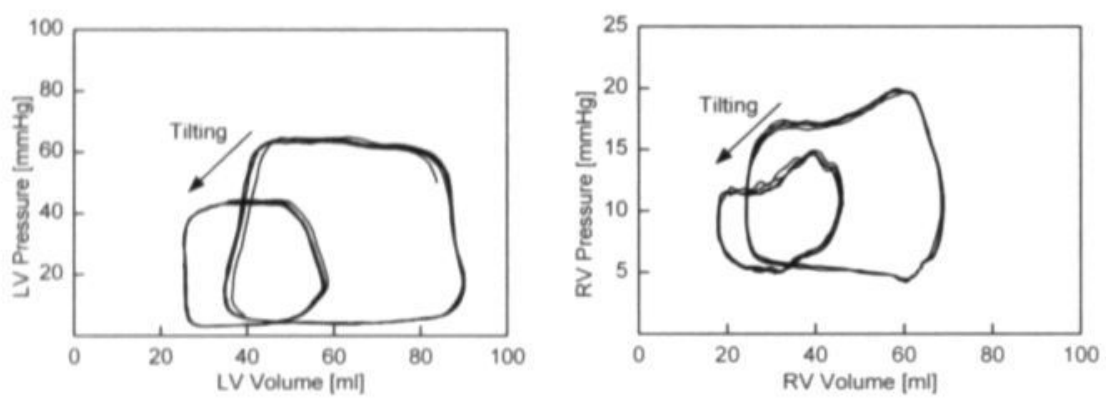

Figure 4-2: Representative left and right ventricular pressure-volume loops before and after tilting with the Octopus device. Upon tilting the stroke volume, left ventricular endsystolic pressure and right ventricular end-diastolic volume decrease, but right ventricular end-diastolic pressure increases.

The ventricles reacted differently to cardiac tilting. This was best seen at the end of the tilting procedure; when the heart was placed back into its normal position, it was observed that the right ventricle immediately responded to the new situation while it took a number of beats for the left ventricle to adjust (Figure 4-3). 


\subsubsection{Right ventricular support}

The Enabler right ventricular support system mildly increased cardiac output and left ventricular end-diastolic volume, but not significantly, and cardiac output remained $23 \%$ lower than the pre-tilting value (Table 4-1). Upon right ventricular support activation, the right ventricular output was decreased by more than $0.51 / \mathrm{min}$ in five out of seven experiments.

These effects are seen in the examples of pressure-volume loops given in Figure 4-4 and a similar result was obtained with the right ventricular support in the untilted heart as shown in Figure 4-5; right ventricular stroke volume was strongly decreased when the right ventricular support was switched on, while left ventricular stroke volume only mildly increased.

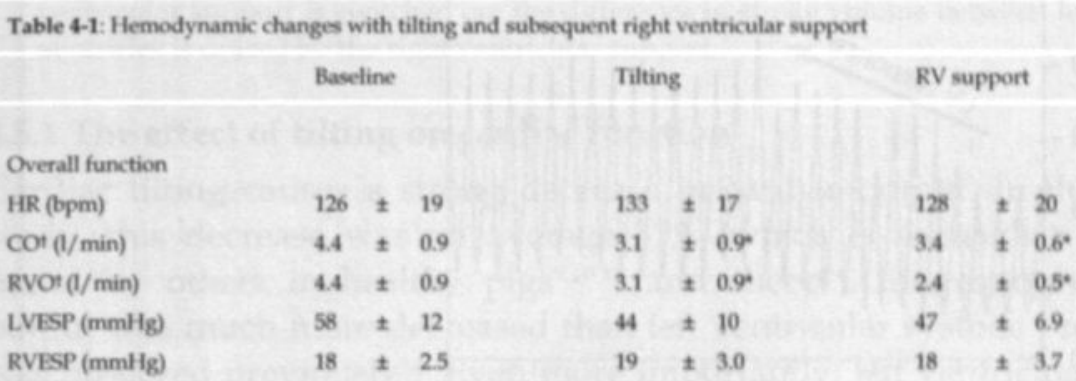

$\begin{array}{lllllll}\text { Left ventricle } & 93 \pm 24 & 72 & \pm 30 & 76 & \pm 22 \\ \text { EDV }(\mathrm{ml}) & 54 \pm 27 & 48 & \pm 33 & 49 & \pm 26 \\ \text { ESV }(\mathrm{ml}) & 8.3 \pm 2.2 & 9.0 \pm 2.2 & 8.7 \pm 1.4 \\ \text { EDP }(\mathrm{mmHg}) & \pm & \pm\end{array}$

Right ventricle

$\begin{array}{lllllll}\text { EDV' }(\mathrm{ml}) & 86 & \pm 41 & 51 & \pm 35^{*} & 50 & \pm 31^{*} \\ \text { ESV' }(\mathrm{ml}) & 50 & \pm 34 & 28 & \pm 27^{*} & 30 & \pm 26^{*} \\ \text { EDP }(\mathrm{mmHg}) & 5.6 \pm 3.5 & 6.9 & \pm 4.2 & 6.4 & \pm 4.4\end{array}$

HR, heart rate; CO, cardiac output; RVO, right ventricular output; LVESP, left ventricular end-systolic pressure; RVESP, right ventricular end-systolic pressure; EDV, end-diastolic volume; ESV, end-systolic volume; RDP, enddiastolic pressure. All data are the mean $\pm S D$ and $n=7$ (except left ventricular EDP, $n=6$ ). tOne stage different using the Friedman test with $\alpha=0.01$ (see Methods Section). $\mathrm{P}<0.05$ versus baseline. None of the variables measured during right ventricular support were significantly different from the tilted position. 


\subsection{Discussion}

The results of this study demonstrate that simultaneous left and right ventricular pressure-volume loops measured by conductance catheters are useful to examine changes in cardiac function during cardiac tilting and subsequent right ventricular support by the Enabler. The conductance technique has been used successfully earlier in the assisted heart ${ }^{3 / 4}$, but the heart was never placed in a non-anatomical position and both ventricles were never simultaneously studied during or after an intervention. This study not only shows that this is feasible, but also that it is necessary in a complicated intervention in order to know which ventricle causes a change in cardiac function, and which ventricle merely responds to the other.

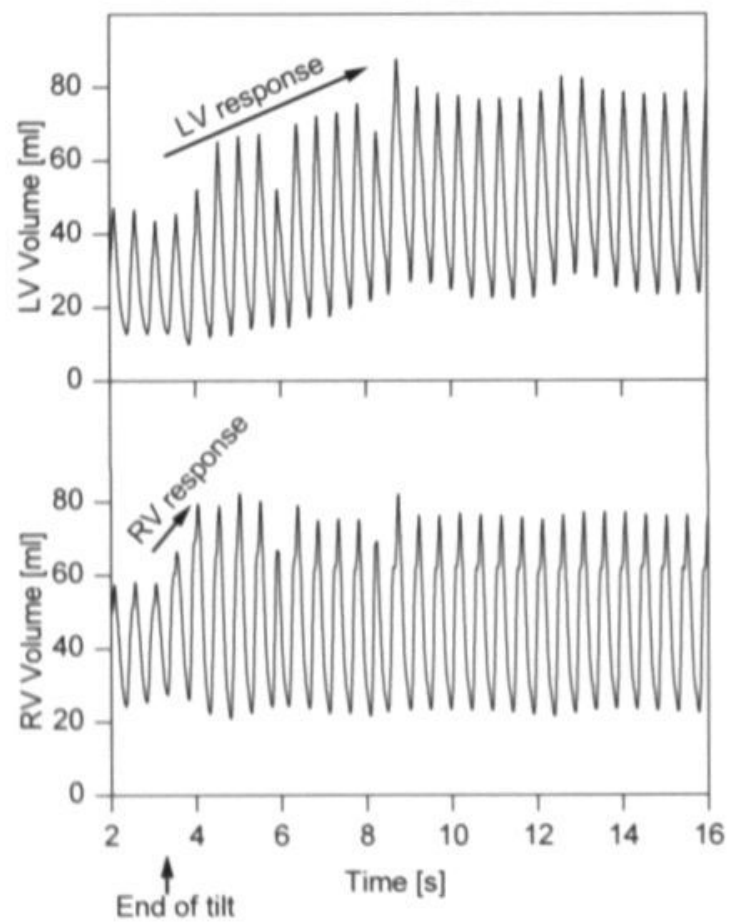

Figure 4-3: Changes in left and right ventricular volume upon repositioning of the heart from a tilt into its normal position. The repositioning occurs between $t=3 \mathrm{~s}$ and $\mathrm{t}=4 \mathrm{~s}$. The slow variation in volume, especially seen in the left ventricle, is caused by ventilation. The right ventricle immediately responds to the new situation by an increase in end-diastolic volume within two to three beats. In contrast, the left ventricle slowly accommodates to the new situation in about ten beats. 

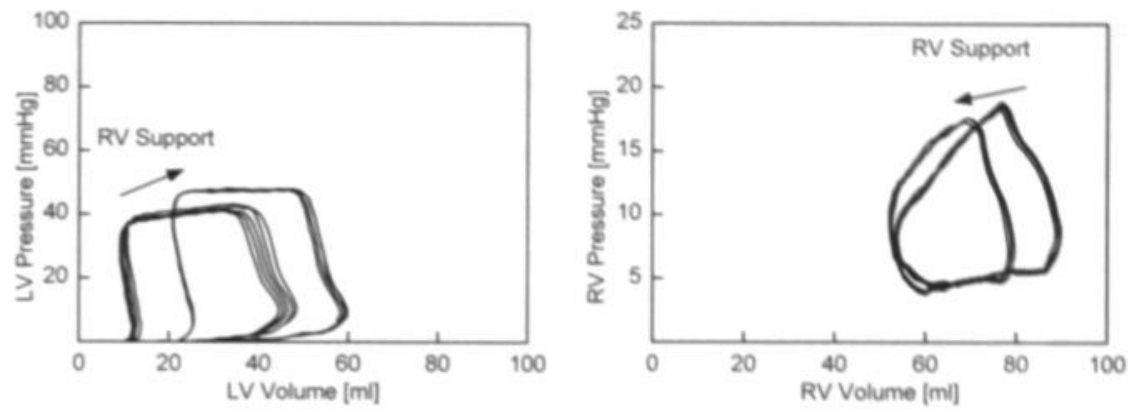

Figure 4-4: Representative left and right ventricular pressure-volume loops before and after Enabler right ventricular support with the Enabler in the tilted heart. The left ventricular stroke volume and end-systolic pressure are increased upon right ventricular support. In contrast, the right ventricular stroke volume is decreased when the right ventricular support is switched on; the difference in stroke volume between left and right ventricles is caused by the right ventricular support.

\subsubsection{The effect of tilting on cardiac function}

Cardiac tilting causes a strong decrease in cardiac output. In the present study, this decrease was on average $31 \%$, which is somewhat less than found by others in healthy pigs ${ }^{9,10,17}$ and sheep ${ }^{14}$. Interestingly, cardiac output was much more decreased than left ventricular systolic pressure, as was observed previously ${ }^{14}$. Even more importantly, left ventricular systolic pressure was increased upon tilting in two out of seven sheep. This shows that blood pressure alone is most likely not a sensitive measure to estimate the extent of the hemodynamic worsening during cardiac tilting in the individual patient.

The observed decrease in cardiac output can be caused by (a) an increase in afterload, (b) a valvular defect, (c) a decrease in contractility or (d) a decrease in preload in either ventricle.

a) Afterload is not increased during cardiac tilting, as the end-systolic pressure in both left and right ventricles does not increase. Therefore, kinking of the aorta or the pulmonary artery does not seem to occur.

b) The introduction of a valvular defect by tilting was discarded earlier by echocardiography observations in two previous studies ${ }^{9,17}$. 


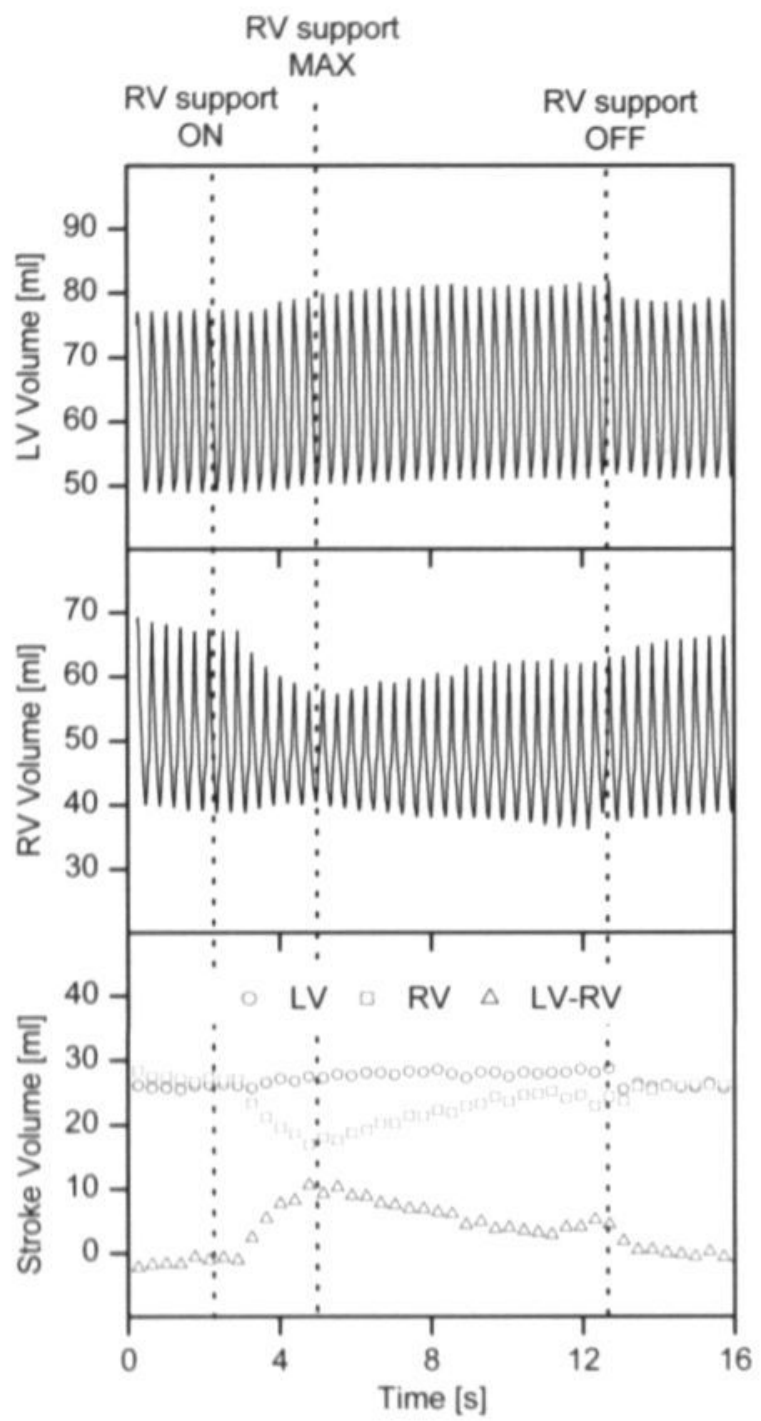

Figure 4-5: Enabler right ventricular support with the heart in its anatomical position. The Enabler is switched on at $\mathrm{t}=3 \mathrm{~s}$ up to maximum flow $(2.0 \mathrm{l} / \mathrm{min})$ at $\mathrm{t}=5 \mathrm{~s}$ and then slowly turned back to zero flow at $t=13 \mathrm{~s}$. The left ventricular stroke volume and end-diastolic volume are slightly increased upon right ventricular support. The right ventricular stroke volume and end-diastolic volume decrease strongly when the Enabler is switched on. This unloading limits the Enabler's positive effect on left ventricular stroke volume. 
c) An acute decrease in contractility upon tilting is unlikely. No signs of tilting-induced ischemia were reported by other investigators ${ }^{10}$ and hypoxia, which may occur due to low blood pressure during tilting, is more likely a consequence than a cause of the low cardiac output. One of the most reliable measures of contractility is the slope of the endsystolic pressure-volume relationship. Although this slope can be measured with a conductance catheter, this was not done as it requires caval vein occlusion, which would have interfered too much with the hemodynamic state of these animals during tilting.

d) A decrease in preload, defined as end-diastolic volume, occurs in both ventricles upon tilting. The right ventricle can be argued to be the most likely cause of the decrease in cardiac output for two reasons. First, the right ventricle immediately reacts to the end of the tilt by increasing its end-diastolic volume and stroke volume, while the left ventricle slowly reacts to the increased filling by the Frank Starling mechanism (Figure $4-3$ ). If the left ventricle was the problem during tilting, then it would have been the first to react to the end of the tilt. Second, a resistance to left ventricular filling would have increased pulmonary pressure and thus right ventricular afterload, which was not observed. In conclusion, reduced right ventricular filling is the major cause of the decrease in cardiac output during cardiac tilting.

The reduced right ventricular filling is not accompanied by a decrease in right ventricular end-diastolic pressure. This contradiction was observed before 9.10 .17 , and may be caused by a mechanical inhibition of right ventricular filling, for instance a compression of the ventricular wall by the tilting procedure. This is supported by a recent echocardiographic study which reported that right ventricular geometry changes during tilting ${ }^{17}$. Another explanation is that the ventricle is filled against gravitation because the apex is pointed upwards during tilting.

It has been shown that an extreme $20^{\circ}$ Trendelenburg maneuver can partially restore cardiac function during a tilt via increased right heart filling pressure and thus increased preload 9.10 . This is in agreement with our finding that right ventricular filling is the problem during cardiac tilting. However, it should be noted that the reported acute two-fold increase in right atrial pressure caused by the Trendelenburg maneuver has the inherent risk of atrial fibrillation ${ }^{18}$, and should therefore be avoided if possible.

\subsubsection{Right ventricular support with the Enabler}

The Enabler right ventricular support is not able to fully recover cardiac output to pre-tilting values. Our results correspond well with the recently published results with the Biomedicus device and the Enabler as a right 
heart bypass, which were also shown to only partially restore cardiac function ${ }^{14,17}$. Another support system, the Hemopump, has also been used in OPCABG 15,16 , but this is a left ventricular assist device and might not be suitable, as it is the right ventricle that needs support.

There are two explanations why the Enabler did not fully restore cardiac output. First, activation of the Enabler further decreases right ventricular output. Likely mechanisms are a reduction in right ventricular filling because the Enabler sucks blood from the right atrium, or an increase in right ventricular afterload caused by simultaneous ejection of the Enabler and the right ventricle. Second, the forward flow of the Enabler, the difference between right and left ventricular output (see Table 4-1), is only $0.9 \mathrm{l} / \mathrm{min}$. Possible explanations are (a) the right ventricular output is overestimated because the conductance slope factor can not be measured (see Methods Section), and (b) the Enabler causes regurgitation across the pulmonary valve, which would mean that part of the Enabler output is used to fill the right ventricle rather than flowing towards the lungs.

In conclusion, current right ventricular support systems can not fully restore cardiac function during tilting. Furthermore, the output of a right ventricular support should not be assumed to be a net extra output, and monitoring of the end result, cardiac output, is therefore crucial.

\subsubsection{Limitations of the study}

In this study, the animals had low blood pressure, cardiac output, ventricular volumes and poor ventricles compared to humans. It can be expected that tilting will be better tolerated by the human heart.

\subsection{Acknowledgements}

This study was financially supported by Hemodynamics Systems Ltd., Yoqneam, Israel. We gratefully acknowledge the biotechnical assistance provided by Jo Habets and Theo van der Nagel, the study support by Veronica Elias-Weissmann, and the comments on the manuscript by David Shoshani. 


\subsection{References}

1. Takaoka H, Takeuchi M, Odake M, Hata K, Hayashi Y, Mori M, Yokoyama M. Depressed contractile state and increased myocardial consumption for nonmechanical work in patients with heart failure due to old myocardial infarction. Cardiovasc Res 1994;28:1251-1257.

2. MacGowan GA, Haber HL, Cowart TD, Tedesco C, Wu C, Feldman MD. Direct myocardial effects of OPC-18790 in human heart failure: benefecial effect on contractile and diastolic function demonstrated by intracoronary infusion with pressure-volume analysis. J Am Coll Cardiol 1998;31:1344-1351.

3. Kitano M, Nishimura K, Park C-H, Okamoto $\mathrm{Y}$, Ban T. Right ventricular function evaluated by volumetric analysis during left heart bypass in a canine model of postischemic cardiac dysfunction. J Thorac Cardiovasc Surg 1995;109:796-803.

4. Park C-H, Nishimura K, Kitano M, Matsuda K, Okamoto Y, Ban T. Analysis of right ventricular function during bypass of left side of the heart by afterload alterations in both normal and failing hearts. J Thorac Cardiovasc Surg 1996;111:1092-1102.

5. Schreuder JJ, van der Veen FH, van der Velde ET, Delahaye F, Alfieri O, Jegaden O, Lorusso R, Jansen JRC, Hoeksel SAAP, Finet G,Volterrani M, Kaulbach HG, Baan J, Wellens HJ. Left ventricular pressure-volume relationships before and after cardiomyoplasty in patients with heart failure. Circulation 1997;96:2978-2986.

6. Bishop A, White P, Chaturverdi R, Brookes C, Redington A, Oldershaw P. Resting right ventricular function in patients with coronary artery disease: pressure volume analysis using conductance catheters. Int J Cardiol 1997;58:223228.

7. Chaturverdi RR, Kilner PJ, White PA, Bishop A, Szwarc R, Redington AN. Increased airway pressure and simulated branch pulmonary artery stenosis increase pulmonary regurgitation after repair of tetralogy of Fallot: real-time analysis with a conductance catheter technique.Circulation 1997;95:643-649.

8. Amirhamzeh MMR, Dean DA, Jia C-X, Cabreriza SE, Yano OJ, Burkhoff D, Spotnitz HM. Validation of right and left ventricular conductance and echocardiography for cardiac function studies. Ann Thorac Surg 1996;62:11041109.

9. Grundeman PF, Borst C, van Herwaarden JA, Mansvelt Beck HJ, Jansen EWL. Hemodynamic changes during displacement of the beating heart by the Utrecht Octopus method. Ann Thorac Surg1997;63:S88-S92.

10. Grundeman PF, Borst C, van Herwaarden JA, Verlaan CWJ, Jansen EWL. Vertical displacement of the beating heart by the Octopus tissue stabilizer: influence on coronary flow. Ann Thorac Surg1998;65:1348-1352.

11. Roach GW, KanchugerM, Mora Mangano C, Newman M, Nussmeier N, Wolman R, Aggarwal A, Marschall K, Graham SH, Ley C, Ozanne G, Mangano DT. Adverse cerebral outcomes after coronary bypass surgery. N Engl J Med 1996;335:1857-1863.

12. Jansen EWL, Lahpor JR, Borst C, Grundeman PF, Bredee JJ. Off pump coronary bypass grafting: how to use the Octopus tissue stabilizer. Ann Thorac Surg 1998;66:576-579. 
13. Geskes GG, Dekker AL, van der Veen FH, Cramers AA, Maessen JG, Shoshani D, Prenger KB. The Enabler right ventricular circulatory support system for beating heart coronary artery bypass graft surgery. Ann Thorac Surg 1999;68:1558-1561.

14. Porat E, Sharony R, Ivry S, Ozaki S, Meyns BP, Flameng WJ, Uretzky G. Hemodynamic changes and right heart support during vertical displacement of the beating heart. Ann Thorac Surg 2000;69:1188-1191.

15. Mack MJ, Acuff TE, Casimir-Ahn H, Lonn UL, Jansen EWL. Video assisted coronary bypass grafting on the beating heart. Ann Thorac Surg 1997;63:S100S103.

16. Lonn U, Peterzen B, Carnstam B, Casimir-Ahn H. Beating heart coronary surgery supported by an axial blood flow pump. Ann Thorac Surg 1999;67:99104.

17. Grundeman PF, Borst C, Verlaan CWJ, Meijburg H, Moues CM, Jansen EWL. Exposure of circumflex branches in the tilted, beating porcine heart: echocardiographic evidence of right ventricular deformation and the effect of left heart bypass. J Thorac Cardiovasc Surg1999;18:316-323.

18. Calkins H, El-Atassi R, Kalbfleisch S, Langberg J, Morady F. Effects of an acute increase in atrial pressure on atrial refractoriness in humans. Pacing Clin Electrophysiol 1992;15:1674-1680. 


\section{Chapter 5}

\section{Right ventricular support}

Published as:

Geskes GG, Dekker AL, van der Veen FH, Cramers AA, Maessen JG, Shoshani D, Prenger KB. The Enabler right ventricular circulatory support system for beating heart coronary artery bypass grafting. Ann Thorac Surg 1999;68:1558-1561. 


\subsection{Abstract}

\section{Background}

Beating heart coronary artery bypass graft surgery of the left anterior descending, diagonal, and right coronary artery can be performed safely with the Octopus Stabilization System. However, tilting of the heart, which is necessary to reach the obtuse marginal and distal right coronary arteries, causes hemodynamic instability. This study was performed to investigate the possible role of the Enabler right ventricular circulatory support system in counteracting this instability.

\section{Methods}

In 8 sheep, the Enabler cannula was introduced via the jugular vein and positioned with the inlet valve in the right atrium and outlet valve in the pulmonary artery. The Octopus was used to expose the inferior wall and the posterior wall of the left ventricle. The hemodynamic effects of this tilting with and without Enabler right ventricular support were recorded, including Pressure Volume (PV) loops measured by conductance catheters in both ventricles.

Results

Tilting caused a reduction in stroke volume (inferior 31\%, posterior $17 \%$ ) and. Enabler activation. increased. stroke volume (inferion $13 \%$, posterion $31 \%)$.

\section{Conclusion}

Tilting the heart has severe hemodynamic consequences that can be partially counteracted by the use of the Enabler for right ventricle support. 


\subsection{Introduction}

It has been demonstrated that beating heart revascularization of the coronary arteries on the anterior and inferior walls of the heart can be performed safely with excellent results. This advancement is due to the introduction of stabilizers such as the Octopus Tissue Stabilization System (Medtronic, Grand Rapids, MI), which stabilize the left anterior descending (LAD), diagonal, and the right coronary arteries. The Octopus also allows access to the obtuse marginal and distal right coronary arteries. However, performing beating heart coronary artery bypass graft surgery (CABG) to these vessels is limited by hemodynamic instability that results from tilting the heart to reach the posterior and inferior wall of the left ventricle ${ }^{1}$.

Tilting leads to a dysfunction of the left and/or right ventricle and causes a decrease in cardiac output and systemic blood pressure. One way to maintain an acceptable cardiac output is the use of the Trendelenburg maneuver to increase the right-sided filling pressures and thereby partially correct the low output of the left ventricle ${ }^{2}$.

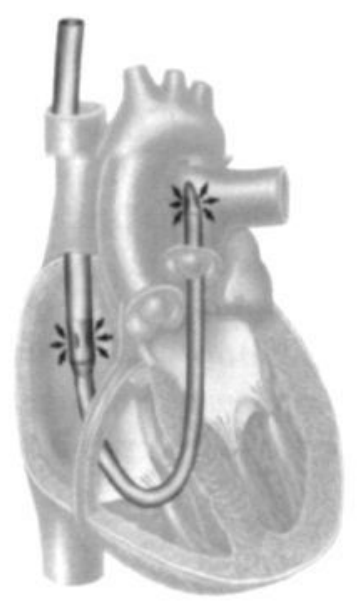

Figure 5-1: The position of the Enabler cannula. The inflow valve lies centrally within the right atrium, the outflow tip lies proximally in the pulmonary artery.

However, the safety of this method in case of a heart with an abnormal ejection fraction of the left and/or right ventricle has not yet been proven.

It is widely understood that heart tilting leads to a dysfunction of the left and right ventricle and causes a decrease in cardiac output and systemic blood pressure. However, it is unclear whether the ventricular problems are interdependent, and if so, which ventricle is the source of the problem. 
The purpose of this sheep study was to evaluate the effectiveness of a new right-side support system (Enabler circulatory support system; HemoDynamics, Yokneam, Israel) ${ }^{3}$ in overcoming both right and left ventricular compromise during tilting. In addition, the impact of the device on tissue damage and hemolysis was examined. 


\subsection{Materials and methods}

\subsubsection{Animals and medication}

Eight healthy female sheep of average weight $66 \mathrm{~kg}$ were used in this study. The animals were premedicated with atropin $(10 \mathrm{mg})$, and anesthesia was induced with thiopental $(15 \mathrm{mg} / \mathrm{kg}$, iv). After endotracheal intubation, anesthesia was maintained with oxygen/nitrous oxide (2:1) and halothane $(1 \%$ to $2 \%$ ). At the end of the experiment, the sheep were killed with pentobarbital (Euthesate, $200 \mathrm{mg} / \mathrm{kg}$, iv) and $\mathrm{KCl}$. Before introduction of the Enabler cannula, heparin was administered $(300 \mathrm{IU} / \mathrm{kg}$ bodyweight as a bolus). During the procedure, the ACT was maintained at more than $400 \mathrm{~s}$.

\subsubsection{Description of the Enabler system}

The Enabler circulatory support system consists of a control console, a disposable pump-head, and a cannula. The control console is connected by means of a tube to the lower chamber of the pump-head. This tube is filled with water. The pump-head contains two chambers that are separated by a flexible diaphragm. The cannula is connected to the pump-head's upper chamber and is filled with a sterile isotonic solution that mixes with the patient's blood upon introduction. The electro-hydraulic control console is 1:1 triggered by the patient's electrocardiogram and activates a servocontroller that manages the cyclical movement of water between the control console and the pump-head. As water is pushed into and out of the pumphead, the diaphragm moves accordingly, thereby driving the blood in the catheter. The cannula sits in the right heart, with an inlet port in the right atrium and the outlet tip in the pulmonary artery. A series of valves within the cannula causes blood to be sucked through the inlet port and expelled through the outlet tip during activation of the control console and pumphead.

\subsubsection{Experimental protocol}

After sternotomy, the 24 French Enabler cannula was introduced via the jugular vein and advanced through the right atrium, tricuspid valve, right ventricle, and pulmonary valve. The distal tip of the cannula was positioned in the proximal pulmonary artery, and the inlet port in the right atrium (Figure 5-1). The Octopus stabilizer was then used to tilt the heart in such a way that the distal branches of the right coronary artery were exposed. After 5 minutes of unsupported tilting, the Enabler was activated during 10 minutes with a pulsatile flow of $2.0 \mathrm{~L} / \mathrm{min}$. The Enabler was then deactivated for 2 minutes, after which the heart was placed back in its normal position. 
After a 30-minute resting period, a second tilting procedure was performed to expose the posterior wall of the left ventricle with the distal obtuse marginal branches. Again, the procedure entailed 5 minutes of unsupported tilting, 10 minutes of Enabler supported tilting, and 2 minutes of unsupported tilting, after which the heart was placed back in its original position. At the end of this procedure, the animals were killed and the right atrium, right ventricle, and pulmonary artery were inspected macroscopically for signs of damage to the endocardium and valves.

\subsubsection{Hemodynamic recordings}

Hemodynamic recordings, including left and right ventricular pressurevolume loops, were obtained with a Swan-Ganz catheter (Arrow, Reading, PA) inserted via the jugular vein, a femoral arterial, and direct left atrial pressure line (Baxter, Santa Ana, CA), a left ventricular conductance catheter inserted via the femoral artery, a right ventricular conductance catheter inserted via the jugular vein (Sentron, Roden, The Netherlands), and a Doppler flow probe (Transonic, Ithaca, NY) on the descending aorta for continuous cardiac output measurement. To obtain absolute cardiac output values with the flow probe, including coronary and carotid artery flow, the Doppler flow probe was calibrated in situ against the cardiac output measured with the Swan-Ganz catheter by the thermodilution method. Left and right ventricular pressure-volume loops were captured

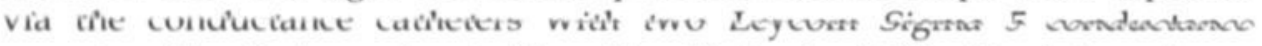
consoles (Cardiodynamics, Leiden, The Netherlands) ${ }^{4.5}$. Absolute volume measurements were obtained by calibration of the conductance signals to the cardiac output as measured by the flow probe, and saline injections were used to estimate the parallel conductance according to the method introduced by Baan and associates ${ }^{6}$. Tilting the heart changes the position of the conductance catheter in the ventricle and makes any previous calibration invalid, so each time the ventricle was tilted or placed back in its anatomical position, a full calibration procedure was performed.

Hemodynamic data were obtained with: (1) the heart in its normal position, (2) with the heart tilted but without support of the Enabler, and (3) with the heart tilted and supported by the Enabler. In the statistical analysis, absolute and percentage changes between these three situations were analyzed using a Student's t test, with significance assumed if the $p$ value was less than 0.05 .

\subsubsection{Hemolysis}

Whether the Enabler pumping induces hemolysis was assessed by measuring free hemoglobin in blood plasma samples. Venous blood samples were obtained before insertion of the Enabler catheter, immediately 
after the inferior wall tilting procedure, and after the posterior wall tilting procedure. Free hemoglobin was measured at 540 and at $575 \mathrm{~nm}$, and values were averaged to obtain the percentage of hemolyzed erythrocytes in the blood, which can be used to calculate the free hemoglobin in milligrams per liter. This measurement is assumed to be more accurate at low free hemoglobin values than measuring free hemoglobin directly in milligrams per liter ${ }^{7}$. 


\subsection{Results}

For several reasons, the protocol could not be completed fully in all 8 animals. In sheep no. 2, the Enabler cannula dislocated from the pulmonary artery during tilting and could therefore not give any circulatory support. Sheep no. 5 developed ventricular fibrillation during posterior wall tilting due to hypoxia caused by ventilator malfunction. In sheep no. 7 , posterior wall tilting caused severe myocardial ischemia, so the protocol had to be abandoned. As a consequence, sheep no. 2 was excluded from all analysis, and the hemodynamic data from the posterior wall tilting in sheep nos. 5 and 7 were also excluded from the analysis.

\subsubsection{Hemodynamic recordings}

The hemodynamic data presented in Table 5-1 and Table 5-2 show that tilting for the exposure of the inferior wall caused a significant decrease compared with baseline values in stroke volume $(31 \% \pm 9 \%)$, cardiac output, and right ventricular volumes, and a significant increase in right atrial pressure. Activating the Enabler significantly increased stroke volume $(13 \% \pm 8 \%)$ and left ventricular volumes compared with the volumes during unsupported tilting. The posterior wall hemodynamic data in Table 5-1 and Table 5-2 show the same general results with an average decrease (compared with baseline) in stroke volume of $17 \% \pm 7 \%$ due to tilting and an increase (compared with unsupported tilting) of $38 \% \pm 15 \%$ with activation of the Enabler. However, due to the limited number of sheep, significance for posterior wall tilting could not be confirmed.

\subsubsection{Pressure-volume loops}

A representative example of the effect of tilting and Enabler pumping on the pressure-volume loops of both ventricles is presented in Figure 5-2. The tilting procedure reduced stroke volume in both ventricles, while switching on the Enabler increased left ventricular performance while further decreasing right ventricular pumping function.

\subsubsection{Hemolysis}

Before insertion of the catheter, the average amount of free hemoglobin was $255 \pm 65 \mathrm{mg} / \mathrm{L}(\mathrm{n}=6)$, and this increased to $390 \pm 65 \mathrm{mg} / \mathrm{L}(\mathrm{n}=6)$ after the inferior wall tilting/pumping procedure. After the second, posterior wall tilting/ pumping procedure amount of free hemoglobin was $422 \pm 162$ $\mathrm{mg} / \mathrm{L}(\mathrm{n}=6)$.

\subsubsection{Macroscopic examination}

Upon macroscopic examination, no damage was found to the right atrium, right ventricle, and pulmonary artery. 
Table 5-1:Hemodynamic measurements (left-sided) during tilting.

\begin{tabular}{|c|c|c|c|}
\hline Parameter & Situation & Inferior Tilt & Posterior Tilt \\
\hline \multirow[t]{3}{*}{$\operatorname{Co}(1 / \min )$} & Normal & $4.3 \pm 1.2$ & $3.6 \neq 1.6$ \\
\hline & Tilted & $3.1 \neq 0.9$ & $3.0 \pm 1.0$ \\
\hline & Enabler On & $3.3 \neq 0.8$ & $3.8 \neq 1.0^{\circ *}$ \\
\hline \multirow[t]{3}{*}{ L.AP (mmHg) } & Normal & $5.9 \neq 0.6$ & $6.0 \neq 1.6$ \\
\hline & Tilted & $6.6 \pm 1.1$ & $7.7 \pm 0.8^{\circ}$ \\
\hline & Enabler On & $6.6 \pm 1.6$ & $9.1 \neq 1.9$ \\
\hline \multirow[t]{3}{*}{ LVESP (mmH Ig) } & Normal & $62 \pm 14$ & $47 \pm 13$ \\
\hline & Tilted & $51 \pm 12$ & $42 \pm 12$ \\
\hline & Enabler On & $53 \pm 9$ & $53 \pm 12^{\circ+}$ \\
\hline \multirow[t]{3}{*}{ LVESV (ml) } & Normal & $41=28$ & $74 \pm 36$ \\
\hline & Tilted & $44 \pm 15$ & $51 \div 30$ \\
\hline & Enabler On & $50 \pm 13^{* *}$ & $65 \pm 40$ \\
\hline \multirow[t]{3}{*}{ LVEDV (ml) } & Normal & $79 \pm 21$ & $110 \div 30$ \\
\hline & Tilted & $67 \pm 14$ & $80 \pm 37$ \\
\hline & Enabler On & $75 \pm 13$ & $99 \pm 45$ \\
\hline
\end{tabular}

CO = Cardiac Output; LAP = Left Atrial Pressure; LVEDV = Left Ventricular End Diastolic Volume; LVESP = Left Ventricular End Systolic Pressure LVESV = Left Ventricular End Systolic Volume

" pe0.05 tilted vs. normal; "* pe0.05 Enabler on vs. titled.

Table 5-2: Hemodynamic measurements (right-sided) during tilting

\begin{tabular}{|c|c|c|c|}
\hline Parameter & Situation & Inferior Tilt & Posterior Tilt \\
\hline \multirow[t]{3}{*}{ RAP $(\mathrm{mmH}$ H) } & Normal & $9 \pm 2$ & $11 \pm 3$ \\
\hline & Tilted & $11 \pm 2^{*}$ & $12 \pm 2$ \\
\hline & Enabler On & - & - \\
\hline \multirow[t]{3}{*}{ RVESP $(\mathrm{mmH}$ g) } & Normal & $20 \pm 2$ & $20 \pm 1$ \\
\hline & Tilted & $20 \pm 3$ & $20 \pm 1$ \\
\hline & Enabler On & $19 \pm 3$ & $21 \pm 2$ \\
\hline \multirow[t]{3}{*}{ RVESV (mmH H) } & Normal & $42 \pm 24$ & $51 \pm 25$ \\
\hline & Tilted & $26 \pm 21^{*}$ & $33 \neq 10$ \\
\hline & Enabler On & $27 \pm 21$ & $34 \pm 11$ \\
\hline \multirow[t]{3}{*}{$\operatorname{RVEDV}(\mathrm{ml})$} & Normal & $71 \pm 28$ & $79 \pm 36$ \\
\hline & Tilted & $45 \pm 26^{\circ}$ & $58 \pm 16$ \\
\hline & Enabler On & $44 \pm 24$ & $54 \pm 16$ \\
\hline
\end{tabular}

RAP = Right Atrial Pressure; RVEDV = Right Ventricular End Diastolic Volume: RVESP = Right Ventricular End Systolic Pressure, RVESV = Right Ventricular End Systolic Volume

"p<0.05 tilted vs, normal; "* pe0.05 Enabler on vs. titled. 


\subsection{Discussion}

The results of this experimental study in sheep show that tilting of the heart to reach the obtuse marginal branches on the posterior wall of the left ventricle and the distal branches of the right coronary artery on the inferior wall causes a significant impairment of right ventricular function and a reduction of left ventricular output. It is not clear whether this impairment of right ventricle function is the result of inflow obstruction of the blood by traction on the inferior caval vein, or the result of disturbance of the contractions of the right ventricle, or the development of tricuspid regurgitation ${ }^{3}$. The decrease in left ventricular output could be caused by right ventricular dysfunction but also by valve regurgitation or a decrease in myocardial contractility. In any event, the Enabler bypasses all of these potential sources of the problem, thus partially compensating the decreased right ventricular function by serving as a right heart support system. By increasing the cardiac output on the right side of the heart, the output of the left ventricle increases as well.
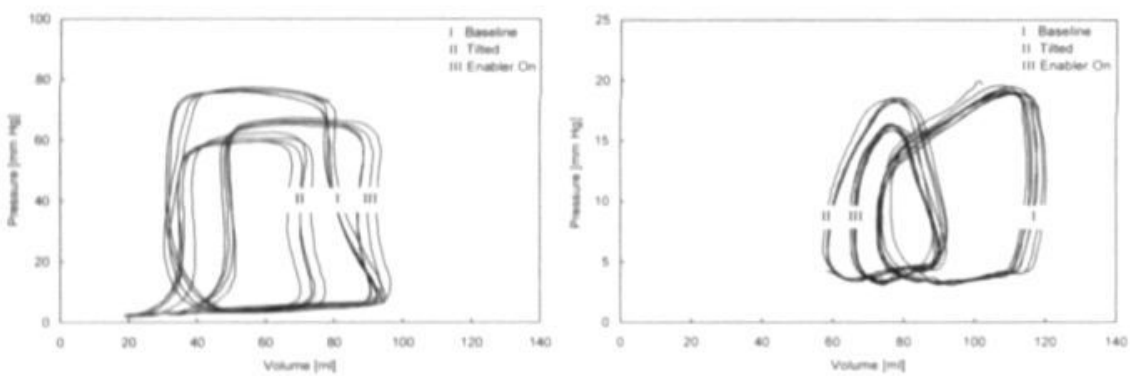

Figure 5-2: Typical pressure-volume loops obtained with a conductance catheter (sheep no.6). Left: Left ventricle. Baseline stroke volume $45 \mathrm{ml}$; Tilted stroke volume $34 \mathrm{ml}$; Enabler On stroke volume $40 \mathrm{ml}$. Right: Right ventricle. Baseline stroke volume $43 \mathrm{ml}$; Tilted stroke volume $33 \mathrm{ml}$; Enabler On stroke volume $23 \mathrm{ml}$. Enabler set at $2.0 \mathrm{~L} / \mathrm{min}$ (Enabler stroke volume $17 \mathrm{ml}$ ).

There was an increase in free hemoglobin observed after pumping. It is not clear whether this is induced by the pump itself or by the tissue trauma caused by the surgical procedure. A full safety study of the Enabler circulatory support system is currently being conducted, during which we will try to establish the cause of this increase in free hemoglobin.

Our results confirm that the Enabler circulatory support system is able to pump blood from the right atrium into the pulmonary artery, and as such, can function as a right ventricular support system. We have found no signs of damage to the endocardium or the tricuspid and pulmonary valve, and minor hemolysis. 
The current model of the Enabler, which provides a flow of 2 to $2.5 \mathrm{~L} / \mathrm{min}$, gave partial support to the right ventricle in this study. However, the net extra cardiac output due to the Enabler was only $0.3 \mathrm{~L} / \mathrm{min}$ during the inferior wall tilt and $0.8 \mathrm{~L} / \mathrm{min}$ during the posterior wall tilt. The difference between provided flow, and net extra cardiac output was caused by a decrease in right ventricular output during the activation of the Enabler. In effect, the Enabler bypasses the right ventricle, creating either a decrease in preload or an increase in afterload, which ultimately results in a reduction of right ventricular output.

Introduction of the cannula via the jugular vein in humans will not be possible due to the cannula's 24 French size. Instead, introduction via the right atrium or right auricle should be used in human sternotomy cases. Another possible application of the femoral version of the Enabler is as a temporary right heart assist device in a patient with a failing right ventricle after cardiac surgery or a myocardial infarction of the right ventricle.

A limitation of this study was that all animals had low cardiac output and filling pressures before starting the protocol.

The Enabler gives partial support to the right ventricle during cardiac tilting necessary to reach the posterior and inferior wall of the left ventricle without causing tissue damage or significant hemolysis. Further study is necessary to isolate the nature of the right and left ventricle problem during cardiac tilting.

\subsection{Acknowledgements}

This study was supported by HemoDynamics Systems Ltd, Yokneam, Israel. 


\subsection{References}

1. Jansen EWL, Grundeman PF, Mansvelt Beck HJ, Heijmen RH, Borst C. Experimental off-pump grafting of a circumflex branch via sternotomy using a suction device. Ann Thorac Surg 1997;63:S93- S96.

2. Grundeman PF, Borst C, Van Herwaarden JA, Mansvelt Beck HJ, Jansen EWL. Hemodynamic changes during displacement of the beating heart by the Utrecht Octopus method. Ann Thorac Surg 1997;63:S88 -S92.

3. Porat E, Ozaki S, Sharony R, et al. Right heart assist with the intra-pulmonary cannula pump (IPCP) effectively supports circulation during heart tilting [Abstract]. International Society for Minimally Invasive Cardiac Surgery, Minneapolis,MN, June 1998.

4. Baan J, Aouw Jong TT, Kerkhof PLM, et al. Continuous stroke volume and cardiac output from intra-ventricular dimensions obtained with impedance catheter. Cardiovasc Res 1981;15:328-334.

5. Bishop A, White P, Chaturverdi R, Brookes C, Redington A, Oldershaw P. Resting right ventricular function in patients with coronary artery disease: pressure volume analysis using conductance catheters. Int J Cardiol 1997;58:223-238.

6. Baan J, Van Der Velde ET, De Bruin HG, et al. Continuous measurement of left ventricular volume in animals and humans by the conductance catheter. Circulation 1984;70:812-823.

7. International Organization for Standardization. Biological evaluation of medical devices-Part 4: Selection for tests for interaction with blood, Amendment 1: Annex D- Evaluation of haemolytic properties of medical devices. Draft Amendment ISO 10993-4:1992/DAM1, 1997. 


\section{Chapter 6}

\section{Intra Aortic Balloon Pump in acute mitral regurgitation}

Published as:

Dekker ALAJ, Reesink KD, van der Veen FH, van Ommen GVA, Geskes GG, Soemers ACM, Maessen JG. Intra-aortic balloon pumping in acute mitral regurgitation reduces aortic impedance and regurgitant fraction. Shock 2003:19(4):334-338. 


\subsection{Abstract}

\section{Objectives}

Acute mitral regurgitation (MR) is present in $10 \%$ of patients presenting with cardiogenic shock. To stabilize these patients intra-aortic balloon pumping (IABP) is recommended, but the mechanism of IABP support in these patients is unknown. This animal study was designed to describe the hemodynamic effect of intra-aortic balloon pumping during cardiogenic shock induced by acute mitral regurgitation.

\section{Methods}

In eight calves, left ventricular pressure-volume loops, aortic and left atrial pressure and aortic, carotid artery and coronary blood flow were recorded. Acute mitral regurgitation (MR) (range $36-79 \%$ ) was created by placing a metal cage in the mitral valve. Hemodynamic data was obtained at control, during acute MR and during acute MR with 1:1 IABP support.

Results

Acute MR caused a decrease in cardiac output $(-32 \%, p=0.018)$, blood pressure and carotid artery flow while left ventricular output $(+127 \%$, $p=0.018$ ), end-diastolic volume and left atrial pressure all significantly increased. Stroke work, ejection fraction and coronary blood flow were not significantly changed and no signs of ischemia were seen on the ECG.

The IABP raised average cardiac output by $31 \%(\mathrm{p}=0.012)$ and significantly raised blood pressure and flow to the brains while decreasing systemic vascular resistance. Left ventricular function and mean coronary blood flow did not change, but diastolic coronary flow became more important as shown by the increase in diastolic fraction from 64 to $95 \%$. $(p=0.028)$. Average mitral regurgitation dropped by $7.5 \%(p=0.025)$.

\section{Conclusion}

In conclusion, application of the IABP during acute MR, lowers aortic impedance resulting in less mitral regurgitation and more output towards the aorta without changing left ventricular function. 


\subsection{Introduction}

Acute mitral regurgitation (MR) is present in $10 \%$ of the patients presenting with cardiogenic shock ${ }^{1}$. Acute MR is the result of papillary muscle rupture caused by endocarditis, degenerative disease of the mitral valve or myocardial infarction. The actual size of the infarction is often quite limited which illustrates that acute MR may induce cardiogenic shock ${ }^{2-4}$. Definite treatment is surgical repair of the mitral valve but immediate hemodynamic support should be instituted to stabilize patients before they undergo surgery. During this period, cardiac output and blood pressure need to be restored using the intra-aortic balloon pump (IABP) and vasodilators such as nitroprusside ${ }^{5-8}$.

The effect of vasodilators in acute MR models has been studied extensively ${ }^{7.9}$, but the hemodynamic effect of the IABP during acute MR has not been documented.

The general hypothesis on the effect of the IABP in acute MR cases is that the afterload reduction by the IABP results in more output towards the aorta than to the atrium. This will reduce the severity of the mitral regurgitation and increase the cardiac output of the left ventricle. In addition, two known beneficial effects of the IABP may occur: The afterload reduction itself may cause a higher output of the left ventricle while diastolic counterpulsation could increase coronary blood flow which may be beneficial to left ventricular contractility.

In this study, these hypotheses on the hemodynamic effects of the IABP are tested in an animal model of acute mitral regurgitation. 


\subsection{Materials and Methods}

\subsubsection{Animal preparation}

All animals received humane care in compliance with the "Guide for the Care and Use of Laboratory Animals" (NIH publication 86-23, revised 1985) and the study was approved by our institution's animal ethics committee. Eight "Roodbont" calves with average weight $109 \mathrm{~kg}(76-148 \mathrm{~kg})$ were premedicated with atropine $(0.05 \mathrm{mg} / \mathrm{kg}$ s.c.). Anesthesia was induced with sodium thiopental (i.v.-bolus $15 \mathrm{mg} / \mathrm{kg}$ ) and maintained with a 1:2 mixture of $\mathrm{O}_{2}: \mathrm{N}_{2} \mathrm{O}$ and halothane $(2 \%)$. After administration of muscle relaxant suxamethonium (i.v.-bolus $0.1 \mathrm{mg} / \mathrm{kg}$ ) and analgetic buprenorfine (i.v.bolus $0.01 \mathrm{mg} / \mathrm{kg}$ ), a left thoracotomy was performed and ventilation was modified to give a peak end-expiration pressure of $5 \mathrm{~cm} \mathrm{H}_{2} \mathrm{O}$. Heparin (i.v.bolus $100 \mathrm{IU} / \mathrm{kg}$ ) was administered and the activated clotting time was measured and kept above 400 seconds during the experiment. During anesthesia, monitoring included ECG, blood pressure, oxygen saturation and capnography. The animals were killed with an overdose of pentobarbital (i.v.-bolus $200 \mathrm{mg} / \mathrm{kg}$ ).

\subsubsection{Instrumentation}

Under fluoroscopy a Swan-Ganz thermodilution catheter (Arrow International, Reading, PA, USA) was advanced via the jugular vein and a $40 \mathrm{ml}$ intra-aortic balloon (Datascope, Fairfield, NJ, USA) was placed via the right femoral artery in the high descending aorta. A conductance catheter, incorporating a pressure sensor (Sentron, Rhoden, the Netherlands), was placed via the right carotid artery in the left ventricle. The conductance catheter was connected to a conductance console (CD Leycom, Zoetermeer, the Netherlands) which was used in dual frequency mode ${ }^{10}$. Solid-state pressure catheters (Sentron, Rhoden, the Netherlands) were placed in the abdominal aorta via the left femoral artery, in the ascending aorta via the left carotid artery and in the left auricle through a small incision. Flow probes (Transonic Systems, Ithaca, NY) were placed on the ascending aorta, the left carotid artery and on a side branch of the left anterior coronary descending artery. From the latter signal, the diastolic fraction was calculated to differentiate between systolic and diastolic coronary blood flow ${ }^{15}$.

To create the acute mitral regurgitation an incision was made in the left atrium through which a retrievable steel wire cage (Günther tulip vena cava filter, William Cook Europe, Bjaeverskov, Denmark), was placed in the mitral valve (Figure 6-1). The amount of mitral regurgitation was defined as the percentage of left ventricular stroke volume flowing towards the atrium. 
This percentage was calculated by the subtracting aortic flow (by flow probe) from left ventricular stroke volume (by conductance catheter) and dividing by left ventricular stroke volume.

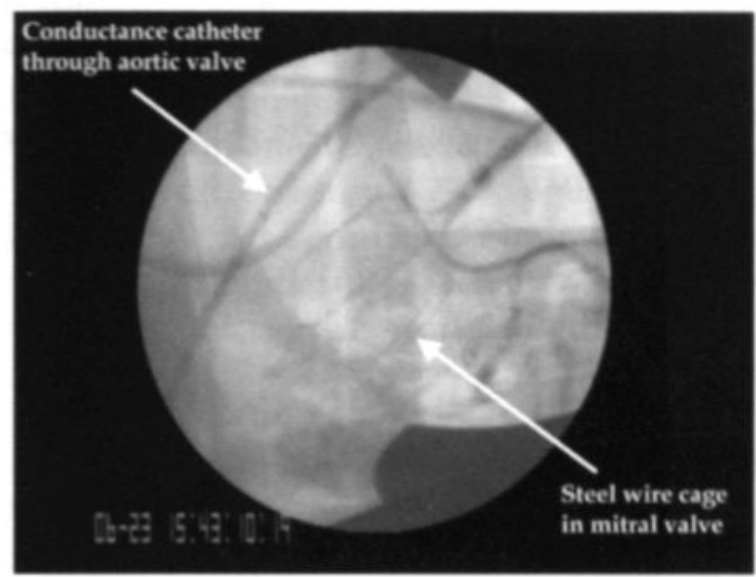

Figure 6-1: Fluoroscopic image which shows the steel wire cage in the mitral valve and the conductance catheter through the aortic valve.

\subsubsection{Conductance calibration}

Parallel conductance was determined by injecting $7.5 \mathrm{ml}$ of $6.5 \%$ hypertonic saline in the pulmonary artery ${ }^{11}$. A $5 \mathrm{ml}$ blood sample was collected and blood resistivity measured by a sampling cuvette (CD Leycom, Zoetermeer, the Netherlands) ${ }^{12}$. The slope factor was determined by comparing conductance derived stroke volume with the aortic flow just prior to the creation of acute mitral regurgitation.

\subsubsection{Measurement protocol}

After instrumentation, the animal was stabilized for at least thirty minutes. After this period, the control measurements were performed. Then acute MR was created by stenting the mitral valve with a steel wire cage as described above. Once the animal was hemodynamically stable, which usually took only a couple of beats, the unsupported acute MR measurement was performed. Immediately after this measurement the IABP support was switched on and, again after stabilization, measurements were performed. After these 1:1 IABP-supported measurements, the acute MR was relieved by pulling back the steel wire cage. 


\subsubsection{Statistical analysis}

A non-parametric Friedman test was used to select those variables in which at least one stage (control, unsupported acute MR and 1:1 IABP supported acute MR) was different from other stages. In these selected variables, statistically significant changes between control and unsupported MR and between unsupported MR and 1:1 IABP supported acute MR were tested using a non-parametric, Wilcoxon signed ranks test. Significance was assumed if the P-value was less than 0.05 . 


\subsection{Results}

\subsubsection{Acute MR}

Hemodynamic data are presented in Table 6-1. It shows that in all animals the introduction of the cage in the mitral valve caused severe acute mitral regurgitation (average regurgitant fraction $65 \%$, range $36-79 \%$ ). This acute MR was accompanied by a significant decrease in cardiac output $(-32 \%$, $\mathrm{p}=0.018)$, blood pressure $(-27 \%, \mathrm{p}=0.018)$ and carotid artery flow $(-26 \%$, $\mathrm{p}=0.018$ ) while left ventricular output, end-diastolic volume and left atrial pressure all significantly increased. Left ventricular systolic function (ejection fraction, stroke work, $\mathrm{dP} / \mathrm{dt}_{\mathrm{MAx}}$ ) and coronary blood flow was unchanged and no signs of ischemia were seen on the ECG.

Afterload dropped as shown by the lower end-diastolic aortic pressure and lower maximal left ventricular pressure. However systemic vascular resistance remained the same, indicating that the afterload reduction is caused by a sudden decrease in retrograde impedance.

These observations are also visualized in the pressure-volume loops given in Figure 6-2: By creating acute mitral regurgitation, the left ventricle produces more output due to the higher preload and lower afterload. However, the higher left ventricular output can not prevent the drop in net cardiac output and blood pressure.

\subsubsection{IABP during acute MR}

Table 6-1 shows that switching on the IABP immediately raised average cardiac output by $31 \%(\mathrm{p}=0.012)$ and significantly raised blood pressure and flow to the brains. Left ventricular output and contractility (dP/dtmAx, stroke work, ejection fraction) did not change. Mean coronary blood flow did not change, but a significant shift from systolic to diastolic flow was observed (diastolic fraction from $64 \%$ to $95 \%, \mathrm{p}=0.028$ ).

Afterload, either defined as the pressure in the ascending aorta when the aortic valve opened or as maximal left ventricular pressure, did not change significantly although systemic vascular resistance was decreased.

The above shows that left ventricular function was unchanged, while general hemodynamics improved. In the example of Figure 6-2 the same can be observed: Left ventricular pressure-volume loops did not change when switching on the IABP but blood pressure and cardiac output improved. 


\section{8 | Chapter 6}

Table 6-1: Hemodynamic data before acute MR, during unsupported acute MR and during IABP supported acute MR.

\begin{tabular}{|c|c|c|c|c|c|c|c|}
\hline HR & [bpm] & 127 & (22) & 123 & (25) & 126 & (26) \\
\hline AOPInein & [mmH $\mathrm{mg}$ ] & 62.4 & (11.7) & 45.7 & $(7.7)^{\circ}$ & 51.4 & $(7.8)^{t}$ \\
\hline $\mathrm{CO}$ & [I min'] & 2.97 & (1.18) & 2.03 & $(0.80)^{*}$ & 2.65 & (1.17) \\
\hline LVo & [I min'] & 2.96 & (1.18) & 6.73 & $(3.86)^{*}$ & 7.12 & (3.99) \\
\hline MR & {$[*]$} & 0.0 & $(0.0)$ & 65.4 & $(15.0)^{*}$ & 57.9 & (17.5) \\
\hline Car, Flow & [I min-1] & 0.54 & $(0.22)$ & 0.40 & $(0.20)^{\circ}$ & 0.48 & $(0.23)$ \\
\hline CBF & {$\left[\mathrm{ml} \min { }^{-1}\right]$} & 59.0 & (22.7) & 50.6 & $(27.3)$ & 49.4 & (30.8) \\
\hline DF & {$[\%]$} & 57.8 & (18.4) & 64.4 & (21.3) & 95.3 & (17.5) \\
\hline \multicolumn{8}{|l|}{ Preload } \\
\hline LAP & [mmHig] & 8.5 & $(5.8)$ & 17.1 & $(8.4)^{*}$ & 17.2 & $(9.3)$ \\
\hline EDV & {$[\mathrm{ml}]$} & 65.4 & (33.6) & 93.1 & $(47.1)^{*}$ & 92.2 & $(46.8)$ \\
\hline \multicolumn{8}{|l|}{ Afterload } \\
\hline AOPw & [mmH & 52.5 & (11.3) & 38.1 & $(6.7)^{*}$ & 41.8 & (8.2) \\
\hline LVPux & [mmHg] & 76.4 & (11.4) & 57.0 & $(8.4)^{*}$ & 57.5 & (8.1) \\
\hline SVK & [aynes scm- & 10as & $(+\infty)$ & 2001 & (roo) & irno & (eas) \\
\hline \multicolumn{8}{|c|}{ Systolic function } \\
\hline EF & $\mid \mathbf{3}]$ & 44 & (18) & 62 & (16) & 64 & (16) \\
\hline dP/dtux & {$\left[\mathrm{mmH} \mathrm{s}^{-1}\right]$} & 767 & (167) & 588 & (206) & 619 & (215) \\
\hline SW & {$[\mathrm{g} \mathbf{m}]$} & 18.4 & (12.1) & 26.4 & (19.4) & 27.9 & (21.2) \\
\hline
\end{tabular}

HR: Heart rate; AOResw: Mean ascending aortic pressure; CO: Cardiac output; LVO: Left ventricular output: MR: Mitral regurgitant fraction (ILVO-COJ/LVO); Car. Flow: Flow in the carotid artery; CBF: Coronary blood flow; DF: Diastolic Fraction: LAP: Left atrial pressure; EDV: Left ventricular end diastolic volume; AOPh: Ascending aortic pressure at end of diastole: LVPux: Maximal left ventricular pressure; SVR: Systemic vascular resistance: EF: Ejection fraction; dP/dtux: Maximum positive derivative of left ventricular pressure over time; SW: Stroke work performed by the left ventricle. Values are mean(sd), $n=8$. "p<0.05 vs. control; tp<0.05 vs. unsupported acute MR 


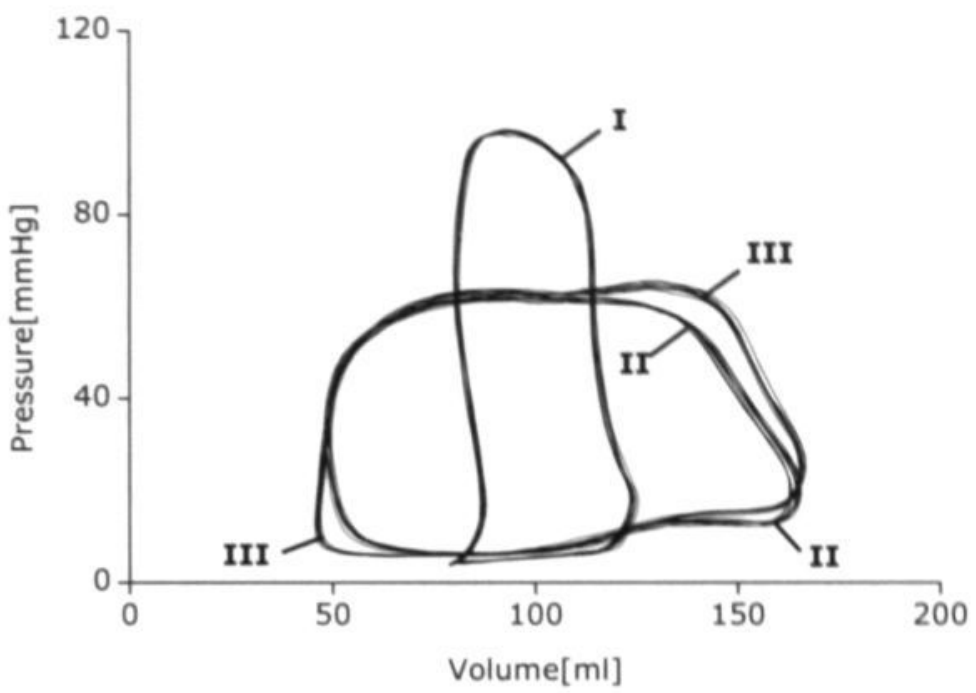

$\begin{array}{llccc} & & \text { Control }(\mathrm{I}) & \text { Acute MR (II) } & \text { Acute MR + IABP (III) } \\ \text { CO } & {[1 / \mathrm{min}]} & 4.7 & 3.0 & 4.1 \\ \text { LVO } & {[1 / \mathrm{min}]} & 4.7 & 14.6 & 15.1 \\ \text { MR } & {[\mathrm{I}]} & 0 & 79 & 73 \\ \text { AOP } & {[\mathrm{mmH}]} & 82.5 & 49.7 & 59.8\end{array}$

Figure 6-2: Representative left ventricular pressure volume loops in one animal. I: Before acute mitral regurgitation, II: During unsupported acute mitral regurgitation and III: During IABP supported acute mitral regurgitation. Important hemodynamic parameters are supplied in the adjacent table. (CO: Cardiac output, LVO; Left ventricular output; MR: Regurgitant fraction; AOP: Mean ascending aortic pressure) 


\subsection{Discussion}

\subsubsection{Acute MR model and cardiogenic shock}

In the clinical setting, acute MR can cause hemodynamic dysfunction resulting in cardiogenic shock and pulmonary edema ${ }^{2}$. In this study, acute MR was induced by placing a steel wire cage in the mitral valve. Immediately, the left ventricle increased its output but still blood pressure and net cardiac output fell by more than $25 \%$ as did carotid artery flow while left atrial pressure doubled. This combination of low cardiac output, low blood pressure, hypoperfusion with adequate intravascular volume and high left atrial pressure is indicative of cardiogenic shock ${ }^{1,5}$.

In the present study, the animals were able to increase their average total left ventricular output (antegrade and retrograde) by $+127 \%(p=0.018)$. This increase was possible due to higher filling and reduced afterload, the latter ensuring that only a limited and non-significant increase in stroke work $(+43 \%, p=N S)$ was necessary to produce the extra stroke volume. This shift from pressure to volume work was purely caused by the decrease in retrograde impedance as systemic vascular resistance remained constant.

Coronary blood flow was not reduced and, as the perfusion pressure was lower, this implies coronary vasodilatation representing immediate compensation. The ECG showed no signs of ischemia, so coronary blood flow was still sufficient for the left ventricle to produce the volume work, which is energetically less costly than pressure work ${ }^{13}$.

In accordance with other investigators ${ }^{2-4}$, we conclude from the present study that cardiogenic shock can be caused by severe mitral regurgitation alone without any dysfunction or ischemia of the left ventricle or changes in the systemic vascular bed.

\subsubsection{Effect of the IABP in acute MR}

The main object of this study was to measure the hemodynamic effect of the intra-aortic balloon pump during acute mitral regurgitation. Clearly, the $\mathrm{IABP}$ had a beneficial effect on cardiac output and blood pressure as well as other vital parameters such as carotid artery flow. However, the cause of these effects is not immediately clear. We hypothesized the following: The $\mathrm{IABP}$ increases coronary blood flow resulting in higher left ventricular contractility and the IABP reduces afterload which results in more left ventricular output and/or less mitral regurgitation. 


\subsubsection{Effect of IABP on coronary flow and left ventricular contractility}

In this study, the IABP did not increase mean coronary blood flow. A possible reason is that during acute MR, the existent coronary blood flow was already sufficient, which is supported by the absence of ischemic signs on the ECG without IABP support.

Furthermore, the IABP does not change left ventricular contractility as stroke work, $\mathrm{dPdt}_{\max }$ and ejection fraction are similar with or without support. In conclusion, the hypothesis that the IABP increases coronary blood flow resulting in higher left ventricular contractility is not confirmed by this study.

Although mean coronary blood flow was similar, the IABP did change the flow pattern: Flow during diastole increased while systolic flow decreased which led to the observed increased diastolic fraction (Table 6-1). This shift from systole to diastole was observed before in non-stenotic coronary arteries $^{14}$. The increase in diastolic flow is caused by the IABP's counterpulsation, while the reduction in systolic flow may have three explanations:

First, there may be a reduced oxygen demand due to the unloading by the IABP which would induce metabolic vasoconstriction ${ }^{14}$. However, in this study the heart was not unloaded by the IABP as stroke work did not change (Table 6-1).

Second, the reduced systolic pressure by the IABP may induce or increase systolic retrograde flow ${ }^{14}$. However, in this study the IABP did not lower left ventricular systolic pressure (Table 6-1).

So the only explanation that agrees with our results, is that the increase in diastolic flow leads to a better myocardial perfusion ${ }^{15}$ which induces metabolic vasoconstriction.

\subsubsection{Effect of IABP on left ventricular afterload and mitral regurgitation}

The observed increase in antegrade cardiac output with IABP support can be the result of lower afterload which would increase left ventricular stroke volume or because of a redistribution of antegrade versus retrograde output.

First, afterload, in its most basic definition, is the wall stress experienced by the ventricle during systole, which is calculated by systolic pressure $\left(\sim \mathrm{LVP}_{\mathrm{MAx}}\right)$ times radius $(\sim \mathrm{EDV})$ divided by the wall thickness. None of these parameters changed when switching on the IABP, so afterload did not change.

Second, in the normal heart, afterload is determined by the impedance of the systemic vasculature and therefore systolic wall stress and the 
impedance of the systemic vasculature are closely related and used side-byside $^{16}$. However, in acute MR left ventricular afterload is determined by the net impedance of two parallel impedances: The aortic impedance and the retrograde impedance of the regurgitation. In our experiments, the latter was lower as is it received $65 \%$ of the flow (Table 6-1), and therefore retrograde impedance was a more important determinant of left ventricular afterload than aortic impedance.

As a result, a decrease in aortic impedance will not change afterload significantly, but will reduce mitral regurgitation and thus increase net cardiac output: A redistribution of antegrade versus retrograde output. In this study, this reduction of mitral regurgitation $(-7.5 \%, p=0.025)$ was observed when the IABP was switched on. The reduction of mitral regurgitation or retrograde output may seem small but as total left ventricular output (retrograde and antegrade) was high, it resulted in $31 \%$ $(p=0.012)$ more antegrade cardiac output.

It is clear from the above that the only explanation for the increase in cardiac output is that aortic impedance is reduced by the IABP. This was noticed by other investigators that showed a decrease in systemic vascular resistance and in characteristic impedance ${ }^{17}$. This decrease in systemic vascular resistance is also seen in this study, although the appropriateness of impedance considerations is questionable as this concept is based on a time invariant impedance which is not the case if a balloon actively pumps in the aorta ${ }^{18,19}$.

Another important consideration is the fact that, in these young animals with elastic aortas, wave velocity is limited to about $3 \mathrm{~m} \mathrm{~s}^{-1}$ in the aorta ${ }^{20,21}$. As the distance from the middle of the balloon to the aortic valve is approximately $30 \mathrm{~cm}$ in these calves, it takes $100 \mathrm{~ms}$ for the decrease in pressure caused by the balloon pump, to fully reach the aortic valve. As these young animals all have a high heart rate, this is not trivial: If the balloon deflates at end-diastole the full decrease in afterload reaches the aortic valve well during systole. In this respect one should also realize that the IABP is commonly triggered to give maximal afterload reduction at the tip of the balloon, where the pressure is measured.

This study shows that the IABP has a different hemodynamic effect than vasodilators in animal models of acute $\mathrm{MR}^{7.9}$. Vasodilators either reduce end-diastolic volume and the regurgitant orifice, or reduce afterload 7.9 . Also, vasodilators do not seem to have an optimal effect on the circulation during acute MR as they do not increase cardiac output and reduce blood pressure in these models ${ }^{79}$. In contrast, the present study shows that the $\mathrm{IABP}$ can raise both cardiac output and blood pressure. 


\subsubsection{Clinical implications}

This study shows the possible benefit and mechanism of IABP support in patients with cardiogenic shock (mainly) caused by acute mitral regurgitation ${ }^{1}$. Others investigators have suggested that the IABP is underutilized in patients presenting with cardiogenic shock ${ }^{22}$. Hopefully, this study contributes to the wider use of the IABP and to clinical investigations into the effectiveness of the IABP in this special category of cardiogenic shock patients.

\subsubsection{Study limitations}

In this animal study we created acute MR in healthy hearts which were able to increase their left ventricular output to compensate some of the regurgitation. In the clinical situation, particularly in a patient with a myocardial infarction and coronary artery disease, the situation is more complicated and other factors could play a role, for example an increase in coronary blood flow during IABP support.

Also, patients with acute MR generally have an increased heart rate ${ }^{23}$, which was not observed in this study as these young calves already had a high heart rate. As mentioned above, the high heart rate also masks the reduction in aortic pressure by the balloon pump.

\subsubsection{Conclusion}

The aim of this study was to evaluate the hemodynamic effect of the IABP during acute MR. We conclude that the IABP lowers aortic impedance resulting in less mitral regurgitation and more output towards the aorta without changing left ventricular function. 


\subsection{References}

1. Hasdai D, Topol EJ, Califf RM, Berger PB, Holmes DR, Jr: Cardiogenic shock complicating acute coronary syndromes. Lancet 356:749-56, 2000.

2. Khan SS, Gray RJ: Valvular emergencies. Cardiol Clin 9:689-709, 1991.

3. Wei JY, Hutchins GM, Bulkley $\mathrm{BH}$ : Papillary muscle rupture in fatal acute myocardial infarction: a potentially treatable form of cardiogenic shock. Ann Intern Med 90:149-52, 1979.

4. Nishimura RA, Schaff HV, Shub C, Gersh BJ, Edwards WD, Tajik AJ: Papillary muscle rupture complicating acute myocardial infarction: analysis of 17 patients. Am J Cardiol 51:373-7, 1983.

5. Hollenberg SM, Kavinsky CJ, Parrillo JE: Cardiogenic shock. Ann Intern Med 131:47-59, 1999.

6. Jeresaty RM: Left ventricular function in acute non-ischaemic mitral regurgitation. Eur Heart J 12 Suppl B:19-21, 1991.

7. Yoran C, Yellin EL, Becker RM, Gabbay S, Frater RW, Sonnenblick EH: Mechanism of reduction of mitral regurgitation with vasodilator therapy. Am J Cardiol 43:773-7, 1979.

8. Ryan TJ, Antman EM, Brooks NH, et al. 1999 update: ACC/AHA guidelines for the management of patients with acute myocardial infarction. A report of the American College of Cardiology/American Heart Association Task Force on Practice Guidelines (Committee on Management of Acute Myocardial Infarction). J Am Coll Cardiol 1999;34:890-911

9. Okabe F, Sohara H, Ueda A, Ito T, Matsumoto S: Mechanisms for improvement of cardiac performance by nifedipine in an acute mitral regurgitation in dogs. Jpn Heart J 26:1019-28, 1985.

10. Steendijk P, Van der Velde ET, Baan J: Left ventricular stroke volume by single and dual excitation of conductance catheter in dogs. Am J Physiol 264:H2198$207,1993$.

11. Baan J, van der Velde ET, de Bruin HG, Smeenk GJ, Koops J,van Dijk AD, Temmerman D, Senden J, Buis B: Continuous measurement of left ventricular volume in animals and humans by conductance catheter. Circulation 70:812-23, 1984.

12. Amirhamzeh MM, Dean DA, Jia CX, Cabreriza SE, Yano OJ, Burkhoff D, Spotnitz, HM: Validation of right and left ventricular conductance and echocardiography for cardiac function studies. Ann Thorac Surg 62:1104-9, 1996.

13. Katz AM: Influence of altered inotropy and lusitropy on ventricular pressurevolume loops. J Am Coll Cardiol 11:438-45, 1988.

14. Kimura A, Toyota E, Lu S, et al. Effects of intraaortic balloon pumping on septal arterial blood flow velocity waveform during severe left main coronary artery stenosis. J Am Coll Cardiol 1996;27:810-816.

15. Kondo M, Kawata K, Azuma A, et al. Relationship between coronary blood flow velocity waveform and transmural distribution of myocardial blood flow in coronary artery. Jpn Heart J 1999;40:783-790.

16. Nichols WW, Pepine Cl: Ventricular/vascular interaction in health and heart failure. Compr Ther 18:12-9, 1992. 
17. Kim SY, Euler DE, Jacobs WR, Montoya A, Sullivan HJ, Lonchyna VA, Pifarre R: Arterial impedance in patients during intraaortic balloon counterpulsation. Ann Thorac Surg 61:888-94, 1996.

18. Chen FY, Aklog L, Couper GS, Cohn LH: Physiology and biomechanics of intraaortic balloon pumping (letter). Ann Thorac Surg 63:294-7, 1997.

19. Quick CM, Young WL, Noordergraaf A: Infinite number of solutions to the hemodynamic inverse problem. Am J Physiol Heart Circ Physiol 280:H1472-9, 2001.

20. Murthy VS, McMahon TA, Jaffrin MY, Shapiro AH: The intra-aortic balloon for left heart assistance: an analytic model. J Biomech 4:351-67, 1971.

21. Bercu BB, Haupt R, Johnsonbaugh R, Rodbard D: The pulse wave arrival time (QKd interval) in normal children. J Pediatr 95:716-21, 1979.

22. Anderson RD, Ohman EM, Holmes Jr. DR, Col I, Stebbins AL, Bates ER, Stomel RJ, Granger CB, Topol EJ, Califf RM: Use of intraaortic balloon counterpulsation in patients presenting with cardiogenic shock: observations from the GUSTO-I Study. Global Utilization of Streptokinase and TPA for Occluded Coronary Arteries. J Am Coll Cardiol 30:708-15, 1997.

23. Wisenbaugh T, Berk M, Essop R, Middlemost S, Sareli P: Effect of abrupt mitral regurgitation after balloon valvuloplasty on myocardial load and performance. J Am Coll Cardiol 17:872-8, 1991. 


\section{Chapter 7}

\section{Propeller pump versus Intra Aortic Balloon Pump}

Published as:

Dekker ALAJ, Reesink KD, van der Veen FH, van Ommen GVA, Geskes GG, Soemers ACM, Maessen JG. Efficacy of a new Intra Aortic Propeller Pump versus the Intra Aortic Balloon Pump: an animal study. Chest 2003;123:2089-2095. 


\subsection{Abstract}

Objective

Compare the efficacy of a new Intra Aortic Propeller Pump to provide hemodynamic support to the Intra Aortic Balloon Pump (IABP) in an acute mitral regurgitation (MR) animal model.

\section{Background}

A new intra aortic propeller pump (Jomed Reitan Catheter Pump) has recently been introduced. The pump's aim is a reduction in afterload via a deployable propeller placed in the high descending aorta which can be set at rotational speeds up to $14000 \mathrm{rpm}$.

\section{Methods}

In nine calves, acute MR was created by placing a vena cava filter in the mitral valve. The propeller pump was tested at 6000,10000 and $14000 \mathrm{rpm}$ and compared to 1:1 IABP support. Cardiac output, coronary blood flow, carotid artery flow, ascending and abdominal aortic pressure, left atrial pressure and LV pressure-volume loops were recorded.

\section{Results}

The propeller pump caused a rpm-dependent reduction of mean ascending aortic pressure reaching $-10 \mathrm{mmHg}(\mathrm{p}<0.05)$ at $14000 \mathrm{rpm}$. However, cardiac output did not improve $(2.6 \pm 0.7$ to $2.5 \pm 1.11 / \mathrm{min}, \mathrm{p}=\mathrm{NS})$ and diastolic coronary flow and carotid flow $(47 \pm 16$ to $35 \pm 15 \mathrm{cl} / \mathrm{min}, \mathrm{p}<0.05)$ were reduced. The IABP improved cardiac output, carotid and diastolic coronary flow.

\section{Conclusions}

In this acute MR animal model, the propeller pump reduced afterload but left out positive effects on cardiac output, which resulted in reduced perfusion of the upper body and the coronary circulation. Therefore, the $\mathrm{IABP}$ gives better hemodynamic support than the new propeller pump in calves with acute mitral regurgitation. 


\subsection{Introduction}

Circulatory support by the Intra Aortic Balloon Pump (IABP) is indicated in acute heart failure or cardiogenic shock either unresponsive to medical therapy or accompanied by acute mitral regurgitation ${ }^{1,2}$. The mechanism of the IABP is afterload reduction and an increase in coronary perfusion'. However, in some patients IABP support is not sufficient to maintain adequate circulation and other circulatory support devices may be indicated ${ }^{1,3}$.

Recently, a new device to continuously reduce afterload has been developed: the Intra Aortic Propeller Pump Jomed Reitan catheter pump, Jomed, Helsingborg, Sweden)4. It is a propeller-based pump placed in the high descending aorta with propeller rotational speeds up to $14000 \mathrm{rpm}$. Like the IABP, the aim of the pump is to reduce pressure proximal to the pump thereby reducing the afterload of the left ventricle. A secondary proposed benefit is the augmentation of perfusion distal to the pump. In the first human application of the propeller pump, excellent results were reported 5 .

In the present study the efficacy of the new propeller pump to support circulation is compared to the intra aortic balloon pump in an animal model of cardiogenic shock due to acute mitral regurgitation. 


\subsection{Methods and Materials}

\subsubsection{Animal preparation}

All animals received humane care in compliance with the "Guide for the Care and Use of Laboratory Animals" (NIH publication 86-23, revised 1985) and the study was approved by our institution's animal ethics committee. Nine "Roodbont" calves with average weight $109 \mathrm{~kg}(76-148 \mathrm{~kg})$ were premedicated with atropine $(0.05 \mathrm{mg} / \mathrm{kg}$ s.c.). Anesthesia was induced with sodium thiopental (i.v.-bolus $15 \mathrm{mg} / \mathrm{kg}$ ) and maintained with a $1: 2$ mixture of $\mathrm{O}_{2}: \mathrm{N}_{2} \mathrm{O}$ and $2 \%$ halothane. After administration of muscle relaxant suxamethonium (i.v.-bolus $0.1 \mathrm{mg} / \mathrm{kg}$ ) and analgetic buprenorfine (i.v.bolus $0.01 \mathrm{mg} / \mathrm{kg}$ ), a left thoracotomy was performed and ventilation was modified to give a peak end-expiration pressure of $5 \mathrm{~cm} \mathrm{H}_{2} \mathrm{O}$. Heparin (i.v.bolus $100 \mathrm{IU} / \mathrm{kg}$ ) was administered and the activated clotting time was measured and kept above 400 seconds during the experiment. Monitoring included ECG, blood pressure, oxygen saturation and capnography. The animals were sacrificed with an overdose of pentobarbital (i.v.-bolus 200 $\mathrm{mg} / \mathrm{kg})$.

\subsubsection{Instrumentation}

Under fluoroscopy, a Swan-Ganz thermodilution catheter (Arrow International, Reading, PA, USA) was advanced via the jugular vein. A conductance catheter, incorporating a pressure sensor (Sentron, Rhoden, the Netherlands), was placed via the right carotid artery in the left ventricle. The conductance catheter was connected to a conductance console (CD Leycom, Zoetermeer, the Netherlands) which was used in dual frequency mode $^{6}$. Solid-state pressure catheters (Sentron, Rhoden, the Netherlands) were placed in the abdominal aorta via the left femoral artery, in the ascending aorta via the left carotid artery and in the left atrium through a small incision. Flow probes (Transonic Systems, Ithaca, NY) were placed on the ascending aorta, the left carotid artery and the left circumflex artery. The propeller pump was placed through a 14 French sheath in the femoral artery. After the measurements with propeller pump support, a 1:1 ECG triggered, 40ml Intra Aortic Balloon Pump (Datascope, Fairfield, NJ, USA) was placed via the same sheath.

The measurement protocol was creation of acute MR, measurement during unsupported acute MR, activation of the propeller pump at a certain rotational speed or IABP support, measurements during supported acute MR, relief of acute MR, stabilization. The IABP measurements were always done after the propeller pump measurements. 


\subsubsection{Acute mitral regurgitation model}

As an animal model of cardiogenic shock, acute mitral regurgitation (MR) with a retrievable cage in the mitral valve, was chosen. This model simulates severe cardiogenic shock but is also reversible which allows multiple propeller rotational speeds to be tested as well as intra aortic balloon pumping without major deterioration of the hemodynamic state of the animal during the experiment.

An incision was made in the left atrium through which a retrievable steel wire cage (Günther tulip vena cava filter, William Cook Europe, Bjaeverskov, Denmark), was placed in the mitral valve (Figure 7-1). The amount of mitral regurgitation was defined as the percentage of left ventricular stroke volume flowing towards the atrium. This percentage was calculated by subtracting forward stroke volume (measured by an aortic flow probe) from left ventricular stroke volume (by conductance catheter) and dividing this by left ventricular stroke volume.

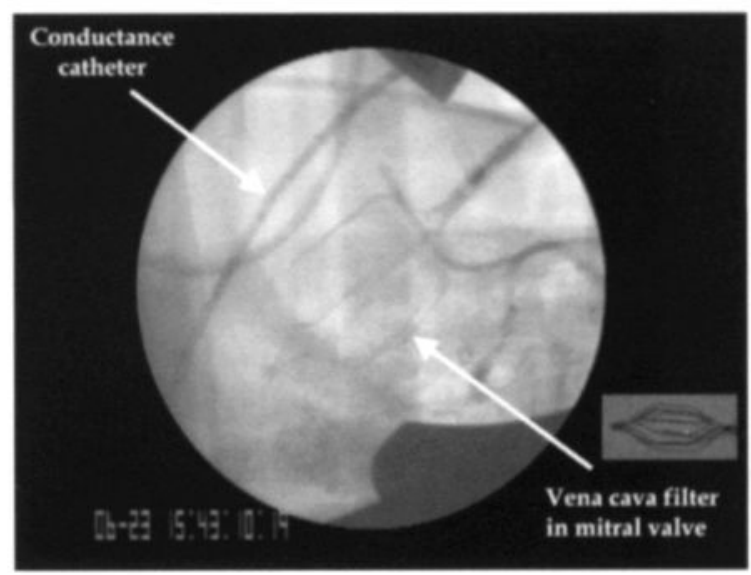

Figure 7-1: Fluoroscopic image of the vena cava filter opening the mitral valve to induce acute mitral regurgitation. The conductance catheter positioned through the aortic valve in the left ventricle, is also seen.

\subsubsection{Intra Aortic Propeller Pump}

The new intra aortic propeller pump is a support device with a deployable propeller (Figure 7-2) which is driven by a flexible central driveshaft ${ }^{4}$. The other end of the driveshaft is a permanent, disk shaped magnet which is placed in the driving unit. The driving unit consists of a rotating magnet that can be set at zero and up to $14000 \mathrm{rpm}$. The pump can only operate continuously, so no triggering is needed.

The propeller pump is placed in the descending aorta at a similar position as the intra aortic balloon. Once this position is reached, the propeller is 
deployed (Figure 7-2) and is ready for use. A solution of $20 \%$ glucose and 5 $\mathrm{IE} / \mathrm{ml}$ heparin was used at $25 \mathrm{ml} / \mathrm{hr}$ to purge and lubricate the pump.

The propeller is guarded by a basket which prevents contact between the propeller and the aortic wall. However, the aorta should have a diameter of at least $21 \mathrm{~mm}$ to prevent stenting. For this reason, the aortic diameter was measured with fluoroscopy before insertion of the propeller pump. In all animals the diameter was between $21 \mathrm{~mm}$ and $24 \mathrm{~mm}$.

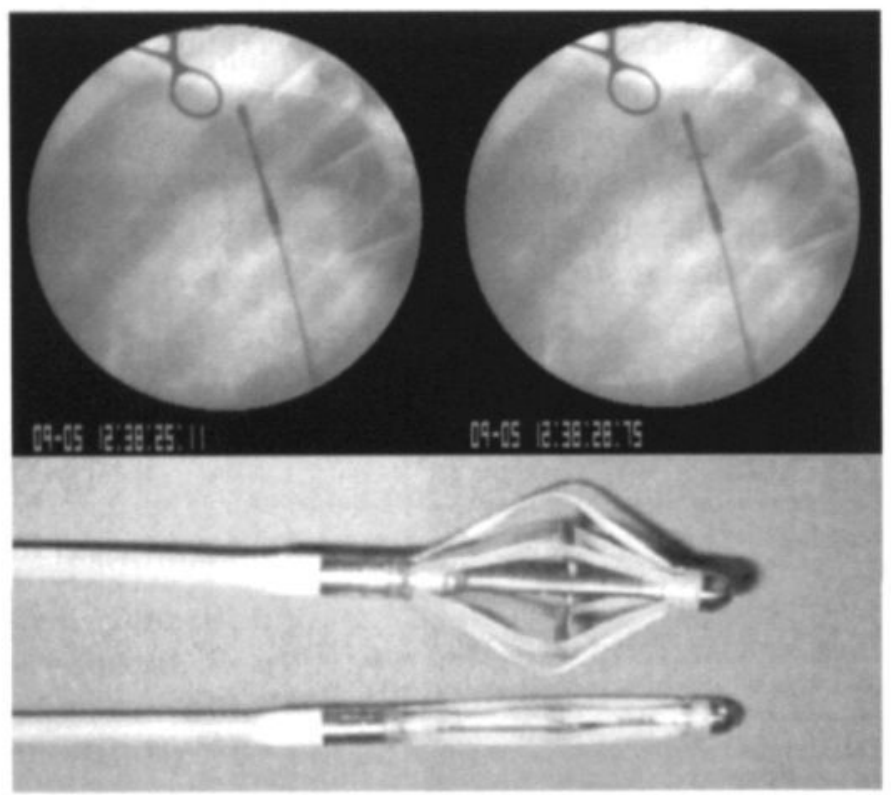

Figure 7-2: The intra aortic propeller pump with undeployed and deployed propeller.

\subsubsection{Conductance calibration}

Parallel conductance was determined by injecting $7.5 \mathrm{ml}$ of $6.5 \%$ hypertonic saline in the pulmonary artery ${ }^{7}$. A $5 \mathrm{ml}$ blood sample was collected and blood resistivity measured by a sampling cuvette (CD Leycom, Zoetermeer, the Netherlands) ${ }^{8}$. The slope factor was determined by comparing conductance derived stroke volume with the aortic flow prior to the creation of acute mitral regurgitation.

\subsubsection{Statistical analysis}

Statistically significant changes between unsupported acute MR and IABP or propeller pump supported acute MR were tested using a non-parametric, Wilcoxon signed ranks test. Significance was assumed if the P-value was less than 0.05 . 


\subsection{Results}

\subsubsection{Instrumentation}

Placement of the new propeller pump was possible through the femoral artery in all animals. Placement and deployment of the propeller could be clearly visualized under fluoroscopy (Figure 7-2). Upon propeller pump activation, a linear relation between gradient across the propeller (mean abdominal minus mean ascending aortic pressure) and rotational speed was found (Figure 7-3).

In all animals severe acute mitral regurgitation could be created with a mean regurgitant fraction of $65 \%$ (range 36-79\%). This regurgitation resulted in cardiogenic shock with low cardiac output, a decreased aortic blood pressure, and a high left atrial pressure.

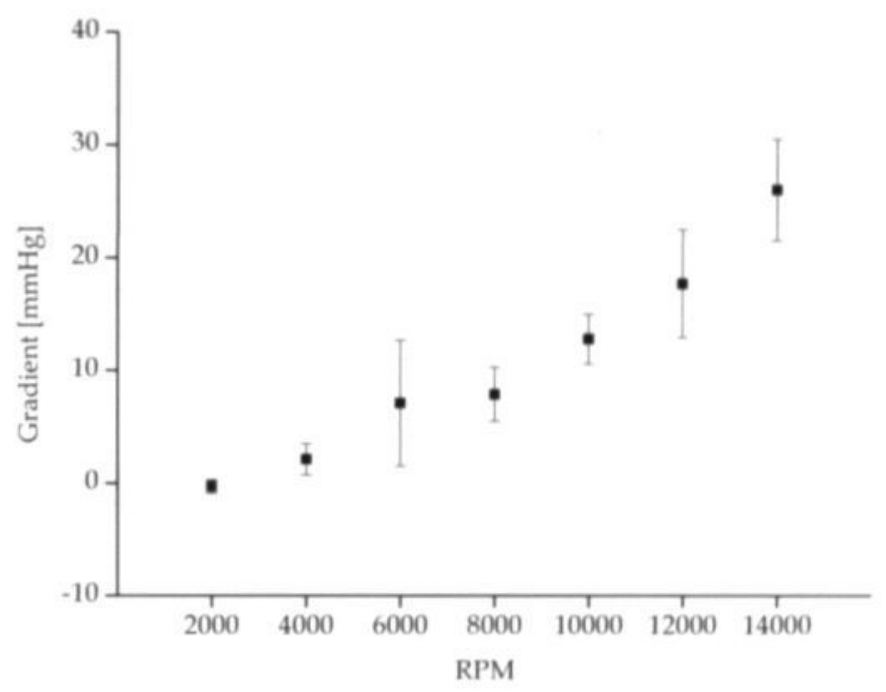

Figure 7-3: Pressure gradient across the propeller at different rotational speeds.

\subsubsection{Comparison of baseline values}

As the protocol dictated that the propeller pump measurements were done before the IABP measurements, the propeller pump and IABP baseline hemodynamic state may have been different. To exclude this, a nonparametric Friedman test was performed on cardiac output and on mean ascending aortic blood pressure recorded during unsupported acute mitral regurgitation just prior to the activation of 6000,10000 and 14000 propeller pump or 1:1 IABP support. No significant difference in hemodynamic state could be found. 


\subsubsection{Hemodynamic effects of propeller pump and IABP}

All hemodynamic data are given in Table 7-1. It shows that the propeller pump at $6000 \mathrm{rpm}$ had no significant effect on the circulation except for a small increase in abdominal aortic pressure. At 10000 and 14000rpm, clear effects were visible. Afterload, mean ascending aortic pressure and left ventricular peak systolic pressure, were decreased. Left atrial pressure simultaneously decreased, but this did not result in a smaller end-diastolic volume and therefore left ventricular preload was preserved. At $14000 \mathrm{rpm}$, left ventricular contractility was depressed as seen by the decrease in stroke work and $\mathrm{dPdt}_{\max }$. Cardiac output was unaffected by propeller pump support, but mean carotid artery and diastolic coronary flow were decreased.

Mean coronary flow was maintained which, together with the decreased diastolic fraction, suggested a shift from diastolic to systolic coronary flow. At $14000 \mathrm{rpm}$, coronary resistance was significantly reduced (Table 7-1).

A number of these observations are seen in the example given in Figure 7-4, where ascending aortic pressure, coronary flow and carotid artery flow are depicted when the propeller pump was switched off from 14000 to 1000 $\mathrm{rpm}$. Ascending aortic pressure and especially diastolic carotid artery flow recovered when the pump was switched off. Coronary flow initially increased but stabilized after 20 seconds. The shift from systolic to diastolic flow is also evident in this example.

Switching on the IABP did not change left ventricular function as contractility (stroke work, $\mathrm{dPdt}_{\max }$ ), afterload (maximal left ventricular pressure) and preload (end-diastolic volume) and left ventricular stroke volume, were all unaffected by IABP activation. The IABP's main effect seems to be a reduction of mitral regurgitation which had a positive effect on the major hemodynamic parameters: cardiac output, mean aortic pressure and carotid flow. Furthermore, the counterpulsation increased diastolic coronary flow although mean coronary flow was unchanged. 
Table 7-1: Hemodynamic changes before and during support with the propeller pump at varieus speeds and 1:1 LABP

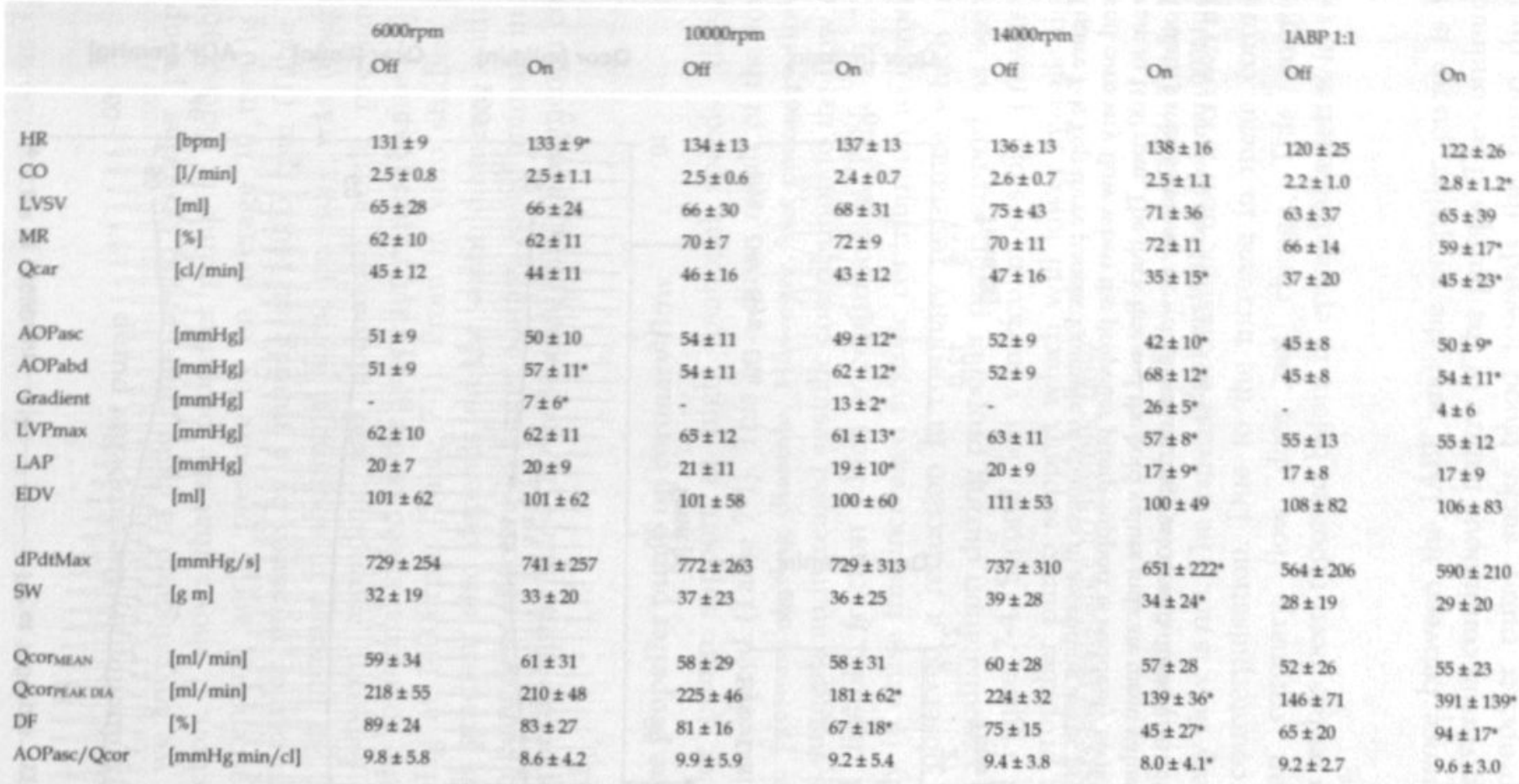

AOPabd: Mean abdominal aortic pressure; AOPasc: Mean ascending aortic pressure; AOPasc' Qcor: Index for coronary resistance, Mean ascending aortic pressure divided by mean coronary flow; CO: Cardiac output; DF: Diastolic fraction, mean diastolic coronary flow dividid by mean coronary flow; dPdtMax: Maximal left ventricular pressure derivative; EDV: Left ventricular end-diastolic volume; Gradient: Difference between ascending and abdominal aordic pressure; HR: Heart rate; LAP: Mean left atrial pressure; LVPmax: Maximal left ventricular pressure; LVSV: Left ventricular stroke volume; MR: Mitral regurgitation; Qcar: Mean carotid artery flow; Qconew: Mean coronary flow; Qcornuk De: Peak diastolic coronary flow; SW: Left ventricular stroke work. All data shown are values averaged over 10 heart beats at end epiration breath-hold. "p<0.05 on versus off 

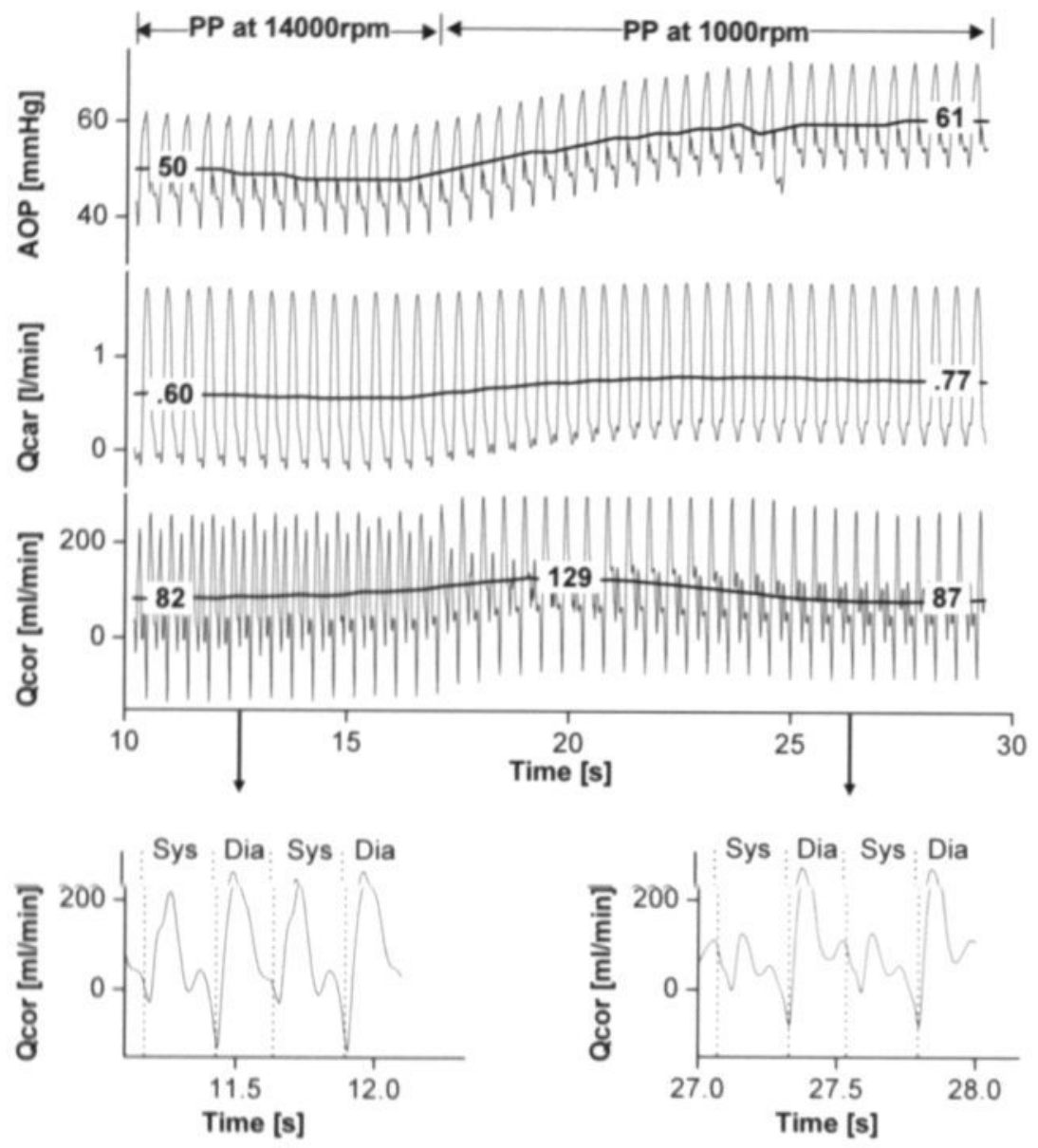

Figure 7-4: Top three panels: Example of changes in ascending aortic pressure, carotid flow and coronary flow when the propeller pump support is suddenly switched off from 14000 $\mathrm{rpm}$ to $1000 \mathrm{rpm}$. The thick line and the bold values indicate mean value.

Bottom panel: Coronary flow in detail during systole and diastole with the propeller pump at $14000 \mathrm{rpm}$ (left) and $1000 \mathrm{rpm}$ (right). 


\subsection{Discussion}

\subsubsection{Afterload reduction by the propeller pump}

In this study we investigated a new intra aortic propeller pump for afterload reduction. It shows that the propeller pump is indeed able to reduce mean ascending aortic pressure by on average $10 \mathrm{mmHg}$ and systolic left ventricular pressure by $6 \mathrm{mmHg}$ at $14000 \mathrm{rpm}$ (Table 7-1). Simultaneously, an increase in abdominal aortic pressure was observed. This gradient between ascending and abdominal aortic pressure is dependent on the rotational speed of the propeller pump (Figure 7-3) and reached $26 \mathrm{mmHg}$ at $14000 \mathrm{rpm}$ (Table $7-1$ ). From in vitro studies, it is known that this gradient also depends on the aortic diameter, with the propeller pump being less effective in larger aortas. As all animals in this study had comparable aortic sizes (21 to $24 \mathrm{~mm}$ ) this phenomenon could not be examined.

\subsubsection{Effect of the propeller pump on coronary flow}

During propeller pump support at high rotational speeds, diastolic coronary flow is reduced (Table 7-1). This is a direct result of the lower ascending aortic pressure during diastole. However, net coronary flow is unaffected. This suggests an increased systolic contribution to the flow and thus a reduced diastolic fraction which is confirmed in Table 7-1. Two factors are likely to cause this increased systolic contribution to coronary flow. First, we observed a reduction in coronary resistance which may imply coronary vasodilatation during propeller pump support, as seen in the example of Figure 7-4. Second, left ventricular systolic pressure is reduced during propeller pump support which will lower systolic tissue pressure and decrease resistance to systolic flow ${ }^{9}$.

During 1:1 IABP support diastolic coronary flow is increased (Table 7-1) while net coronary flow is not. The increase in diastolic flow is known to be caused by the counterpulsation. Due to the increase in mean coronary resistance, mean coronary flow does not change. This suggests vasoconstriction as has been reported before in epicardial arteries in nonischemic hearts ${ }^{10}$.

The main difference between the IABP and the propeller pump is the counterpulsating versus continuous nature of the pumps. The continuous nature of the propeller pump sucks blood towards the pump during diastole which explains the reduction in diastolic coronary and carotid artery flow (Table 7-1 \& Figure 7-4). An obvious solution would then be to drive the propeller in a counterpulsating manner. However, the driveline 
and the propeller itself are unable to withstand the forces generated by stopping let alone reversing the propeller every heart beat.

In conclusion, the propeller pump and the IABP have opposite effects on coronary flow. The propeller pump favors systolic coronary flow, while the IABP increases diastolic coronary flow. As diastolic flow is crucial to perfuse the subendocardial myocardium"1, it is likely that IABP support gives better subendocardial perfusion than propeller pump support.

\subsubsection{Effect of the propeller pump on cardiac output}

Although the propeller pump reduced afterload, this did not result in more cardiac output in this animal model. It is important to realize that in this acute mitral regurgitation model, the amount of mitral regurgitation and thus cardiac output is determined by the ratio of the impedance of the aorta versus the retrograde impedance during systole. Table 7-1 shows that the pressure (and thus the impedance) of the aorta is lower, but that left atrial pressure (or retrograde impedance) is lower as well during propeller pump support. The lower aortic pressure therefore does not result in less mitral regurgitation. In contrast, the IABP significantly reduced the amount of mitral regurgitation which has a positive effect on cardiac output.

While this explains why mitral regurgitation is not decreased upon propeller pump activation, it does not answer the more important question: Why is left ventricular stroke volume not increased with lower afterload? First, it should be noted that although the propeller pump creates a pressure gradient in the aorta of up to $26 \mathrm{mmHg}$ at $14000 \mathrm{rpm}$, the average reduction in mean ascending aortic pressure is $10 \mathrm{mmHg}$ and the reduction in left ventricular systolic pressure is only $6 \mathrm{mmHg}$ (Table 7-1). The latter can be explained by the observation that the propeller pump reduces pressure continuously rather than only during systole and the fact that left ventricular afterload is determined by the aortic and the atrial pressure in this mitral regurgitation model.

Still, upon propeller pump activation, one would expect stroke work to remain similar with the lower afterload, which would result in more left ventricular stroke volume. This does not occur and consequently, stroke work is reduced which is statistically significant when the propeller pump is set at $14000 \mathrm{rpm}$. Now the concept of preload recruitable stroke work ${ }^{12}$, states that a reduction in stroke work at similar preload (end diastolic volume does not change) implies less contractility. The decrease in $\mathrm{dPdt}_{\max }$ is also an indication of a loss of contractility.

We therefore conclude that left ventricular stroke volume is not increased with lower afterload because contractility of the left ventricle is reduced 
with propeller activation at $14000 \mathrm{rpm}$. This reduction in contractility may be linked to the observed reduction in diastolic coronary flow.

\subsubsection{Redistribution of blood by the propeller pump}

As mentioned above, the propeller pump did not increase cardiac output. Without an increase in cardiac output, the propeller pump will merely shift blood from the upper to the lower body. This was confirmed by the significant reduction in carotid artery flow and increase in abdominal aortic pressure at 10000 and $14000 \mathrm{rpm}$. This has an important clinical implication: In patients in cardiogenic shock where the propeller pump is applied, cardiac output should be closely monitored and if cardiac output does not increase, a reduction in flow to the brain should be expected.

\subsubsection{Study Limitations}

In this study the propeller pump and the IABP were tested in animals with acute mitral regurgitation, which is present in only $10 \%$ of cardiogenic shock patients ${ }^{13}$. In patients requiring hemodynamic support due to a different pathology, continuous afterload reduction offered by the propeller pump may be more beneficial. Further animal studies with ischemic heart disease, right ventricular failure or aortic regurgitation models may answer this question.

Finally, this study was designed as a proof-of-principle study and not as a safety study. However, a propeller rotating at such a high speed in the aorta raises important safety issues such as hemolysis and thrombogenesis. Future studies should address this problem.

\subsubsection{Conclusion}

In calves with acute mitral regurgitation, the intra aortic propeller pump has no significant hemodynamic effect at a setting of $6000 \mathrm{rpm}$ and a negative effect on general hemodynamics at 10000 and $14000 \mathrm{rpm}$. In contrast, the IABP at 1:1 assist has a profound positive effect on the systemic and coronary circulation. The IABP therefore provides better circulatory support than the new propeller pump in calves with acute mitral regurgitation. 


\subsection{References}

1. Ryan TJ, Antman EM, Brooks NH, et al. 1999 update: ACC/AHA guidelines for the management of patients with acute myocardial infarction. A report of the American College of Cardiology/American Heart Association Task Force on Practice Guidelines (Committee on Management of Acute Myocardial Infarction). J Am Coll Cardiol 1999;34:890-911.

2. Anderson RD, Ohman EM, Holmes DR, Jr., et al. Use of intraaortic balloon counterpulsation in patients presenting with cardiogenic shock: observations from the GUSTO-I Study. Global Utilization of Streptokinase and TPA for Occluded Coronary Arteries. J Am Coll Cardiol 1997;30:708-715.

3. Phillips SJ, Zeff RH, Kongtahworn C, et al. Benefits of combined balloon pumping and percutaneous cardiopulmonary bypass. Ann Thorac Surg 1992;54:908-910.

4. Reitan O, Sternby J, Ohlin H. Hydrodynamic properties of a new percutaneous intra-aortic axial flow pump. Asaio J 2000;46:323-329.

5. Lönn U. Human use of the jomed reitan catheter pump. In: Annual Report 2000. Jomed Corporation, Helsingborg, Sweden, 2000:35.

6. Steendijk P, Van der Velde ET, Baan J. Left ventricular stroke volume by single and dual excitation of conductance catheter in dogs. Am J Physiol 1993;264:H2198-2207.

7. Baan J, van der Velde ET, de Bruin HG, et al. Continuous measurement of left ventricular volume in animals and humans by conductance catheter. Circulation 1984;70:812-823.

8. Amirhamzeh MM, Dean DA, Jia CX, et al. Validation of right and left ventricular conductance and echocardiography for cardiac function studies. Ann Thorac Surg 1996;62:1104-1109.

9. Spaan JA. Mechanical determinants of myocardial perfusion. Basic Res Cardiol 1995;90:89-102.

10. Kimura A, Toyota E, Lu S, et al. Effects of intraaortic balloon pumping on septal arterial blood flow velocity waveform during severe left main coronary artery stenosis. J Am Coll Cardiol 1996;27:810-816.

11. Kondo M, Kawata K, Azuma A, et al. Relationship between coronary blood flow velocity waveform and transmural distribution of myocardial blood flow in coronary artery. Jpn Heart J 1999;40:783-790.

12. Glower DD, Spratt JA, Snow ND, et al. Linearity of the Frank-Starling relationship in the intact heart: the concept of preload recruitable stroke work. Circulation 1985;71:994-1009.

13. Hasdai D, Topol EJ, Califf RM, et al. Cardiogenic shock complicating acute coronary syndromes. Lancet 2000;356:749-756. 
Chapter 8

Future pressure-volume loops in cardiac surgery 


\subsection{Introduction}

In this thesis pressure-volume loops were applied to answer research questions in cardiac surgery. This has been typical for pressure-volume applications in general, not only in cardiac surgery: Pressure-volume loops have mainly been applied in (pre)clinical research such as evaluation of new diagnostic techniques, drugs or other treatments. In contrast, clinical decision making in individual patients is rarely done using pressurevolume loops, and therefore the role of pressure-volume loops in daily health care is very limited.

This chapter will discuss the question: Will there be clinical applications of pressure-volume loops in future cardiac surgical patients? To answer such a question, one has to identify the future cardiac surgical patient, and determine whether pressure-volume loops can give valuable information in these patients.

\subsection{Cardiac surgery and heart failure}

Currently, the vast majority of patients at a cardiac surgery department are treated for coronary artery disease or valvular disease. More recently, cardiac surgeons have begun to treat arrhythmia patients with procedures such as epicardial ablation for atrial fibrillation'. But despite the importance of these three patient groups, there are two reasons why the heart failure patient is the cardiac surgical patient of tomorrow.

First, the number of congestive heart failure patients is steadily increasing and is estimated at $2.2 \%$ of persons 45 year or older which corresponds to at least 150.000 patients in the Netherlands alone ${ }^{2}$.

Second, medical treatment of heart failure seems to be at a dead-end as trials with new drugs all show minimal benefit to the patient. New hopes for heart failure treatment are therefore non-pharmacological: Resynchronization therapy, surgical ventricular remodeling, mechanical support and cell therapy. Cardiac surgeons will play a crucial role in these four treatments.

\subsection{Pressure-volume loops in surgical heart failure treatment}

\section{Resynchronization therapy}

In heart failure patients with left bundle branch block, one treatment option is left or bi-ventricular pacing. This application of pacing is also referred to as resynchronization therapy and has a well documented benefit ${ }^{3}$. In most patients the pacing leads are placed via catheterization of the coronary sinus. However, these leads can also be placed on the epicardium in a minimal invasive surgical procedure. The best position of the pacing lead and the proper time delay can be determined with pressure-volume loops. 


\section{Mechanical support}

Mechanical support can be used to recover the failing heart. This has long been known in post-cardiotomy and myocarditis patients', but recent reports suggested that recovery of chronic heart failure is also possible: Young cardiomyopathy patients who received what was meant to be a permanent assist device, showed such a strong recovery of cardiac function that their assist device could safely be removed ${ }^{5}$. This raises challenging questions such as: Can recovery of heart failure be achieved with mechanical support in larger patient population? Which patients would benefit from such a treatment? How can we measure recovery? Can drugs speed up the process? As ventricular function and heart failure can be quantified and characterized with pressure-volume analysis, it is most likely the ideal method to answer these questions.

\section{Procedures aimed at changing the geometry of the failing heart}

Surgical treatment of dilated cardiomyopathy has already been mentioned as one of the areas where pressure-volume loops have a proven track record $^{6-8}$. As heart failure emerges as one of the main cardiac diseases of the coming years, new devices and surgical procedures will continue to emerge that are targeted at surgically improving the geometry of the failing heart (Acorn', Myosplint ${ }^{10}$, Surgical Ventricular Restoration ${ }^{11}$ ).

Pressure-volume loops offer the opportunity to validate these procedures and to determine if the better systolic function associated with these procedures is not counterbalanced by a worse diastolic function ${ }^{12,13}$. For the individual patient, pressure-volume loops might be used for correct patient selection and to direct post-operative care towards treating remaining or new systolic and diastolic dysfunction.

\section{Cell transplantation}

Perhaps the most intriguing concept to treat heart failure is to replace the diseased myocardium with cells that can perform cardiac work ${ }^{14}$. Goal of cell transplantation is to improve the contractility of the heart. Pressurevolume loops have the unique property to be able to measure contractility quantitatively. Eventually the decision will have to be made if the concept works, how much cells to implant in the individual patient, to evaluate the patients over time and to decide to begin or repeat treatment. To answer questions like these, pressure-volume loops may be beneficial. 


\subsection{Conclusion}

Pressure-volume loops in cardiac surgery are here to stay. Researchers will always appreciate the fact that from a thermodynamical, physiological and empirical viewpoint, pressure-volume loops are central to our understanding of the heart. With the upcoming interest in ventricular function by clinicians dealing with heart failure patients, it can be expected that the interest in pressure-volume loops will steadily rise.

\subsection{References}

1. Maessen JG, Nijs JF, Smeets JL, Vainer J, Mochtar B. Beating-heart surgical treatment of atrial fibrillation with microwave ablation. Ann Thorac Surg 2002;74:S1307-1311.

2. Redfield MM, Jacobsen SJ, Burnett JC, Jr., Mahoney DW, Bailey KR, Rodeheffer RJ. Burden of systolic and diastolic ventricular dysfunction in the community: appreciating the scope of the heart failure epidemic. Jama 2003;289:194-202.

3. Abraham WT, Fisher WG, Smith AL, Delurgio DB, Leon AR, Loh E, Kocovic DZ, Packer M, Clavell AL, Hayes DL, Ellestad M, Trupp RJ, Underwood J, Pickering F, Truex C, McAtee $\mathrm{P}$, Messenger J. Cardiac resynchronization in chronic heart failure. N Engl J Med 2002;346:1845-1853.

4. Young JB. Healing the heart with ventricular assist device therapy: mechanisms of cardiac recovery. Ann Thorac Surg 2001;71:S210-219.

5. Farrar DJ, Holman WR, McBride LR, Kormos RL, Icenogle TB, Hendry PJ, Moore $\mathrm{CH}$, Loisance DY, El-Banayosy A, Frazier $\mathrm{H}$. Long-term follow-up of Thoratec ventricular assist device bridge-to-recovery patients successfully removed from support after recovery of ventricular function. J Heart Lung Transplant 2002;21:516-521.

6. Schreuder JJ, Steendijk P, van der Veen FH, Alfieri O, van der Nagel T, Lorusso R, van Dantzig JM, Prenger KB, Baan J, Wellens HJ, Batista RJ. Acute and shortterm effects of partial left ventriculectomy in dilated cardiomyopathy: assessment by pressure-volume loops. J Am Coll Cardiol 2000;36:2104-2114.

7. Schreuder JJ, van der Veen FH, van der Velde ET, Delahaye F, Alfieri O, Jegaden O, Lorusso R, Jansen JR, Hoeksel SA, Finet G, Volterrani M, Kaulbach HG, Baan J, Wellens HJ. Left ventricular pressure-volume relationships before and after cardiomyoplasty in patients with heart failure. Circulation 1997;96:2978-2986.

8. Schreuder JJ, van der Veen FH, van der Velde ET, Delahaye F, Alfieri O, Jegaden $\mathrm{O}$, Lorusso R, Jansen JR, van Ommen V, Finet G, et al. Beat-to-beat analysis of left ventricular pressure-volume relation and stroke volume by conductance catheter and aortic Modelflow in cardiomyoplasty patients. Circulation 1995;91:2010-2017.

9. Pilla JJ, Blom AS, Brockman DJ, Bowen F, Yuan Q, Giammarco J, Ferrari VA, Gorman JH, 3rd, Gorman RC, Acker MA. Ventricular constraint using the acorn cardiac support device reduces myocardial akinetic area in an ovine model of acute infarction. Circulation 2002;106:1207-211.

10. McCarthy PM, Takagaki M, Ochiai Y, Young JB, Tabata T, Shiota T, Qin JX, Thomas JD, Mortier TJ, Schroeder RF, Schweich CJ, Jr., Fukamachi K. Device- 
based change in left ventricular shape: a new concept for the treatment of dilated cardiomyopathy. J Thorac Cardiovasc Surg 2001;122:482-490.

11. Athanasuleas CL, Stanley AW, Jr., Buckberg GD, Dor V, DiDonato M, Blackstone EH. Surgical anterior ventricular endocardial restoration (SAVER) in the dilated remodeled ventricle after anterior myocardial infarction. RESTORE group. Reconstructive Endoventricular Surgery, returning Torsion Original Radius Elliptical Shape to the LV. J Am Coll Cardiol 2001;37:1199-1209.

12. Burkhoff $\mathrm{D}$. New heart failure therapy: the shape of things to come? J Thorac Cardiovasc Surg 2001;122:421-423.

13. Ratcliffe M. Batista's operation: what have we learned? J Am Coll Cardiol 2000;36:2115-2118.

14. Chachques JC, Shafy A, Duarte F, Cattadori B, Goussef N, Shen L, Carpentier A. From dynamic to cellular cardiomyoplasty. J Card Surg 2002;17:194-200. 


\section{Summary}

The heart consists of two pumps: the right and left ventricle. The function of the heart is to displace blood from a low-pressure reservoir (the atria) to a high pressure reservoir (the pulmonary artery and the aorta). The change in pressure and volume inside the left ventricle during a heart beat can be described in four phases:

1) In the contraction phase the heart muscle contracts thereby raising pressure inside the ventricle. No blood enters or leaves the ventricle in this contraction phase, the phase is isovolumic. 2) When the pressure inside the ventricle becomes higher than the pressure in the aorta the ejection phase starts. In this phase the volume of the ventricle reduces while pressure remains more or less constant. 3) At the end of ejection, the relaxation phase occurs in which the heart muscle relaxes and pressure drops inside the ventricle. The relaxation phase is also isovolumic. 4) Once ventricular pressure is lower than atrial pressure, the filling phase commences. During this phase the ventricle is filled from the atrium and ventricular volume increases at slightly increasing pressure. After filling is complete, another heart cycle starts.

If pressure and volume during a heart cycle are plotted in the xy-plane, one gets a square loop: the pressure-volume loop.

Pressure-volume loops offer insight in the function of the heart, just like they do in other systems such as steam engines or water pumps. Chapter 1, the introduction, discusses in detail what information can be obtained from pressure-volume loops. Furthermore the various techniques to measure pressure-volume loops are compared with emphasis on the conductance catheter technique. Finally past applications of pressure-volume loops in cardiac surgery are reviewed and it is found that few studies are conducted in this field.

This thesis deals with new applications of the conductance catheter technique in three typical cardiac surgery subjects: valvular disease, coronary artery bypass grafting and mechanical support.

\section{Valvular disease}

Aortic valve stenosis is a common disease in which the aortic valve becomes too narrow thereby making ejection more difficult. To be able to eject through the stenotic valve, the left ventricle thickens and increases its muscle mass (hypertrophy). With progressive narrowing, the hypertrophy may be insufficient to maintain cardiac output and heart failure may develop. Therefore, a patient with symptomatic aortic valve stenosis should 
receive surgery in which the aortic valve is replaced by a prosthetic valve. In most patients, the hypertrophy and symptoms disappear after the operation; the disease is reversible. But in an important group of patients, hypertrophy and symptoms do not improve or even worsen. These patients may have been operated too late, at a stage where the disease has become irreversible. In chapter 2, pressure-volume loops are used to describe in detail the left ventricular function just before the aortic valve is replaced. After follow-up some of the measured parameters may prove to predict post-operative outcome and especially the reversibility of the disease.

In aortic valve regurgitation, blood leaks from the aorta to the left ventricle during the relaxation and filling phase. The relaxation phase is therefore no longer isovolumic. Conceptually a non-isovolumic relaxation phase can be detected in a pressure-volume loop, but this has never been tried. In chapter 3 , the diagnosis aortic valve regurgitation with pressure-volume loops is compared to echocardiography. It turns out that aortic valve regurgitation is sometimes visible in a pressure-volume loop but that the correlation with echocardiography is disappointing.

\section{Off-Pump Coronary Artery Bypass Grafting}

The coronary arteries supply the heart with blood. The most common heart disease is the disease in which one or more of the coronary arteries become too narrow leading to a reduced supply of blood and thus oxygen downstream: the downstream region becomes ischemic. An ischemic part of the heart muscle will not be able to function properly and the muscle cells will eventually die. Coronary artery bypass grafting (CABG) is commonly performed in these patients. In this cardiac surgical procedure a new vessel is placed between the aorta and the ischemic muscle.

In conventional CABG the heart is arrested with the use of cardiopulmonary bypass, in order to be able to suture the vessel to the heart (anastomosis). However, the cardiopulmonary bypass has known complications (e.g. neurological) and thus alternative procedures are intensively studied. One possibility is to perform beating heart CABG or off-pump CABG (OPCAB) in which only the anastamosis site is stabilized with a tissue stabilizer. The stabilizer can also be used to turn and lift the heart in order to facilitate an anastomosis on the inferior and posterior wall. However, this so-called cardiac tilting causes hemodynamic complications such as a lower blood pressure and cardiac output, which limits the use of this technique. In chapter $\mathbf{4}$ pressure-volume loops are used to show the filling of the right ventricle is the cause of the hemodynamic complications. In chapter $\mathbf{5}$ a new right ventricular support device is tested which is meant to support the right ventricle during the tilting procedure. However, it is 
concluded that this new pump can only partially restore normal hemodynamics.

\section{Mechanical support}

Mechanical support of the heart is indicated when the heart itself does not have enough output to maintain a viable circulation despite maximal medical treatment. This pump failure can occur due to an endocarditis, a large myocardial infarct, after open-heart surgery, acute valvular regurgitation or due to acute worsening of chronic heart failure. Nowadays the intra-aortic balloon pump (IABP) is the most common mechanical support. However, the supporting characteristic of the IABP are not well established in cardiogenic shock due to acute mitral valve regurgitation. Chapter 6 describes a study with pressure-volume loops which shows that the IABP reduces mitral regurgitation and has thus a very positive effect on cardiac output and the circulation as a whole.

The IABP is minimal invasive but often has only a limited effect on the circulation. Other mechanical support modalities (extracorporeal life support, assist device) are more effective than the balloon pump in supporting the circulation, but are also much more invasive with more serious complications. A minimal invasive device with better supporting characteristics than the IABP would be very useful in cardiology and cardiac surgery. In chapter 7 a new minimal invasive propeller pump, which possibly meets these criteria, is compared to the intra-aortic balloon pump. This pump is minimal invasive but the study shows that it is less effective than the IABP to support the circulation.

In the final chapter 8, possible future applications of pressure-volume loops in cardiac surgical patients are presented. It is concluded that especially the growing number of heart failure patients may benefit from pressure-volume analysis. 


\section{Samenvatting}

Het hart bestaat uit twee pompen: de rechter en linker hartkamer. Het is de taak van de kamers om een bepaald volume bloed te verplaatsen van een laag druk compartiment (rechter en linker boezem) naar een hoog druk compartiment (long- en lichaamslagader/aorta). De verandering in druk en volume in de linker hartkamer gedurende een hartcyclus kan in vier fases worden beschreven:

1) In de contractie fase trekt de hartspier samen waardoor de druk in de hartkamer verhoogt. Aangezien tijdens deze fase geen bloed het hart in- of uitstroomt geschiedt deze drukverhoging op constant kamer volume; de contractiefase is isovolumisch. 2) Als de druk in de linker hartkamer hoger is dan de druk in de aorta, dan opent de aortaklep en begint de ejectiefase. In deze fase vermindert het volume in de hartkamer maar blijft de druk min of meer constant. 3) Aan het einde van de ejectie, ontspant het hart, valt de druk in de kamer en sluit de aortaklep. Deze relaxatiefase is ook weer isovolumisch. 4) Als de druk in de hartkamer lager is dan de druk in de boezem, dan opent de mitralis klep en begint de vullingsfase. Tijdens de vullingsfase stijgt het volume van de kamer onder licht oplopende druk. Als de vulling van het hart is voltooid, begint een nieuwe hartcyclus.

Als de druk en het volume tegen elkaar worden uitgezet gedurende een hartslag, dan levert dat een vierkante lus op welke iedere hartslag tegen de klok in wordt doorlopen. Dit wordt ook wel een druk-volume lus genoemd (pressure-volume loop).

Druk-volume lussen leveren inzicht in het functioneren van het hart, zoals ze ook gebruikt kunnen worden voor het beschrijven van andere pompen zoals stoommachines en waterpompen. In hoofdstuk 1, de introductie, wordt in detail besproken welke informatie uit de druk-volume lussen van het hart kan worden verkregen. Verder wordt aandacht besteed aan de meetmethode, waarbij de nadruk ligt op de meting van druk-volume lussen met een zogenaamde conductantie catheter. Vervolgens worden de hartchirurgische toepassingen van druk-volume lussen besproken en blijkt dat deze techniek nog maar mondjesmaat wordt toegepast binnen de hartchirurgie.

Dit proefschrift behandelt de toepassing van druk-volume lussen van het hart in drie hartchirurgische onderwerpen: klepziekten, bypass operaties en mechanische ondersteuning. 


\section{Klepziekten}

De klep tussen de linker hartkamer en de aorta, de aortaklep, kan lekken (aorta klep insufficiëntie) of vernauwd zijn (aortaklepstenose). In het geval van aortaklepstenose verdikt de hartspier (hypertrofie) om zo voldoende druk te ontwikkelen om door de vernauwde klep te kunnen ejecteren. Op een gegeven moment in de ziekte, kan de hypertrofie de stenose niet meer compenseren hetgeen uiteindelijk resulteert in hartfalen. Een patiënt met belangrijke aortaklepstenose en symptomen dient derhalve te worden geopereerd waarbij de aortaklep vervangen wordt door een prothese. In de meeste patiënten vermindert de hypertrofie na de operatie en verdwijnen de klachten; de ziekte is dus omkeerbaar. Echter, in een belangrijke groep patiënten blijven de klachten en hypertrofie bestaan of worden ze zelfs erger. Deze patiënten zijn waarschijnlijk te laat geopereerd waardoor de verslechtering van de hartspier onomkeerbaar is geworden. In hoofdstuk 2 worden druk-volume lussen gebruikt om vlak voor de klepvervanging de functie van de linker kamer tot in detail te beschrijven. Door deze patiënten te vervolgen blijken wellicht sommige van de gemeten parameters voorspellend te zijn voor het uitblijven van de vermindering in klachten en hypertrofie.

Als de aortaklep lek is, stroomt er bloed uit de aorta naar de hartkamer tijdens de relaxatie- en vullingsfase, de relaxatiefase is dus niet langer isovolumisch. Dit moet te detecteren zijn in druk-volume lussen, maar dit is nog nooit geprobeerd. In hoofdstuk 3 wordt de diagnose aortakleplek met behulp van druk-volume lussen vergeleken met echocardiografie. Het blijk dat aortkleplek soms te zien is in druk-volume lussen, maar dat de correlatie met echocardiografie matig is.

\section{Bypass operatie op een kloppend hart}

De kransslagaders ontspruiten in de aorta en voorzien het hart zelf van bloed. De meest voorkomende hartziekte is vernauwing van de kransslagaders. Door deze vernauwing krijgt het hartweefsel benedenstrooms van de vernauwing te weinig bloed en zuurstof (ischemie). Ischemisch hartspierweefsel kan niet meer functioneren en zal uiteindelijk afsterven. Om dit te voorkomen, wordt in een bypass operatie een extra vat aangelegd van de aorta naar het ischemische hartspierweefsel.

Om het vat te kunnen vasthechten op de hartspier (anastomose) wordt tijdens een conventionele bypass operatie het hart stilgelegd met behulp van een hart-long machine. De hart-long machine heeft ook complicaties (m.n. neurologische) en derhalve wordt gezocht naar alternatieven. Een mogelijkheid is de operatie uit te voeren op het kloppende hart waarbij, met behulp van een stabilisator, alleen de plek van de anastomose wordt 
stilgelegd. Om anastomoses op de achter- en onderwand te kunnen maken, moet het kloppende hart worden opgetild en gedraaid hetgeen ook kan met de stabilisator. Deze procedure gaat echter gepaard met hemodynamische complicaties zoals een val in bloeddruk en slagvolume. Deze complicaties beperken de mogelijkheden van de kloppend hart bypass operatie.

In hoofdstuk 4 wordt met behulp van druk-volume lussen aangetoond dat de slechtere vulling van de rechter kamer de oorzaak is van de hemodynamische complicaties. In hoofdstuk 5 wordt onderzocht of een nieuwe rechter ventrikel ondersteuningspomp tijdens het optillen van het hart nuttig is. Geconcludeerd wordt dat deze nieuwe pomp maar gedeeltelijk de hemodynamische complicaties kan voorkomen.

\section{Mechanische ondersteuning}

Ondersteuning van het hart met een mechanische pomp is nodig als het hart zelf niet meer genoeg pompt ondanks maximale medicinale behandeling. Dit pompfalen kan optreden bij ontsteking van de hartspier, na een groot hartinfarct, acuut hartklep lek, na een hartoperatie, of bij acuut verergeren van chronisch hartfalen. Op dit moment wordt de intra aorta ballon pomp het meest toegepast als mechanische ondersteuning. Echter, in het geval van acuut mitralis klep lek (klep tussen de linker boezem en kamer) is deze pomp nog niet goed gekarakteriseerd. In hoofdstuk 6 wordt een onderzoek beschreven waarin, met behulp van druk-volume lussen, wordt gedemonstreerd dat de ballon pomp het mitralis klep lek vermindert, hetgeen een zeer gunstig effect heeft op de circulatie.

De ballon pomp maakt minimaal inbreuk op het lichaam (minimaal invasief) maar heeft vaak slechts een beperkt positief effect. Andere vormen van mechanische ondersteuning (extra corporal life support, assist devices) zijn veel invasiever en kennen derhalve een hogere complicatiegraad, maar zijn wel veel effectiever dan een ballon pomp. Een systeem dat minimaal invasief en maximaal effectief is, zou zeer gewenst zijn in de hartchirurgie en cardiologie. Hoofdstuk 7 beschrijft een nieuwe minimaal invasieve propeller pomp. Helaas blijkt uit deze studie dat de nieuwe pomp minder effectief is dan de ballon pomp.

Tenslotte wordt in hoofdstuk $\mathbf{8}$ de mogelijke toekomstige toepassingen van druk-volume lussen besproken. Geconcludeerd wordt dat de techniek vooral nuttig zou kunnen zijn voor het groeiende aantal patiënten met hartfalen. 


\section{Nawoord}

Vijf jaar geleden kwam ik naar Maastricht om de opleiding tot klinisch fysicus te volgen. Ik had niet verwacht dat ik hier iets zou leren over gecoate stents en pingpongballen, Parmezaanse kaas en Ceciliaanse veau flambé, Camel beach in de zon en Bari in de sneeuw, een breakfast session in Chicago en een late-night session in de Baja Beach club. Maar wat ik vooral niet had verwacht, is dat zovelen me wilde helpen om deze promotie voor elkaar te krijgen. Deze mensen wil ik hier graag bedanken.

Zo zijn Theo van der Nagel, Ruud Kruger, Jan Hollen, Koen Reesink, Loes Sauren, Audrey Cramers en Jo Habets onmisbaar geweest bij de experimenten die beschreven zijn in dit proefschrift. Dank ook aan Jan Schreuder die me heeft geïntroduceerd in het onderwerp van deze promotie.

Gijs Geskes, Cecile Soemers, Vincent van Ommen, Paul Barenbrug en de afdeling extra-corporale circulatie onder leiding van Dick de Jong wil ik graag bedanken voor hun hulp zowel in de kliniek als op het lab. Paul Roekaerts voor het zijn van een zo strenge criticus. Het secretariaat en de staf van cardio-thoracale chirurgie voor hun ondersteuning. Thomas van Brakel, Erik Fransen en Lysette Liegeois voor hun hulp gedurende de laatste jaren.

Registreren van data is één, maar het juist uitwerken van data is zo mogelijk nog belangrijker. De software van Paul Steendijk heeft mij hierbij enorm geholpen.

Naast promotieonderzoek ben ik gedurende deze periode ook opgeleid tot klinisch fysicus en ik wil mijn collega fysici graag bedanken voor hun tijd en de bereidheid hun kennis en ervaring met mij te delen. Met name Ernst van Waalwijk van Doorn bedank ik voor het feit dat hij mijn opleiding zo goed heeft gecoördineerd in turbulente tijden en voor de ruimte die hij me heeft gegeven om onderzoek te doen. Pim Dassen voor zijn statistische en overige adviezen. Tenslotte Michaël Lansbergen voor de leuke tijd gedurende de opleiding.

De leden van de beoordelingscommissie, prof.dr.ir. Theo Arts, prof.dr. Bart Meyns, prof.dr. Jan Baan, prof.dr. Michael Jacobs en dr. Vincent van Ommen, wil ik hartelijk bedanken voor hun interesse in mijn proefschrift en de bereidheid deel uit te maken van de beoordelingscommissie. 
Bas Mochtar wil ik bedanken voor het accepteren van het promotorschap en zijn steun gedurende de laatste jaren.

Jos Maessen, een van de co-promotores, paart kennis en kunde aan een ongelooflijke gedrevenheid. Als principal investigator heeft hij veel van deze onderzoeken mogelijk gemaakt, waarvoor mijn grote dank.

Tenslotte dank aan diegene die het meest aan mijn promotie heeft bijgedragen, Erik van der Veen. Sinds onze ontmoeting in maart 1998 bij de vakgroep Cardiologie, is zo'n beetje alles veranderd. Wat me nog het meest verbaast, is dat hij me tijdens deze continue chaos toch heeft geleerd hoe je onderzoek opzet, publicaties maakt, een congres organiseert, etc. maar ook hoe je die zaken versiert met wat italianen, mooie vrouwen, goed eten en een bezoekje links en rechts. Ik heb de afgelopen vijf jaar niet alleen veel van hem geleerd maar ook veel gelachen en dat is een prachtige combinatie.

André Dekker

Maastricht, 18 mei 2003 


\section{Publicaties}

\section{Artikelen}

Hoelen CGA, de Mul FFM, Pongers R, Dekker A. Three-dimensional photoacoustic imaging of blood vessels in tissue. Optics Letters 1998;28:648650 .

Geskes GG, Dekker AL, van der Veen FH, Cramers AA, Maessen JG, Shoshani D, Prenger KB. The enabler right ventricular circulatory support system for beating heart coronary artery bypass graft surgery. Ann Thorac Surg 1999;68:1558-61.

Dekker ALAJ. Onderzoek met mensen. Wet medisch-wetenschappelijk onderzoek met mensen. Good clinical practice. Klinische Fysica 1999;4:2629.

Dekker AL, Geskes GG, Cramers AA, Dassen WR, Maessen JG, Prenger KB, van der Veen FH. Right ventricular support for off-pump coronary artery bypass grafting studied with bi-ventricular pressure--volume loops in sheep. Eur J Cardiothorac Surg 2001;19:179-84.

Hoelen CGA, de Mul FFM, Dekker A. Detection of photoacoustic transients originating from microstructures in optically diffuse media such as biological tissue. IEEE Trans Ultrason Ferroelectr Freq Control 2001;48:3747.

Dekker ALAJ, Reesink KD, van der Veen FH, van Ommen GVA, Geskes GG, Soemers ACM, Maessen JG. Intra-aortic balloon pumping in acute mitral regurgitation reduces aortic impedance and regurgitant fraction. Shock 2003:19:334-338.

Dekker ALAJ, Reesink KD, van der Veen FH, van Ommen GVA, Geskes GG, Soemers ACM, Maessen JG. Efficacy of a new Intra Aortic Propeller Pump versus the Intra Aortic Balloon Pump: an animal study. Chest 2003;123:2089-2095.

Dekker ALAJ, Barenbrug PJC, van der Veen FH, Roekaerts P, Mochtar B, Maessen JG. Pressure-volume loops in patients with aortic stenosis. J Heart Valve Dis 2003;12:325-332. 


\section{Boek}

Dekker ALAJ. Right ventricle conductance measurements. Eindhoven: Technische Universiteit Eindhoven, 1999. ISBN 90-5282-980-2.

\section{Gepubliceerde abstracts}

Dekker AL, Geskes GG, Habets JW, van der Nagel T, Cramers AA, Prenger KB, Maessen JG, van der Veen FH. Right and left ventricular pressurevolume loops for in-depth investigation of cardiac function. J Mol Cell Cardiol 1999;31:Sa25.

van der Veen FH, Dekker ALA, Geskes GG, Habets JW, van der Nagel T, Maessen JG. Left and right ventricular pressure-volume loops to study the effect of cardiac tilting and the enabler circulatory support system on ventricular pump function. Eur Heart J 1999;20(Abstract Suppl):437.

de Swart H, Prinzen FW, Dekker A, Wellens HJJ. Pacing site influences contractility of the normal dog heart. Pacing Clin Electrophysiol 2000;23:682.

Dekker A, Geskes G, Cramers A, Dassen W, Maessen J, Prenger K, van der Veen F. Effect op de hartfunctie van tilting en rechter ventrikel ondersteuning. Klinische Fysica 2001;2:38-39.

Dekker ALAJ, Reesink KD, van der Veen FH, van Ommen GVA, Geskes GG, Soemers ACM, Maessen JG. The new jomed reitan catheter pump vs. iabp during acute mitral regurgitation. Neth Heart J 2002;10(suppl 1):24.

Geskes G, Maessen J, Dekker A, Reesink K, Soemers C, van der Veen E, van Ommen V. The new jomed reitan catheter pump vs. iabp during acute mitral regurgitation. Heart Surg Forum 2002;5(suppl 2):S176.

Dekker ALAJ, Reesink KD, van der Veen FH, van Ommen GVA, Geskes GG, Soemers ACM, Maessen JG. Comparison of IABP and the new Jomed Reitan catheter pump in acute mitral regurgitation. Eur Heart J 2002;23(Abstract Suppl):710.

Reesink K, Dekker AL, van der Nagel T, van der Veen F, van Ommen GVA, Ganushchak Y, Geskes G, Soemers ACM, Maessen JG. New Impella intracardiac minipump supports the left heart significantly better than aortic balloon pumping. Neth Heart J 2002;11:485.

Reesink K, Dekker A, van der Nagel T, van der Veen E, van Ommen V, Ganushak Y, Geskes G, Soemers C, Maessen J. New Impella intracardiac 
minipump supports the acutely failing left heart significantly more effective than intraaortic balloon pumping. J Am Coll Cardiol 2003;41(6 suppl A): $215 \mathrm{~A}$.

\section{Patenten}

Dekker ALAJ. Monitoring Mayer wave effects based on a photoplethysmographic signal. USPTO Serial No: 10/081,887. Filed: February 22, 2002

Dekker ALAJ. Monitoring respiration based on plethysmographic heart rate signal. USPTO Serial No: 10/081,719. Filed: February 22, 2002

Dekker ALAJ. Monitoring physiological parameters based on variations in a photoplethysmographic baseline signal. USPTO Serial No: 10/081,165. Filed: February 22, 2002

Dekker ALAJ. Apparatus and methods for monitoring respiration with a pulse oximeter. USPTO Serial No: 10/081,168. Filed: February 22, 2002 


\section{Biografie}

André Dekker werd geboren op 20 juni 1974 te Eindhoven. Na het VWO op het Gymnasium Celeanum te Zwolle en het Sint Ludgercollege te Doetinchem, is hij in 1991 begonnen met de studie Technische Natuurkunde aan de Universiteit Twente. Deze studie heeft hij verbreed met een biomedische en bedrijfskundige aantekening. In 1996 heeft hij gereisd door Australië en stage gelopen op de afdeling radiotherapie van het Royal Adelaide Hospital. Hij is afgestudeerd in 1998 bij de vakgroep Technische Optica van de Universiteit Twente met als onderwerp de foto-akoestische detectie van bloedvaten in weefsel. In datzelfde jaar startte hij zijn specialisatie tot klinisch fysicus aan de Technische Universiteit Eindhoven en het Academisch Ziekenhuis Maastricht. Als onderdeel van deze opleiding heeft hij in 1999 stage gelopen bij Datex-Ohmeda in Louisville, Colorado, USA op het onderwerp weefseloptica. De eerste helft van deze opleiding werd in maart 2000 succesvol afgerond middels het behalen van de titel Master of Technology Design. In april 2001 ontving hij de Jonge Onderzoekers Prijs van de Nederlandse Vereniging voor Klinische Fysica voor zijn onderzoek naar mechanische ondersteuning tijdens kloppend-hart bypass operaties. In februari 2002 voltooide hij de opleiding en werd hij geregistreerd als algemeen klinisch fysicus. Sinds 1 maart 2002 werkt hij als klinisch fysicus bij de afdeling Cardio-thoracale Chirurgie van het Academisch Ziekenhuis Maastricht. Hij is getrouwd met Caroline Claessens en heeft twee kinderen, Noah en Zoé. 


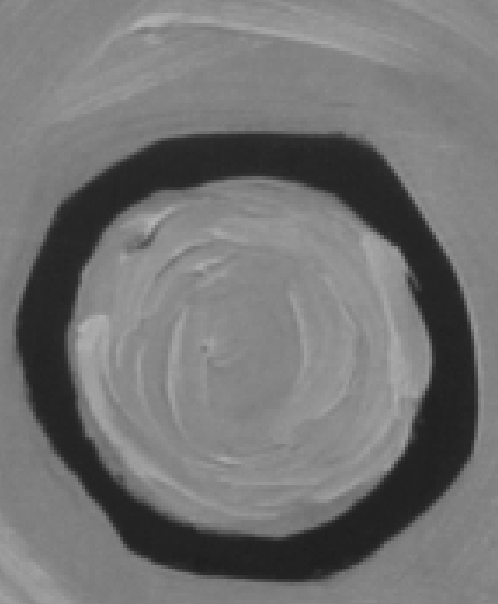

